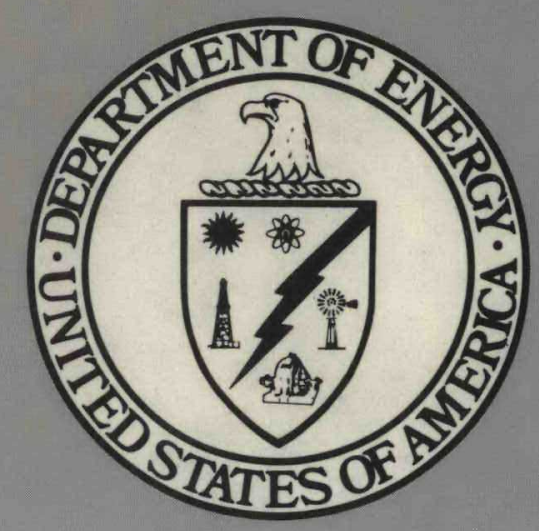

SAN/1011-117

\title{
SEISMIC DESIGN VERIFICATION OF LMFBR STRUCTURES
}

Topical Report

APPLIED TECHNOLLGY

Any Further Distribution by any Holder of this Document or of the Data Therein to Third Parties Representing Foreign Interests, Foreign Governments, Foreign Companies and Foreign Subsidiaries or Foreign Divisions of U.S. Companies Should Be Coordinated with the Director, Division of Reactor Research and Development, DOE.

July 1,1977

Work Performed Under Contract No. EY-76-C-03-1011

Agbabian Associates

El Segundo, California
Released for Annotrnoment in Energy Research A hatraets. Mistribution Limitel to Participants in the LMFBR Program, Others request from TIC 


\section{DISCLAIMER}

This report was prepared as an account of work sponsored by an agency of the United States Government. Neither the United States Government nor any agency Thereof, nor any of their employees, makes any warranty, express or implied, or assumes any legal liability or responsibility for the accuracy, completeness, or usefulness of any information, apparatus, product, or process disclosed, or represents that its use would not infringe privately owned rights. Reference herein to any specific commercial product, process, or service by trade name, trademark, manufacturer, or otherwise does not necessarily constitute or imply its endorsement, recommendation, or favoring by the United States Government or any agency thereof. The views and opinions of authors expressed herein do not necessarily state or reflect those of the United States Government or any agency thereof. 


\section{DISCLAIMER}

Portions of this document may be illegible in electronic image products. Images are produced from the best available original document. 


\title{
NOTICE
}

\begin{abstract}
This report was prepared as an account of work sponsored by the United States Government. Neither the United States nor the United States Department of Energy, nor any of their employees, nor any of their contractors, subcontractors, or their employees, makes any warranty, express or implied, or assumes any legal liability or responsibility for the accuracy, completeness or usefulness of any information, apparatus, product or process disclosed, or represents that its use would not infringe privately owned rights.
\end{abstract}

This report has been reproduced directly from the best available copy.

Available from DOE Technical Information Center, P.O. Box 62, Oak Ridge, TN 37830

Price: Paper Copy $\$ 6.50$ 


\title{
SEISMIC DESIGN VERIFICATION OF LMFBR STRUCTURES
}

\author{
Topical Report
}

APPLIED TECHNOLOGY: ANY FURTHER DISTRIBUTION BY ANY HOLDER OF THIS DOCUMENT OR OF THE DATA THEREIN TO THIRO PARTIES REPRESENTING FOREIGN INTERESTS, FOREIGN GOVERNMENTS, FOREIGN COUNTRIES, AND FOREIGN SUBSIOIARIES OR FOREIGN DIVISIONS OF U.S. COMPANIES SHOULD BE COORDIHATED WITH THE DIRECTOR, DIVISION OF REACTOR RESEARCH AND OEVELOPMENT, U.5. ENERGY RESEARCH AND DEVELOPMENT ADMINISTRATION.

\section{AGBABIAN ASSOCIATES \\ EI Segundo, California 90245}

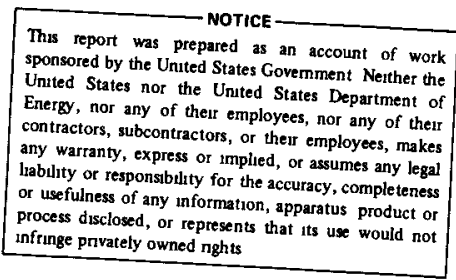

Date Submitted-1 July 1977

\section{PREPARED FOR THE DIVISION OF REACTOR DEVELOPMENT AND DEMONSTRATION ENERGY RESEARCH AND DEVELOPMENT ADMINISTRATION \\ WASHINGTON, D.C.}

UNDER CONTRACT NO. EY-76-C-03-1011
Released for Announ wisent in Energy

Research Aharorts. Listributio "Lintitk to Participants in the LMFBR Prógrym. Others request from TIC 


\section{PREFACE}

This topical report was prepared by Agbabian Associates under Contract EY-76-6-03-1011. The objective of this contract is to develop and update seismic design criteria and analysis methods for future nuclear power plant structures, equipment, and piping. This report deals with one aspect of this overall objective, namely, seismic design verification procedures for nuclear power plant structures. Technical monitor for the Reactor Development and Demonstration Division (RDD) of the Energy Research and Development Administration was C. Chester Bigelow. Project Manager for Agbabian Associates was George A. Young. Authors of the report were

George A. Young

LeRoy Gebhardt 


\section{ABSTRACT}

Code of Federal Regulations 10 CFR 50, Appendix B provides quality assurance requirements for nuclear power plants and fuel reprocessing plants which stipulates that design verification can be provided by performance of design reviews and by the use of alternate or simplified calculation methods, or by the performance of a qualification test that demonstrates adequacy of performance under the most adverse design conditions. This report provides an assessment of the seismic design verification procedures currently used for nuclear power plant structures, a comparison of dynamic test methods available, and conclusions and recommendations for future LMFB structures.

The results of this investigation indicates that it is physically and technically possible to provide a seismic type environment adequate for a qualification test of nuclear power plant structures. However, the expense of the test and the damage liability resulting to other nearby conventional structures makes such tests impractical and unfeasible. As a result, seismic design verification of nuclear power plant structures is currently being provided only by design reviews and alternate calculations. The study further indicates that these procedures can provide results that are comparable to the reliability of qualification testing only when it is certain that the design assumptions are all correct and have been previously verified.

A comparison of experimental determinations of mode frequencies and damping of structures using ambient transient, steady state mechanical oscillator, underground explosive, and earthquake excitation concludes that ambient transient tests will not provide useful information on the response of massive LMFBR structures. Also, only in special cases will meaningful information result from steady state mechanical oscillator tests. Additional test information on the response of nuclear power plant structures in strong earthquake ground motion environments is needed to verify design assumptions. 
Two approaches are recommended. First, tests using underground chemical explosives to generate the test environment are recommended if appropriate decommissioned plants can be found that are located where the test environment will not cause damage to other nearby structures. Second, a study is recommended of experimental, demonstration, and commercial reactors in areas having high seismic activity, to select appropriate facilities for additional strong motion instrumentation as instrumentation currently provided for nuclear power plants does not permit a complete interpretation of the dynamic response of the structure. 
INTRODUCTION AND SUMMARY . . . . . . . . . . . . 1

1.1 Introduction . . . . . . . . . . . . . . . 1

1.2 Summary . . . . . . . . . . . . . . . 1

2 ASSESSMENT OF SEISMIC DESIGN VERIFICATION

PROCEDURES . . . . . . . . . . . . . . . . . . 11

2.1 Introduction ............. 11

2.2 Regulatory Requirements ......... . 11

2.3 Current Seismic Design Verification

Procedures for Structures . . . . . . 16

2.4 Assessment of Current Seismic Design Verification Procedures for Structures. . 17

3 COMPARISON OF DYNAMIC TESTING METHODS . . . . . 39

3.1 Introduction........... . . . 39

3.2 Dynamic Test Methods . . . . . . . . 39

3.3 Comparison of Test Results....... . 47

3.4 Summary of Test Results . . . . . . . 94

4 CONCLUSIONS AND RECOMMENDATIONS ......... 99

4.1 Introduction . . . . . . . . . . 99

4.2 Conclusions .............. . . 100

4.3 Recommendations ............ 102

5 REFERENCES .................. 105 


\section{ILLUSTRATIONS}

Figure

$\underline{\text { Page }}$

1 Comparison of Computed Free-Field Spectra for Soil Site Using Shake and TRI/SAC Computer Codes

2 Discrete Mass Model of a Nuclear Power Plant

Structure....................

3 Two-Dimensional Finite Element Model of Nuclear

Power Plant Structures . . . . . . . . . 30

4 Examples of Discrete Mass and Finite Element

Models of Containment Structure........ 34

$5 \quad$ Plan and Elevations of San Diego Gas and Electric Company Building . . . . . . . . . . . . . 52

6 Plan and Elevation of Millikan Library, California Institute of Technology . . . . . .

7 Comparison of Mode Shapes for San Diego Gas and Electric Company Building . . . . . . . . . .

8 Plan View of Twentieth Floor Showing Fundamental Floor Modes................ 56

9 Response of the Eighth Floor in the Fundamental Mode; E-W Direction of Millikan Library as a Function of Steady Load..............

E-W Fundamental Frequency as a Function of Displacement (Load) Amplitude, Millikan Library.

Measured Structure and Foundation Displacements, E-W Fundamental Mode, Millikan Library . . . .

Sectional Elevation of CVTR Building through Fuel Transfer Canal . . . . . . . . . . . . . .

13 Horizontal Section of CVTR Building at

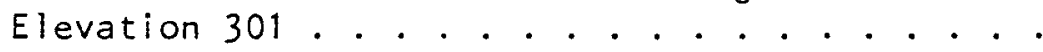




\section{ILLUSTRATIONS (CONTINUED)}

Figure

Page

16 Ground Acceleration-Time Records for Corona Blasts of 1952 and 1958 ........... . 74

17 Radial and Transverse Acceleration Records for 1952 Test............... . . . 75

18 Response Spectra for 1958 Corona Quarry Blast at $800 \mathrm{Ft}$ Station ............. . . 77

19 Comparison of Corona Quarry Blast Response Spectrum with RG 1.60 Spectra....... . 78

E-W Sectional Elevation of EGCR Building . . .

N-S Sectional Elevation of EGCR Building . . . .

22 EGCR Building North-South Mode Shapes and Instrumentation Points . . . . . . . . . . . . .

23 EGCR Building East-West Mode Shapes and Instrumentation Points . . . . . . . . . . .

24 EGCR Building Torsional Mode Shapes and Instrumentation Points........... . . 84

25 General Geological Map Showing Location of Buildings in Table 6 Relative to Epicenter and Center of Energy Release of February 9, 1971 San Fernando Earthquake. . . . . . . . . .

26 Comparison of Estimated First Mode Response of Millikan Library during San Fernando Earthquake with Steady-State Vibratory Test Data. . . . . .

\section{TABLES}

Table

1 Vibration Generator Characteristics.......

2 Comparison of Fundamental Periods of Buildings Determined from Theoretical Computations and from Ambient Transient Wind Loads 
Table

3 Comparison of Fundamental Periods of Buildings Determined by Ambient Transient and Steady-State Vibratory Tests.................

4 Comparison of Modal Frequencies Obtained for CVTR Building by Ambient Transient and SteadyState Vibratory Tests... . . . . . . . . . . .

5 Comparison of EGCR Containment Structure Fundamental Frequencies Determined from SteadyState Vibrations, and Underground Explosions with Theoretical Values ..............

6 Comparison of Fundamental Building Periods before, during, and after San Fernando Earthquake of February 9, 1971 . . . . . . . . . . . 
CHAPTER 1

INTRODUCTION AND SUMMARY

\subsection{INTRODUCTION}

Seismic design verification of nuclear power plant structures has two important objectives. First, and foremost, it must verify that the predicted response of the structures at equipment and piping support points has been reliably estimated as the structure response at these points is used as input to the seismic design analysis of the equipment and piping systems. Second, seismic design verification of the structure is needed to assure satisfactory and reliable behavior of the structure in strong earthquake ground motion environments. This report provides a review of seismic design verification requirements for nuclear power plant structures and an assessment of the procedures that are currently used. It should be particularly noted that seismic design verification of piping and equipment is not included in the scope of this study but will be provided in a later study. The objective of this study is to determine if improved verification procedures are needed for future Liquid Metal Fast Breeder Reactor (LMFBR) structures. A summary of the results of this investigation follows.

\subsection{SUMMARY}

The results of this investigation are reported in the remaining three chapters, which should be consulted for additional details. A brief summary of the essential information in each chapter follows.

\subsubsection{ASSESSMENT OF CURRENT PROCEDURES}

Regulatory requirements for seismic design verification of nuclear power plant structures and an assessment of current procedures are summarized in Chapter 2 of this report. Code of Federal Regulations 10 CFR 50, Appendix B, which provides quality assurance requirements for nuclear power plants and fuel reprocessing plants, stipulates that design verification can be provided by 
performance of design reviews and by the use of alternate or simplified calculational methods, or by the performance of qualification tests. The qualification test procedure defined requires that the test demonstrate adequacy of performance under the most adverse design conditions. This implies that the tests would have to be performed at both the operating Basis Earthquake (OBE) and at the Safe Shutdown Earthquake (SSE) levels. The study indicates that because of the potential damage to Category 11 and 111 items in the nuclear power plant, and because of the possible damage to other nearby conventional structures, as well as the expense and difficulty of creating the seismic test environment, the qualification test procedure is not used. Seismic design verification of nuclear power plant structures is currently provided only by design reviews and alternate calculations.

An assessment of seismic design verification procedures has been made to determine if one procedure is more reliable than the other. It is concluded that the qualification test procedure provides proof through testing that a completely integrated structural system is, or is not, adequate for the most adverse seismic design environment, regardless of whether the design procedures are correct or incorrect. It is further concluded that the design review and alternate calculation procedure is actually a verification of the correctness of documents, and this procedure can give comparable reliability of results only when it is certain that the design assumptions are all correct, and have been previously verified.

A review of the confidence level in seismic design assumptions for nuclear power plant structures indicates that the greatest uncertainty lies in the mathematical modeling of structure and soil/structure behavior. There is also some concern for errors in design details, and unforeseen structural modes of response. The question is then raised whether verification of design assumptions can be provided by lower energy level tests than required for the qualification test environment. 


\subsubsection{COMPARISON OF DYNAMIC TEST METHODS}

A comparison of different methods used to dynamically test structures is provided in Chapter 3. A comparison is made of tests in which the loads have been induced by ambient transient vibrations, steady-state mechanical oscillators, explosions, and natural earthquakes. From these comparisons the following has been summarized:

a. Primarily because of inadequate mathematical modeling of conventional structures, variations of 100 to $200 \%$ between the theoretically computed and the experimentally measured modal periods (i.e., by ambient transit, steady-state, and explosiveinduced vibratory test procedures) have been observed. The computed fundamental periods have been found to be in error both above and below the measured values. When the computed periods are compared with periods measured for structures during a strong earthquake, the variations have been as high as 100 to $300 \%$. It is postulated that variations between computed fundamental periods for conventional nuclear power plant structures, based on present licensing practice, and values that might be measured in the SSE environment, would normally be as great as $100 \%$. It is further postulated that if the very best analytical modeling procedures are used (i.e., better than average practice), the variation can be reduced to about $50 \%$.

b. Ambient transient vibratory tests of multistory buildings having a depth of embedment of about $10 \%$ of the aboveground height, or less, give modal period determinations in excellent agreement with those determined by steady-state vibratory test methods. Modal damping determinations (1 to $2 \%$ ) are less certain, particularly when modes are closely spaced. However, levels of excitation are usually three orders of magnitude below those resulting in a strong earthquake environment. 
However, modal period determinations for multistory buildings in a strong seismic environment can be expected to be 50 to 200\% higher, and damping will be at least a factor of 3 to 5 higher, than determined from ambient transient vibration tests. Ambient transient tests on more massive and more deeply embedded structures, which are characteristic of nuclear power plant structures, have not produced reliable results.

c. Steady-state vibratory tests of multistory buildings produce response accelerations at least one order of magnitude lower than result in a strong earthquake environment, and for massive, embedded structures, the response may be two orders of magnitude lower. For multistory buildings having a depth of embedment of about $10 \%$ of the aboveground height, or less, more reliable damping and slightly more reliable modal periods can be obtained with steady-state tests than with ambient transient tests. Modal period determinations for multistory buildings in a strong seismic environment, however, will be 50 to $200 \%$ higher, and damping will be a factor of 3 to 5 higher than determined by steady-state vibratory tests. More massive structures, similar to some nuclear power plant structures, which have a depth of embedment of about $10 \%$ of the aboveground height, or less, and which are supported on rock with nearly strain-independent properties, should also yield comparable modal data when tested with steady-state vibratory procedures. However, steady-state vibratory tests will probably provide little useful information for massive structures when the depth of embedment is greater than 10 to $20 \%$, and/or the supporting media is soil with nonlinear stress/strain characteristics.

d. Buried explosives can be used to simulate a strong earthquake environment for testing nuclear power plant structures. However, charge weights of 100 to 500 tons buried at distances 
of 1200 to $1500 \mathrm{ft}$ from the structure are needed to provide realistic response. For these conditions, the duration of strong motion will probably not exceed $2 \mathrm{sec}$, and the freefield response spectra will be deficient below frequencies of 2 to $3 \mathrm{~Hz}$. Much greater charge weights with several time delays would be required to provide more realistic durations of strong motion, and to extend the free-field response spectra into lower frequencies at Regulatory Guide 1.60 spectra levels. Because of the large area that would be subjected to strong ground motion, and the expense of the test, this test procedure can seldom be used to test commercial nuclear power plant structures. Tests at low charge weights, such as one ton or under, are not recommended.

e. The best experimental information on the response of structures to a strong earthquake environment can be obtained by placing strong motion recorders at selected points in the structure and in the free-field soil environment near the structure. However, the disadvantages of this method of testing are the expense of instrumenting many structures in order to make certain that some measurements are obtained, and the long delay before meaningful data can be collected. Also, present instrumentation procedures for multistory buildings do not usually provide sufficient information for an adequate analys is of torsional response, or the influence of soil/structure interaction on the response of the structure. The same shortcomings exist for normal instrumentation of nuclear power plants.

\section{2 .3 CONCLUSIONS}

This investigation has lead to the following conclusions, which are also 1 isted in Chapter 4 , relative to qualification tests and lower energy level verification tests. 


\subsubsection{Qualification Tests}

As a result of this investigation, it is concluded that it is physically possible to provide a seismic environment adequate for providing a qualification test of nuclear power plant structures. However, this could only be provided by using more than 500 tons of buried chemical explosives, or by underground nuclear explosives. In both cases, an area several square miles in extent would be subjected to ground motions of sufficient intensity to damage conventional structures. Category 11 and 111 items associated with the nuclear power plant would also experience some damage. The cost of the test with chemical explosives would be expensive, and the limitations on underground nuclear tests greatly restrict the areas in which such tests can be performed. Therefore, al though qualification tests of nuclear power plant structures are physically possible, such tests are not practical, nor feasible, because of the expense of the tests and the damage liability.

\subsubsection{Lower Energy Level Verification Tests}

Lower energy level tests to verify the correctness of seismic design assumptions were also considered. The results of this investigation indicate that the greatest uncertainties in design assumptions are associated with the mathematical modeling of the structure, and the modeling representation of the soil/structure interaction. Because of these uncertainties, analyses and designs are intentionally made on a conservative basis. However, based on this investigation, it is postulated that modal periods computed by procedures in current practice may frequently be in error by as great as $100 \%$ for the SSE environment. It is further postulated that if the very best analytical modeling procedures are used (i.e., better than average practice), the error in modal periods might be reduced to about $50 \%$. Damping values used in seismic analyses are intended to be conservative, but the actual damping characteristics for the SSE environment are based more on judgment than on experimental verification. There is, therefore, a need to provide experimental verification of modal periods, vectors, and damping where possible. 
It is concluded from this investigation that only in unusual cases can ambient transient vibratory test data be used to provide a reliable estimate of the dynamic response of typical nuclear power plant structures. It is therefore concluded that ambient transient vibration tests should not be used for low-level testing of nuclear power plant structures.

This investigation indicates that steady-state mechanical oscillator tests can be used to obtain general information on structural modes when the depth of embedment is about $10 \%$ or less of the aboveground height of the structure, and the structure is supported on rock with nearly strain independent properties. Such tests should be provided as a part of the verification program. However, before making such tests, analytical studies using the best mathematical modeling procedures available should be made to determine whether a level of response can be achieved that will provide meaningful results. In those cases where meaningful results can be obtained, the mathematical models should be used to extrapolate the structural response to the OBE and SSE ground motion levels. Damping and material behavior assumptions, however, should remain conservative as these properties cannot be verified with low energy level tests and analysis.

For nuclear power plant structures having more than $20 \%$ embedment, and/or when the supporting media is soil with nonlinear stress/strain characteristics, steady-state vibratory tests will provide little useful information. For such cases, reliance will have to be placed on more sophisticated verification analyses than are conventionally used in design, and upon special tests and observations of structures of the same generic class in strong ground motion environments. These would include special tests with explosiveinduced ground motions, and the observed behavior of instrumented nuclear power plant structures in strong natural earthquake environments. 


\subsubsection{RECOMMENDATIONS}

Based on the above conclusions, it is evident that some improvements should be instituted in the seismic design verification procedure for future LMFBR structures. These structures will generally be large and massive, and will probably be embedded more than $20 \%$ of the aboveground height. Careful study will therefore be required for each case to determine whether meaningful experimental data can be obtained from low energy level tests. For those cases where steady-state mechanical oscillator tests will yield reliable information (see Sec. 1.2.3.2), such tests should be performed and mathematical models of the structure and supporting rock media should be used to extrapolate the response to the OBE and SSE ground motion levels. For those sites where such tests will not provide reliable information (i.e., deep embedment and/or soil sites), more sophisticated analyses should be provided than are used in conventional design analyses to verify the structure response in the OBE and SSE ground motion environments, as has been noted above.

It is evident that additional test information is needed on nuclear power plant structure behavior in a strong earthquake ground motion environment. To provide information on the behavior of massive, deeply embedded nuclear power plant structures, the following programs are recommended:

a. It is recommended that an experimental program be planned and conducted for a relatively few nuclear power plant structures that are relatively deeply embedded in soil sites. Plants should be selected that have been decommissioned, and should be located, if possible, where an earthquake-like environment can be generated with underground chemical explosives without causing damage to other nearby structures. If these conditions can be satisfied, a test plan should be formulated, based on a dynamic analysis of the structure, to make certain that an adequate test environment can be generated, and that proper instrumentation to measure the ground motion environment and structure response can be provided. These tests should then 
be performed and modal periods, vectors, and damping measured. The modal periods and vectors should be compared with the analytical results, and the damping compared with present practice.

b. If decommissioned nuclear power plants with the site conditions described in a can be found, but if off-site environmental conditions prevent the development of an earthquake-like environment with chemical explosives, then it is recommended that an analysis be made to determine if it is possible to generate earthquake-level response with pulse-loading techniques such as described in Section 3.2.4 from the work of Masri and Safford, 1976. If it is found that an adequate input can be generated by this method, then it is recommended that a test plan be formulated using this type of loading device. Modal periods, vectors, and damping should then be determined by this experimental method and compared with analysis results and practice, as indicated in $a$.

c. Currently, strong motion recorders are required to be installed at all commercial reactors. However, as has been found with the instrumentation program in California for multistory buildings, the instrumentation is generally not sufficient to permit a complete analytical verification of the structure and soil/ structure response to strong earthquake ground motion. It is, therefore, recommended that a study be made of experimental, demonstration, and commercial reactors in areas having high seismic activity, and that representative structures on soil sites be selected for the installation of the additional strong motion instrumentation required to make a complete interpretation possible of the response of the structure and of the soil during a strong earthquake. Complete dynamic analyses using 
adequate mathematical models should also be performed when planning the instrumentation to make certain adequate instrumentation is provided. It should be particularly noted that only sites having a reasonable probability of experiencing strong earthquake ground motion should be selected for additional instrumentation. 
CHAPTER 2

ASSESSMENT OF SEISMIC DESIGN VERIFICATION PROCEDURES

\subsection{INTRODUCTION}

This chapter summarizes regulatory requirements pertaining to seismic design verification of nuclear power-plant structures. It also provides an assessment of the procedures as currently practiced. Federal requirements are set forth in Code of Federal Regulations 10 CFR 50, Appendix $B$, which provides quality assurance requirements for nuclear power plants and fuel reprocessing plants. Guidance in interpretation of the requirements is provided in Regulatory Guide (RG) 1.64 by the U.S. Nuclear Regulatory Commission (USNRC, 1975). RG 1.64, by reference incorporates the American Standards Institute (ANSI, 1974) Standard N45.2.11, with some exceptions. The requirements of the U.S. Energy Research and Development Administration (ERDA) are provided in RDT Standard, RDT-F-2-2 and RDT-F-2-4T (ERDA, 1973, 1974). These documents should be consulted for a complete background in regulatory requirements.

\subsection{REGULATORY REQUIREMENTS}

Appendix $B$ of 10 CFR 50 requires that every applicant for a construction permit include in the Preliminary Safety Analysis Report (PSAR) a description of the quality assurance program to be applied to the design, fabrication, construction and testing of the structures, systems and components of the facility. Information pertaining to the managerial and administrative controls to assure safe plant operation must also be provided in the Final Safety Analysis Report (FSAR). Thus, Appendix B establishes quality assurance requirements not only for design, but for construction and operation of the facility as well. Also, the requirements apply to all activities affecting safety-related functions, and include designing, purchasing, fabricating, handling, shipping, storing, cleaning, erecting, installing, inspecting, testing, operating, maintaining, repairing, refueling, and modifying. Before proceeding further, definitions of the terms quality assurance, quality control, design, and design verification are needed. 
Quality assurance is defined in 10 CFR 50, Appendix B, as "all those planned and systematic actions necessary to provide adequate confidence that a structure, system or component will perform satisfactorily in service." Quality assurance is further defined to include quality control which is defined as "those quality assurance actions related to the physical characteristics of a material, structure, component or system which provides a means to control the quality...to predetermined requirements."

Design control procedures set forth in 10 CFR 50, Appendix $B$ provide that measures be established to assure that applicable regulatory requirements and the design basis for the structures, systems, and components be correctly translated into specifications, drawings, procedures and instructions, and that procedures be provided for verifying, or checking, the adequacy of the design. Three procedures for verifying the adequacy of the design are enumerated. These are, (1) performance of design reviews, (2) use of alternate or simplified calculational methods, or (3) by the performance of a suitable testing program. It is important to note that the above provisions are defined as design control procedures and that the conjunction $O P$ is used rather than and. This could be interpreted to imply that any one of the control procedures may be used, and that all three procedures are not required for a given facility. However, a slightly different interpretation is given in ANSI N45.2.11, as noted in the next paragraph.

Design is defined in ANSI N45.2.11, as the "technical and management processes which commence with identification of design input and which leads to and includes the issuance of design output documents." Design input is defined as, "those criteria, parameters, bases, or other design requirements upon which detailed final design is based." Design output is defined as, "documents such as drawings, specifications, and other documents defining technical requirements of structures, systems, and components." Finally, Design Verification is defined as, "the process of reviewing, confirming, or substantiating the design by one or more methods to provide assurance that the design meets the specified design inputs." Here, it should be specifically noted that one or more methods is indicated rather than any one method. 
The methods of providing design verification described in ANSI 45.2.11 are the same three design control methods defined in 10 CFR 50, Appendix $B$ and $l i s t e d$ above (i.e., design reviews, al ternate calculations, and qualification testing). The extent of the design verification required is indicated in ANSI 45.2.11 to be "a function of the importance to safety of the item under consideration, the complexity of the design, the degree of standardization, the state of the art, and the similarity with previously proven designs. However, the applicability of standardized or previously proven designs, with respect to meeting pertinent design inputs, including environmental conditions, shall be verified for each application." With this as background, description of the three methods of providing design verification are quoted below from ANSI 45.2.11.

\subsubsection{VERIFICATION BY DESIGN REVIEWS}

Design reviews are critical reviews to provide assurance that design documents such as drawings, calculations, analyses or specifications are correct and satisfactory. Design reviews can range from multi-organization reviews to singleperson reviews. The depth of review can range from a detailed check of the complete design to a limited check of such things as the design approach and the results obtained. The results of the review shall be documented and measures taken to ensure that the findings are implemented. Whether the review is conducted by one individual or a multi-organization there are a number of basic questions that shall be addressed such as:

1. Were the inputs correctly selected and incorporated into design?

2. Are assumptions necessary to perform the design activity adequately described and reasonable? Where necessary, are the assumptions identified for subsequent re-verifications when the detailed design activities are completed?

3. Are the appropriate quality and quality assurance requirements specified?

4. Are the applicable codes, standards and regulatory requirements including issue and addenda properly identified and are their requirements for design met? 
5. Have applicable construction and operating experience been considered?

6. Have the design interface requirements been satisfied?

7. Was an appropriate design method used?

8. Is the output reasonable compared to inputs?

9. Are the specified parts, equipment, and processes suitable for the required application?

10. Are the specified materials compatible with each other and the design environmental conditions to which the material will be exposed?

11. Have adequate maintenance features and requirements been specified?

12. Are accessibility and other design provisions adequate for performance of needed maintenance and repair?

13. Has adequate accessibility been provided to perform the in-service inspection expected to be required during the plant life?

14. Has the design properly considered radiation exposure to the public and plant personnel?

15. Are the acceptance criteria incorporated in the design documents sufficient to allow verification that design requirements have been satisfactorily accomplished?

16. Have adequate pre-operational and subsequent periodic test requirements been appropriately specified?

17. Are adequate handling, storage, cleaning and shipping requirements specified?

18. Are adequate identification requirements specified?

19. Are requirements for record preparation review, approval, retention, etc., adequately specified?

\subsubsection{VERIFICATION BY ALTERNATE CALCULATIONS}

Verification of some types of calculations or analyses may be achieved by comparison with alternate methods of calculation or analyses. This shall be performed by a person or persons other than those who performed the original calculation. Where alternate calculations are performed to verify the correctness of the original calculation, a review shall be performed to address the appropriateness of assumptions, input data, and the code or other calculation method used. 
The alternate method used for comparison may be a more simplified approach or less rigorous, such as when a hand calculation is used to check the computer code output. Although the simplified or less rigorous method may not exactly check the original calculation or analysis, it must provide results consistent with the original calculation or analyses.

\subsubsection{VERIFICATION BY QUALIFICATION TESTING}

Design verification for some designs or specific design features can be achieved by suitable qualification testing of a prototype or initial production unit.

In those cases where the adequacy of a design is to be verified by a qualification test, the testing shall be identified and documented. Testing shall demonstrate adequacy of performance under the most adverse design conditions. All pertinent operating modes shall be considered in determining these design conditions where it is intended that the test program confirm the adequacy of the overall design. Where the test is only intended to verify a specific design feature, the other features of the design shall be verified by other means. For example, it may be most effective to verify that an instrumentation cabinet is designed to withstand the maximum earthquake-caused vibratory motions by actually subjecting the cabinet and its associated components to shaker tests which correspond to these vibratory motions. The shaker tests will not, however, verify that the circuitry is designed correctly or that the component in the cabinet will perform its intended function. Other tests or verification means are required to confirm that remaining design functions are adequately performed by the instrumentation and that those components perform the intended functions for the varying design conditions to which they are subjected.

Qualification testing shall be performed in accordance with written test procedures which incorporate or reference the requirements and acceptance limits contained in applicable design documents. The test procedures shall include provisions for assuring that prerequisites for the given test have been met, that adequate instrumentation of the required range and accuracy is available and used, and that necessary monitoring is performed. Prerequisites include such items as calibrated instrumentation, appropriate equipment, trained personnel, condition of test equipment and the item to be tested, suitable environmental conditions and provisions for data acquisition. Test results shall be documented and evaluated by the responsible designer to assure that test requirements have been satisfied. 
If testing indicates that modifications to the item are necessary to obtain acceptable performance, the modification shall be documented and the item modified and retested or otherwise verified to assure satisfactory performance. When tests are being performed on models or mock-ups, scaling laws shall be established and verified. The test configuration shall be clearly defined and documented. The results of model test work shall be subject to error analysis, where applicable, prior to use in final design work.

\subsection{CURRENT SEISMIC DESIGN VERIFICATION PROCEDURES FOR STRUCTURES}

The qualification test procedure described above requires that testing shall demonstrate adequacy of performance under the most adverse design conditions. Therefore, the use of this method for seismic design verification of nuclear power plant structures would require testing at both the Operating Basis Earthquake (OBE) and Safe Shutdown Earthquake (SSE) levels. The latter would require testing under very intensive, and in some cases, almost destructive ground-shaking environments. Since nuclear powerplant structures are large, massive and complex, and their construction must be integrated with the installation of equally complex piping and equipment component systems, the qualification testing of complete nuclear power plant structures is not currently used for reasons that are almost obvious. First, as will be discussed in Chapter 4, there are no practical means of producing either the OBE or SSE ground-shaking environments for such large massive structures without doing damage to other structures. Second, the plant could not be placed in service after testing without extensive refurbishing, because of potential damage to Category $\|$ and $|1|$ items, (i.e., Category 11 items are required to survive the OBE but not the SSE environments). Qualification testing at the most adverse conditions is therefore not feasible. As a result, seismic design verification of nuclear power plant structures is currently provided by using both design reviews and alternate calculations supported by numerous quality control tests of materials, but not by qualification testing of the completed structure. 


\subsection{ASSESSMENT OF CURRENT SEISMIC DESIGN VERIFICATION PROCEDURES FOR STRUCTURES}

Careful review of the seismic design control methods described in Section 2.1.1, 2.1.2, and 2.1.3 indicates that there is an important difference in verification based on design reviews and alternate calculations, and one based on qualification testing, keeping in mind that quality control tests of materials are common to both procedures. The former provides a verification of the design as defined in ANSI N45.2.1, which is the "technical and management process which commence with identification of design input and which leads to and includes the issuance of design output documents." This procedure is, therefore, actually a verification of the correctness of documents. In contrast, the latter would demonstrate the adequacy of a complete prototype structural system in the most adverse seismic design environment. In order to evaluate current seismic design verification procedures, it will be assumed at this point that qualification testing of nuclear power-plant structures is a viable alternative verification procedure. Based on this assumption, two questions need to be considered. These are: (1) Is one procedure more reliable than the other, and (2) if so, what does the more reliable procedure provide that is not provided by the other?

Qualification testing provides proof through testing that a completely integrated structural system is, or is not, adequate when subjected to the most adverse seismic design environment. This is true regardless of whether the design procedures are correct, or incorrect. For example, the design procedures could be grossly incorrect, yet a very conservative structure could result that would be more than adequate for the seismic design environment considered. The test in this case would verify the adequacy of the structural system, but it would not verify the correctness of the design documentation, nor the correctness of the design assumptions.*

\footnotetext{
FDesign assumption is used here as an inclusive term that includes all assumptions pertaining to analysis, design, construction, and operation that could affect the integrity of the completed structure in a seismic environment.
} 
However, if the qualification tests are adequately planned and conducted, the results could be used to verify the adequacy of both the design assumptions and the completed structural system. Therefore, qualification testing, if properly planned and conducted, could provide additional important information that may not be provided by the design review and alternate calculation procedure which would be a verification of design as sumptions.

It follows from the above discussion that only when the design assumptions are known to be completely correct, can it be assumed that the design review and alternate calculation procedure will lead to a complete seismic design verification for nuclear power plant structures. When this is not known to be true, the qualification test procedure would be the more reliable procedure, if it could be provided. This leads to two additional questions that must be answered in order to evaluate current seismic design verification procedures. These are: (1) What is the confidence level in the assumptions used in current seismic design procedures, i.e., are there design assumptions that need to be verified, and (2) if there are, can this be accomplished by procedures * other than by qualification testing? Discussion of these two questions follows.

\subsubsection{CONFIDENCE LEVEL IN SEISMIC DESIGN ASSUMPTIONS}

Confidence level in this discussion will be expressed in a qualitative sense. Considered on this basis, the confidence level in the assumptions used in the seismic design of a nuclear power plant structure are low, for example, when compared to the confidence level in the assumptions used to design a cylindrical steel vessel for an internal pressure. The reasons

\footnotetext{
*For example, could testing in a less severe seismic environment than the $O B E$ and SSE be used to verify design assumptions. However, this alone would not be complete design verification. Design reviews or qualification testing would still be required. This will be discussed in Section 2.4.2.
} 
are obvious but some of the reasons should be noted to clarify the problem. Basically, the pressure vessel loading is simple and well understood, the structural configuration is simple and easy to analyze, the material behavior can be easily defined, and the engineering profession has a long experience record of successfully designing and testing such items under service load and overload conditions. In contrast, the seismic loading of the structure and the structural configuration are both complex, and the material behavior under strong seismic loading may not be well represented in the analytical models. Also, there have been no planned tests of such structures in OBE and SSE environments.

The above comparison is somewhat unfair since a pressure vessel is usually only one item in a much more complex mechanical system, and only one load has been considered. When the confidence level in the assumptions for the seismic design of the structure is compared to the confidence level in the assumptions used for the design of a complete mechanical system for all loads, including seismic, the two levels of confidence will be found to be more comparable. This is particularly true for the seismic design since the input to the mechanical system is filtered through the structure. Therefore, it is evident that either a complete system test should be provided, or the uncertainties in the design assumptions for the overall system should be isolated and special verification procedures developed. A brief discussion of uncertainties in the seismic design assumptions for nuclear power plant structures, and the manner in which the assumptions should be treated follows. For convenience in discussion, the assumptions will be divided into four categories. These are assumptions that pertain to seismic input, material properties, dynamic analyses and design details. The discussion which follows is not intended to be a comprehensive review of all design assumptions, but a review of a few critical assumptions in each category. 


\section{4 .1 .1 Seismic Input}

Seismic engineering is a developing technology and it is generally recognized that there is limited information available on which to base predictions of the level of vibratory ground motion that should be assigned to the $O B E$ and SSE for most nuclear power plant sites. This uncertainty is considered by requiring the use of conservative criteria. At the present time, the basic seismic input can be verified only by the design review which makes certain that conservative regulatory requirements have been correctly interpreted and applied. Once established and verified, it becomes basic input to both the seismic design and the seismic design verification. In other words, the seismic environment defined for the design is the same seismic environment that must be produced if qualification testing is provided. Uncertainties in assumptions relative to the definition of the criteria ground motions, therefore, do not impact the determination of the adequacy of the seismic design verification procedure. However, this applies only to the basic site input and does not apply to free-field calculations based on the seismic input criteria. This will be discussed under dynamic analyses.

\subsubsection{Material Properties}

A great number of field and laboratory tests are required to provide design information on the physical properties of the soil and rock supporting the nuclear power plant structures. Laboratory tests and quality control tests are also required to determine and control the physical properties of the materials incorporated into the structure. Information on the unit weights as well as on the strength and stress/strain properties under both static and dynamic loads are required for both the subsurface and structural materials. The testing procedures are well defined, and reasonable estimates of the properties of the test samples can be made. However, there is some uncertainty in converting test sample properties to in situ soil and rock properties which are needed as basic input to the mathematical models used to provide seismic analyses of the free field and of the soil/structure 
system. The uncertainty in converting sample properties of concrete to inplace concrete structural properties is considerably less than for the soil and rock, but greater uncertainty exists for concrete than for steel. A brief discussion of the two general material categories (i.e., soil and rock, and concrete and steel) follows.

The uncertainty in converting soil and rock sample properties to in situ properties results primarily from three factors. First, in many soils, considerable sample disturbance results during the drilling and sample extraction process which may materially alter the material properties. Second, tests of small core samples may not properly represent the mass, or in situ properties. Core samples in rock, for example, may not have an adequate representation of joints, weathered zones, etc. Also the in situ state of stress, which should be duplicated in testing of the samples, may not be known. Third, soils and some rock have nonlinear stress/strain properties that are nearly always strain dependent. These properties are difficult to determine experimentally, and even more difficult to approximate by an equivalent elastic assumption, which may be used in free-field and soil/structure interaction mathematical model analyses.

Procedures used to determine the soil and rock properties are described and discussed in several documents, such as SW/AJA, 1971 which should be consulted for discussion of procedures. For the discussion here, it is sufficient to note that these uncertainties in design are usually handled by assuming that critical properties, such as the shear moduli, may vary by as much as $\pm 50 \%$. Parametric analyses are made, therefore, using a range in material properties. The density of soil or rock can be closely estimated (within 2 to $3 \%$ ) and represents no problem.

Experimental verification of the in situ properties using large or fullscale tests, if physically possible, would of course reduce the uncertainty in the assigned material properties, and would lead to less conservative design. However, it is reasonable to conclude that the material properties can be conservatively defined. The uncertainty associated with the assumptions 
used to express the nonlinear soil and rock behavior as equivalent linear behavior in mathematical models used in dynamic analyses is a different problem. It will be considered in the next section, as this conversion is primarily a modeling assumption.

Modulus, density, and stress/strain properties of steel and concrete construction materials, as noted above, can be determined with greater certainty than soil and rock properties as these materials can be produced under controlled conditions. Variations in concrete modulus may have to be assumed in analyses to test the effect of modest variations in this property, but this is not required with steel. The nonlinear stress/ strain characteristic of concrete, and the yield behavior of steel are well understood and can be defined by control tests. Uncertainties do not arise in this area until attempts are made to model this behavior for elements of the structure for the dynamics analysis. This uncertainty is also discussed more fully in the next section.

\section{4 .1 .3 Dynamic Analyses}

The previous two sections have indicated that the uncertainties in the definition of the seismic input is currently considered by using conservative criteria, and that basic material properties can be reasonably well defined by field and laboratory testing, with the uncertainties in properties being treated conservatively by making parametric analyses that consider the predicted range in material properties. However, assumptions must also be made relative to material behavior in the formulation of mathematical models for dynamic analysis. Uncertainties in these assumptions, as well as in some of the other modeling assumptions are discussed in this section. As previously noted, the discussion will not consider all modeling assumptions but is a limited discussion designed to indicate the general confidence level that should be assigned to the mathematical models used in the dynamic analyses. The analytical procedures used for free field and structure analyses will be considered separately. 


\subsection{Free Field Analyses}

Acceptable procedures for defining vibratory ground motion are described in the Standard Review Plan (SRP) of the U.S. Nuclear Regulatory Commission (NRC,'1975). Section 2.5 .2 of this document requires that the wave transmission characteristics of the site materials be described as a function of the significant frequencies, and that the type of seismic waves producing the maximum ground motion be determined. This section indicates that the SHAKE computer program (Schnabel, et al, 1972) can be used for this frequency dependent analysis when the maximum ground motion results from vertically propagating shear waves. It is indicated that the shear wave model is also currently accepted by NRC for site conditions where the maximum ground motion may result from compressional and surface waves, although reference is made to the work of Trifunac and Udwadia (1974) and Drake (1972) for these conditions.

Section 3.7 .1 of the SRP describes acceptable procedures for defining design response spectra and time histories to be used as input in seismic analyses of nuclear power plant structures. This section indicates that the design response spectra should be defined for the free field or rock conditions (i.e., with no structures present) and that it should ordinarily be considered applicable at the finished grade level (ground surface) of the site. If the proposed structures are to be deeply embedded then the free-field ground motion at the elevation of the base of the structures will be different than defined for the ground surface. Acceptable procedures for computing the ground motion input at the base level of the proposed structures are also set forth in Section 3.7.1. This section discusses time histories to be input only at the base of the model and identifies deconvolution analyses using the SHAKE and LUSH computer codes as an acceptable method. Even though this section indicates that other equivalent computer codes and analysis techniques are acceptable, the combined application of the SHAKE/LUSH computer codes for computing the base input and the soil/structure response have become an almost standard 
procedure, even for deeply embedded structures in rock. This has apparently unintentionally resulted from the emphasis given in the SRP to only these two codes and to the requirement for only base input which is a unique requirement of these two codes. Because of the nearly universal use of the SHAKE code to define the ground motion at the base level of the proposed structures, a review of important assumptions in this modeling procedure is essential. To avoid confusion, it should be noted that the deconvolution routine in the LUSH and FLUSH* codes (which are used for the soil/structure interaction models) is comparable to the SHAKE code.

An important material modeling assumption in the SHAKE and FLUSH codes is that the nonlinear stress-strain characteristics of the soil and rock can be represented by equivalent elastic shear moduli and equivalent viscous damping coefficients based on the estimated soil properties and anticipated strain levels. The codes are, therefore, completely elastic codes. This is an important assumption. Other important characteristics of these two codes are that they are based on the assumptions that the soil (or rock) layers are horizontal, and that the input to the models can be represented by simple, one-dimensional (1-D) vertically propagating stress waves. A vertically propagating shear (S) wave is used to represent the horizontal component of motion and a decoupled vertically propagating compressional ( $P$ ) wave is used to represent the vertical component. It should be noted that both models iterate to a solution in which the computed effective strain levels in the various elements are compatible with the assumed shear modul $i$ and damping based on relationships that are stored in the code, or are input by the investigator at the start of the analysis. Since the horizontal and vertical components of motion are decoupled, and are considered in separate analyses, the models iterate to separate solutions having different equivalent moduli and damping even though the two motions are actually coupled and occur simultaneously, unless the analyst takes special steps to restrict the iteration routine when considering one of the components (i.e., the vertical). Reference should be made to

*The FLUSH code is an improved version of the LUSH code. All reference in the remainder of this report will be to the FLUSH code unless noted otherwise. 
Schnabel, et al., 1972, and to Lysmer 1975 for additional details concerning these codes.

Actually, seismic waves are three dimensional, and the material behavior is usually nonlinear. Two-dimensional (2-D) nonlinear and threedimensional (3-D) elastic analyses are possible, but analyses at this level of sophistication are not currently used to support nuclear power plant design. The current state of the art is therefore represented by $1-D$ and 2-D elastic analyses. Because of the simplicity of present modeling procedures and the anomalies that are frequently exhibited in the analyses, NRC currently limits the attenuation in ground motion with depth to not less than $60 \%$ of the criteria motions defined for grade level (ground surface).

In order to demonstrate the uncertainties associated with the assumptions currently used in free field analyses, Figure 1 provides ground surface (El 815) and foundation level (El 721) response for a soil site based on a 1-D SHAKE code analys is and a 2-D TRI/SAC code analysis (SAN/1011-112). If the applicant uses the 1-D code for predicting the seismic motion at the foundation level, an attenuation of $70 \%$ will be indicated at a frequency of $2 \mathrm{~Hz}$ and present NRC procedures would permit a reduction of up to $40 \%$ for this case. However, if the 2-D code is used to make the prediction, no attenuation would be indicated, or permitted, at $2 \mathrm{~Hz}$. Since the material property assumptions are approximately the same in both models, the discrepancy is probably due to the overly simplified characteristics of the 1-D model. Unfortunately, there is no experimental verification for either the 1-D or 2-D model, and neither model can be verified by design reviews and conventional alternate calculations.

Three alternatives are available. First, no attenuation in ground motion with depth might be assumed for the site, which could be a very conservative assumption. Second, expensive calculations could be made using 3-D elastic and 2-D nonlinear mathematical models. However, 


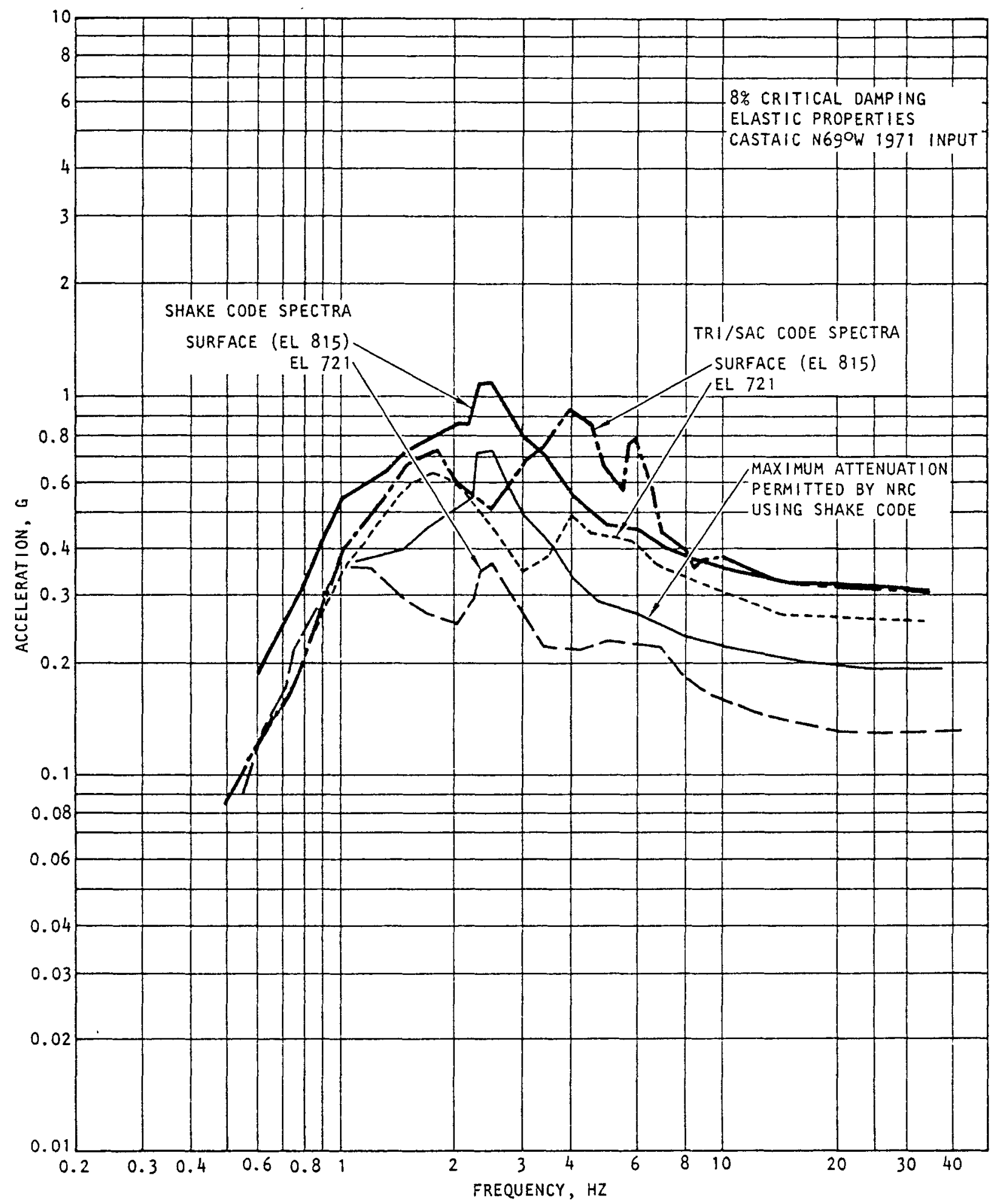

AA8330

FIGURE 1. COMPARISON OF COMPUTED FREE-FIELD SPECTRA FOR SOIL SITE USING SHAKE AND TRI/SAC COMPUTER CODES 
significant questions might still be raised concerning the adequacy of the modeling assumptions used, in the absence of any experimental verification of the results. The third alternative would be to provide experimental verification of the computed attenuation in seismic motion with depth, assuming that this is possible. This would be desirable regardless of whether 1-D or 2-D mathematical free-field models are used. Therefore, it must be concluded that there are modeling assumptions used in freefield analyses in which the confidence level would be greatly enhanced, if experimental verification could be provided.

\subsection{Structure Analyses}

Dynamic seismic analysis of Category I nuclear power plant structures, systems, and components are usually based on several mathematical models. The primary model treats the mass, stiffness, and damping characteristics of the structures, including the soil/structure interaction effects. Masses of large equipment items that cannot be justifiably uncoupled from the structure are also included. For complex structures, secondary models may be required to provide more detailed structure response. Separate mathematical models are also required to predict the dynamic response of equipment and piping. Free-field earthquake ground motions are used as dynamic input to the primary, soil/structure interaction models and are developed by the procedures discussed above in Section 2.3.1.3.1. The floor response computed from the primary model is then used as dynamic input to the mathematical models of equipment and piping. The soil/structure interaction analysis performed with the primary model is, therefore, one of the fundamental steps in the overall seismic dynamic analysis and will be discussed first, followed by a brief consideration of the structural models. Equipment and piping analyses are not within the scope of this study and will not be discussed. 
Current soil/structure interaction analysis procedures fall in two broad categories, depending upon the type of model used. One category uses discrete mass models of the structures which are supported by a series of linear elastic springs that introduce the equivalent stiffness of the supporting soil, or rock. Radiant energy losses and the hysteretic damping characteristics of the soil are approximated by equivalent viscous dampers. Figure 2 provides a section through a typical discrete mass model in which the base and floors of the structure are assumed to be rigid. The rigid base is in turn supported on translational, rotational, and torsional linear elastic soil springs.

The second general model category uses a system of discrete structural and soil continuum elements interconnected at their node points to represent the soil/structure system, and is referred to as a finite element model. An example of a 2-D finite element model is provided in Figure 3. Although the present analytical state of the art includes 3-D finite element capability, few if any authentic 3-D dynamic finite element soil/structure interaction analyses have been provided for nuclear power plant structures. This limitation, similar to the same limitation in freefield analyses, has apparently been imposed by computer costs, and for complex structures, by computer program capacity. Therefore, the present state of the art consists of either 3-D discrete mass, or 2-D finite element modeling procedures. Each type of model has certain advantages and disadvantages which will be summarized to indicate potential uncertainties in the basic assumptions associated with the two general types of models.

The advantages of the discrete mass model when compared to the 2-D finite element model are that the former can treat 3-D response and the analysis costs are less in computer-time charges. Generally, models for both procedures require about the same man-hours to prepare. The primary disadvantages of the discrete mass models are nearly all related to the simplified manner in which soil/structure interaction is treated. In order to select the soil springs and damping elements, the structure is 


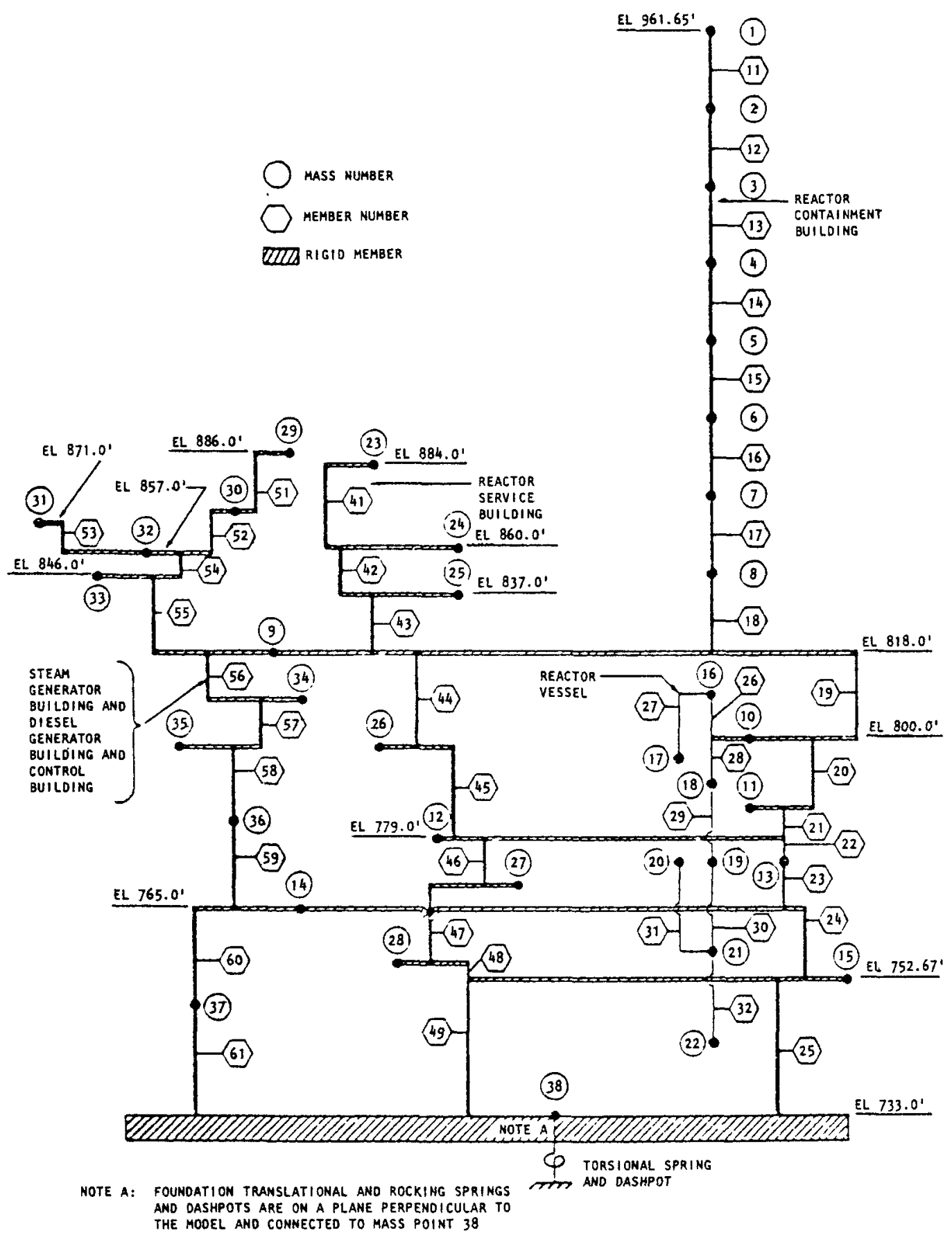

FIGURE 2. DISCRETE MASS MODEL OF A NUCLEAR POWER PLANT STRUCTURE (FrOM SAN/1011-110) 
BACKFILL

TOZT BUILDING FOUNDATION

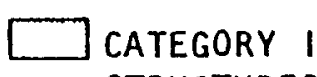

STRUCTURES

EL 815

EL 721

w

EL 241

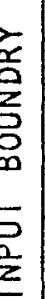

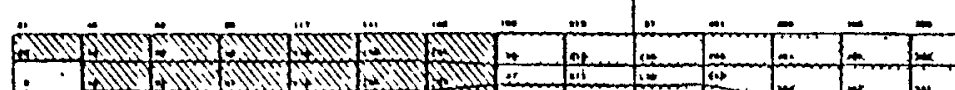

REACTOR

SERVICE BUILDING

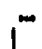
REACTOR CONTAINMENT TURBINE BUILDING BUILDING

F STEam GENERATOR BUILDING 
assumed to have a rigid base (see Fig. 2), the foundation shape is assumed to be rectangular or circular, and the depth of embedment of the structure is usually neglected. Based on these assumptions, and assuming that the soil behaves elastically, soil spring constants are conveniently computed from equations based on static loads and elastic half-space theory. These equations were initially developed to treat foundation vibration problems induced by heavy rotating, or reciprocating, equipment (i.e., steady-state vibrations of equipment supported by relatively rigid foundations). Actually, nuclear power plant structures are not rigid, the foundation shapes are usually irregular, the complex may consist of several closely spaced structures, the structures may be deeply embedded, and the supporting soil behavior may be nonlinear. Also, the soil spring constants are frequency dependent which is usually neglected. Radiation dampers* are selected from equations also based on elastic half space theory and are frequency dependent which is usually neglected, and there may be interaction between two or more structures which is also neglected. Thus, the greatest uncertainties associated with this type of model is in the interaction representation as sumptions.

The advantages of a finite element model over a discrete mass model result primarily from the fact that the finite element model provides an excellent distribution of the mass and stiffness of the structure and supporting rock or soil. For this reason, this model can more realistically treat the flexibility of the structure, the effects of embedment, layered supporting media, and the presence of adjacent structures. A proper finite element model automatically introduces radiant energy losses, and can respond in an almost unlimited number of (planar) modes in contrast to the

FLoss of energy from the model due to reflected stress waves that radiate away from the base of the structure is modeled through the use of viscous dampers. For embedded structures, radiant damping may reach 60 to $120 \%$ of critical damping. 
limited number of interaction modes possible with discrete mass models. Nonlinear behavior also can be considered with nonlinear finite element models, but few analyses have been provided for nuclear power plant structures. Also, it should be noted that the FLUSH code is nearly universally used as the finite element model. However, this code has all of the problems noted above for the SHAKE code. For example, the horizontal and vertical components of motion are uncoupled, simple, vertically propagating 1-D wave motion is used as input, and energy cannot radiate away from the structure nor out of the model.

It should be apparent from the above discussion that some of the assumptions associated with the soil/structure interaction representations for discrete mass models (also with the FLUSH code models) could be verified by alternate analyses using 2-D nonlinear and 3-D linear finite element models. However, as noted in the discussion of free-field analyses, in the absence of experimental verification some uncertainty would still exist.

It should also be noted that within a typical engineering organization there frequently exists only one opinion on how best to analyze certain difficult problems, such as soil/structure interaction, which leads to an intellectual incest within the organization and inhibits its members from viewing a problem from a different perspective. In the absence of experimental data, an entire industry, or a significant school of thought within the industry, may clearly be affected. This condition may well exist today in the nuclear power plant industry relative to methods of providing soil/structure interaction analyses, and methods of verification. There is therefore a strong need for some form of experimental verification of dynamic seismic free field and soil/structure interaction analyses to advance the confidence level in the analysis assumptions.

There are other assumptions in structural models that require verification. In some cases this can be conveniently handled by providing 
alternate analytical solutions. However, there are few examples where such alternate analyses have been provided. An example where suct, analyses have been provided is given in Figure 4. Referring first to Figures 2 and 3 , it will be noted that the reactor containment structure is modeled as a discrete mass cantilever beam model in both examples, even though the structure is a cylindrical shell. If modeled as a shell structure, ovaling modes of response can be represented, but if modeled as a cantilever beam model, the ovaling modes must be neglected. Figure 4 provides an example where the containment structure was modeled in both configurations. The results indicated that for the particular proportions of this structure, the ovaling modes were of little relative importance.

There are other aspects to this problem. Referring to Figure 3 , the dynamic response at the node point at the base of the containment structure cantilever model will be highly concentrated, when in reality it is distributed three dimensionally around the perimeter of the shell and does not really occur at the node point indicated in Figure 3 . While the response of the containment shell may be well represented by the cantilever model, the local response in the base structure below El 815 will be overestimated by this model. Thus, a two or three dimensional representation of the containment structure would have been a better approximation of the response. Here alternate analytical solutions would be required to determine the probable error resulting from the simpler model.

A slightly different problem exists in Figure 2 relative to the cantilever models. Here, three cantilever models are attached to a rigid plate representing the top floor of the substructure. Each cantilever model has a different fundamental mode and will vibrate out of phase when subjected to strong earthquake ground motion. This will transfer complex response to the substructure floor. However, the floor has been assumed to be rigid, so the more complex floor response will not be included in the results. Three dimensional models of the structures in Figures 2 and 3 would give a better estimate of the structural response, but this would add greatly 


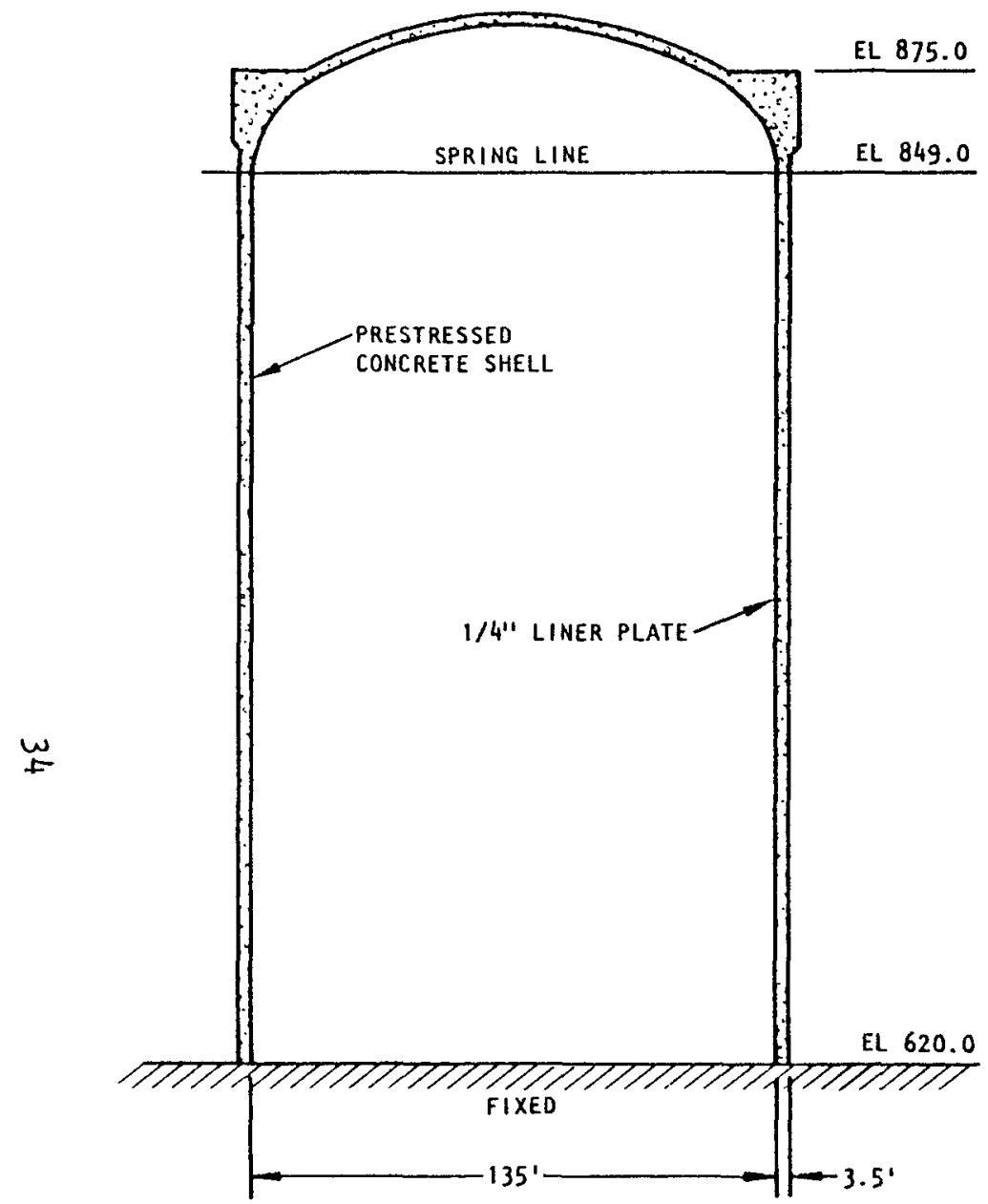
(a) Section through containment structure

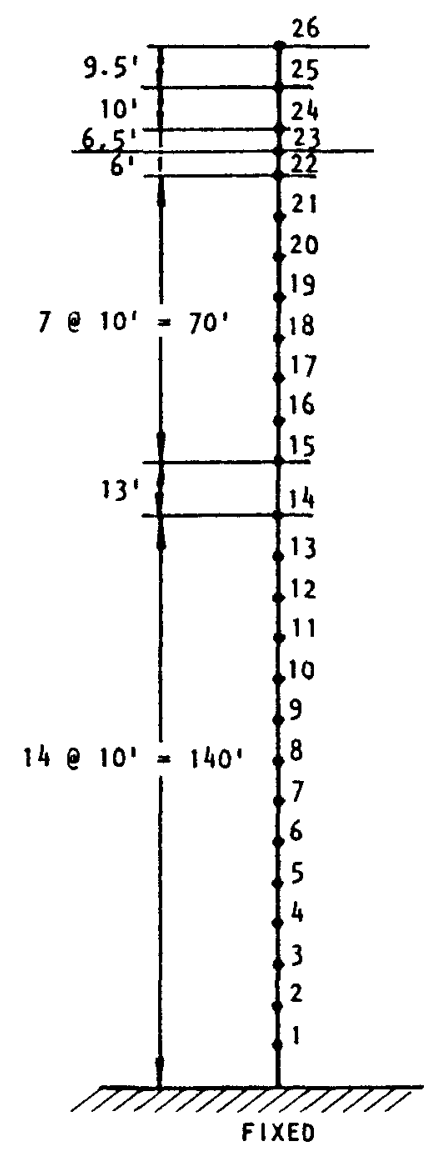

(b) Discrete mass model of containment structure

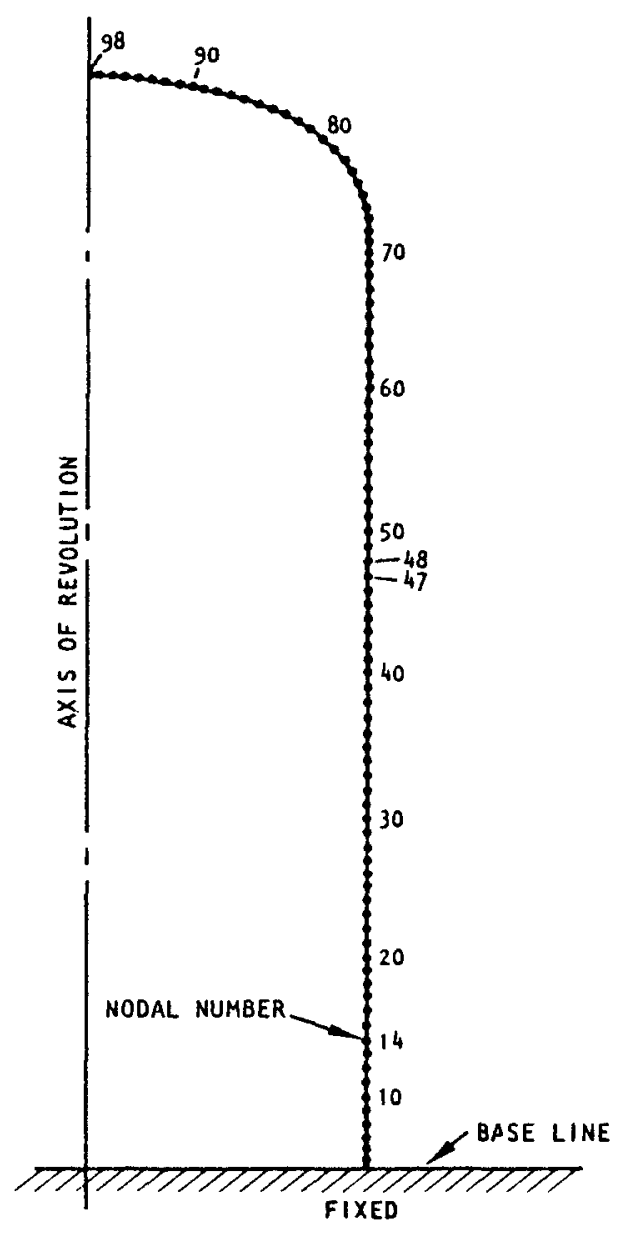

(c) Finite element shell model of containment structure

FIGURE 4. EXAMPLES OF DISCRETE MASS AND FINITE ELEMENT MODELS OF CONTAINMENT STRUCTURE (FROM FENG, ET AL, 1975) 
to the cost of the analysis and in some cases the models might exceed the capacity of the computer.

From the above discussion, it is evident that structure models currently used simplify the true structure response. Good engineering judgment must be exercised to make certain that the simplified response is a conservative estimate of the true response. However, engineering judgment and intuition do not provide design verification. There is also the problem that simplified conservative analyses may result in unnecessarily expensive designs. Damping in structural materials, for example, is difficult to estimate. As a result it is invariably conservatively underestimated in the analysis assumptions. Therefore, there is no question but what verification of the design assumptions associated with the dynamic analyses of nuclear power plant structures by some form of experimental testing would greatly enhance the confidence level in the assumptions, and perhaps lead to less conservative design.

\subsubsection{Design Details}

In nearly every strong earthquake in which severe damage has resulted to engineering structures, some of the damage has invariably been traced to faulty design details. Design codes are, therefore, altered after each major earthquake to provide more stringent detailing requirements. Qualification tests of military structures subjected to blast and ground shock effects, and qualification testing of military equipment have also frequently revealed overloaded details in the design, or overlooked modes of response, that are strikingly evident from the test results. Because of constant improvements in the design codes, and because of the special care that is exercised in the design of nuclear power plant structures, the likelihood of critical omissions in predicted nuclear power plant structural behavior is significantly reduced, but in the absence of some form of experimental verification of response, it is not possible to assure that such omissions have been completely eliminated. Some form of experimental verification of response is therefore justified, solely for the purpose of detecting unforeseen modes of response, and errors in design details. 


\subsubsection{VERIFICATION OF DESIGN ASSUMPTIONS}

Section 2.2 has indicated that design verification of nuclear power plant structures is currently provided only by design reviews and alternate calculations. Qualification testing is not used because of the expense and the possible damage to other nearby structures, and because of the possible damage to Category $\| 1$ and 111 items of the nuclear power plant. The introductory paragraphs of Section 2.3 have raised the question of whether design reviews and alternate analyses provide as reliable a verification procedure as qualification testing (assuming it could be provided). The discussion indicates that it is not as reliable, unless the design assumptions are known to be correct (i.e., have been verified). The confidence level in different design assumptions have then been discussed and it has been demonstrated that there are design assumptions that need additional verification in order to enhance the confidence in the design review-alternate calculation design verification procedure. In some cases this could be provided by more sophisticated analyses, but it is evident that some form of test verification is also needed to enhance the confidence level in the design as sumptions.

Recommended verification procedures can be better presented after different test methods have been reviewed in Chapter 3 . However, to illustrate that test verification of design assumptions will not be a simple exercise, assume that the tests would be performed on a prototype structure. Two characteristics of the tests are immediately evident. First, because of the damage that might otherwise result to Category 11 and 111 items, and also because of the practical limits on the energy that can be introduced in the input, the seismic test environment will need to be significantly below the $O B E$ and SSE environments. Second, the dynamic response of a nuclear power plant structure (including the soil) may be nearly linearly elastic at the test level, but will usually become nonlinear in the stronger SSE environment. Therefore, extrapolation of response into the nonlinear range from the measured response in the linear elastic range will be difficult. 
There are certain benefits that would definitely result from lower level testing. For example, unique modes of structural response and some errors in design details should be detectable. However, it will be difficult to verify assumptions associated with free field and soil/structure interaction analyses, and associated with the damping assumptions assigned to the soil and structural materials. To some extent, this will also apply to the stress-strain behavior of the structural materials in the regions where yield behavior is approached in the SSE environment. Proper verification of design assumptions may, therefore, require both experimental tests and more sophisticated analyses. This subject will be considered further in Chapter 4. 


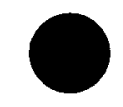

• 


\title{
CHAPTER 3
}

COMPARISON OF DYNAMIC TESTING METHODS

\subsection{INTRODUCTION}

This chapter describes various methods of dynamically loading large structures to obtain experimental data on response characteristics. It is based upon a review of the technical literature describing dynamic tests of multistory buildings and relatively small nuclear power plant structures. Following the description of the test methods, examples of test results and a comparison of the test methods are provided.

\subsection{DYNAMIC TEST METHODS}

Methods of providing dynamic tests of large structures can be summarized from papers by Hudson, 1970 and 1976, as follows:

a. Free Vibration Tests

Initial Displacement--pull-back and quick release Initial Velocity--impacts, rockets

b. Forced Vibration Tests

Transient Excitations

\author{
Wind \\ Microtremors \\ Explosions \\ Natural earthquakes \\ Steady-State Resonance Excitation \\ Mechanical Oscillators \\ Man-excited
}




\author{
Variable Frequency Excitation \\ Sweep frequency--rundown \\ Pulse sequences \\ c. Vibration Table Tests \\ Dynamic testing of structures requires excitation or loading, \\ instrumentation to measure response, and data processing to aid in the inter- \\ pretation of the results. Since the primary concern here is in the feasibility \\ of different methods of loading, instrumentation and data processing will \\ not be discussed. However, these are important aspects of any test program \\ and must be carefully considered when planning the tests. The extent of the \\ discussion that follows has been determined largely by the applicability of \\ the method to testing nuclear power plant structures.
}

\title{
3.2.1 FREE VIBRATION TESTS
}

Initial displacement tests, which are also known as snap-back, pull-back or "twang" tests, are provided by giving the structure an initial displacement by means of an applied force which is suddenly released allowing the structure to vibrate freely. The free, transient vibration of the structure is then recorded and analyzed to obtain frequencies, mode shapes and damping values. One of the difficulties associated with the use of this method for testing nuclear power plant structures is that the very large forces needed to provide adequate displacements require strong anchor points as well as points on the structure that can withstand large loads. Also, as a practical matter, the most that can be achieved with this method is excitation of the horizontal modes by applying loads to the above ground more flexible portions of the structure. Such tests have been performed on water tanks (Carder, 1936) and steel stacks (Cloud, 1963). Even for simple structures the results are not always entirely satisfactory. If the loads are not carefully applied, or if the structures are not symmetrical, response occurs about both principal axes, which produce 
records that exhibit beating and make the data hard to interpret. Clearly, simple, vertical cantilever type structures are more amenable to this method of testing than a nuclear power plant because of their greater flexibility and fewer significant modes.

Another method of exciting test structures is to provide an inpulse or initial velocity. This can be accomplished by means of rockets, explosive cartridges, pendulums or falling weights, whose time of load application is short compared to the period of the structure. Rockets appear to be the most promising loading concept and have been used to test a concrete chimney (Hudson, 1970). However, since only a short pulse load is applied, the method is again much more applicable to simple vertical cantilever structures than to massive complex nuclear power plant structures. A more sophisticated extension of this method will be considered under variable frequency excitations with pulse sequences in Section 3.2.4.

\subsubsection{TRANSIENT EXCITATION}

Transient excitations that have been used to excite structure response for dynamic tests include relatively low level ambient vibrations that result from wind, operating machinery, street traffic and microseismic activity, and stronger input resulting from underground explosions and from natural earthquakes. A brief description of these two general types of structure excitations follows.

Ambient vibrations from wind, operating machinery, street traffic and microseismic activity have been used for more than four decades to measure the dynamic response of structures. The U.S. Coast and Geodetic Survey (USCGS, 1936) was one of the first to use the measured wind induced response of buildings to calculate building frequencies. In this method, highly sensitive seismometers are placed at various points on the structure, depending upon the mode shapes of interest. The response measured by the seismometers are amplified and recorded on magnetic tape. The analog data is then digitized, filtered and processed using random vibration theory and spectral analyses to obtain estimates of the modal frequencies, vectors, and damping. 
Advancements in instrumentation and data processing during the past two decades have refined the method to where it is now possible to obtain a relatively complete set of data including higher modal frequencies, vectors, and damping values (see Crawford and Ward, 1964, Ward and Crawford, 1966, and Cherry and Brady, 1965). The method has been used to determine dynamic characteristics of a variety of structures including high rise buildings (Trifunac, 1970), suspension bridges (McLamore et al., 1971), the concrete. intake tower of a dam (Keightley et al., 1961) and a nuclear power plant (ES, 1968).

The response of structures to ground motions induced by underground explosions have also been measured in sufficient tests to indicate that this is an acceptable loading procedure. Both underground chemical and nuclear explosions have been used. This is one of the few procedures in which the structure is excited by base motion due to stress waves propagating through the soil and rock. The response, therefore, includes soil/structure interaction effects. The method has great promise but has two strong disadvantages. First, it is quite expensive, and second, because of other cultural developments that may be near many nuclear power plant sites, the liability for damage to these developments during planned tests could be quite high.

An early example of using the ground motion generated by an underground explosion as a dynamic test environment for a structure was reported by Hudson, et al., 1954. In this example 370,000 lb of explosive (Nitramon) was detonated in a rock quarry approximately 400 yards from the structure. This test was repeated six years later in conjunction with a second blast in which 1,347,000 ib of explosives were detonated with two time delays of $17 \mathrm{msec}$ each. Studies performed by the U.S. Coast and Geodetic Survey (Carder and Cloud, 1959) have established relationships between charge size, distance from point of detonation and peak ground acceleration. Underground military structures have also been tested with chemical explosives. Test procedures for military structures are summarized 
in a recent corps of Engineers guideline manual on Hardness Verification, see COE, 1977.

The ground motion produced by underground nuclear explosions have also been used as a means of excitation of various structures, see AEWES, 1972 and Medearis, 1975. For example, the response of a microwave tower, an athletic gymnasium and an earthdam to the detonation of three $30 \mathrm{KT}$ nuclear devices which were located from 4 to $40 \mathrm{miles}$ from the facilities and more than one mile below ground was measured. The ground motion resulting from an underground nuclear explosion more nearly resembles that of an earthquake than any other type of input. This results because the depth of the detonation is deep, and because the distance to the point of detonation is great enough to permit the stress waves to propagate by multiple paths. This produces an input having a broad band response spectrum similar to an earthquake. However, because of the restrictions on underground nuclear testing, and the broad land area affected by the detonation, tests of this type can be carried out in only limited areas and under limited conditions.

In the city of Los Angeles, California (also in San Francisco), high rise buildings have been instrumented with strong motion recorders at the base and at two upper levels. As a result, the response of some of the structures to strong earthquake ground motion has been recorded, see NOAA, 1973a. This obviously provides the most realistic test conditions possible. However, long periods of waiting are required to collect response information with this type of testing, and the instrumentation usually is not adequate to permit optimum interpretation of results. Nevertheless, on a long term basis it represents a test procedure for obtaining reliable information, if the instrumentation is adequately planned.

\subsubsection{STEADY STATE RESONANCE EXCITATION}

Steady state resonance excitation of test structures using a sinusoidally varying, unidirectional force is probably the most common 
type of dynamic testing of structures currently used. In this test, the frequency of the applied force is first held constant at one value while measurements of the structure response are recorded. The frequency of the applied force is then changed, and the response measurements repeated. The end product of such a test is a set of frequency response curves for various points on the structure from which natural frequencies, mode shapes and damping can be extracted. Nonlinearities in the test system can also be investigated by varying the amplitude of the applied load at the different test frequencies and noting the change in resonant frequency.

Acceleration of mass is the method normally used to generate the forces applied to the structure with this method of testing as there is usually no adequate means of reacting the large mechanical forces necessary to drive a massive structure. Among the devices developed for this purpose are ones that utilize rotating eccentric masses, rectilinear reciprocating masses and electromagnetic drives, Hudson, 1976. The type that has been used most often employs two counterrotating eccentric masses of equal moment, arranged so that the reaction force on the structure is rectilinear. Devices employing this principle have been used for many years. For a detailed description of a modern force generator, see Hudson, 1962.

The characteristics of vibration generators available in this country and in USSR are summarized in Table 1. The EERI/CIT units are used by the University of California, Los Angeles and by the California Institute of Technology. The hydraulically operated rectilinear reciprocating mass unit was developed to test structures associated with underground nuclear tests at the Nevada Test Site, see Smallwood et al, 1975. The EERI/CIT units are capable of producing response of the order of $0.01 \mathrm{~g}$ in large structures, Trifunac, 1972. It should be noted in Table 1 that the larger USSR unit is reportedly capable of producing a maximum force more than an order of magnitude greater than the other test devices.

Hudson, 1976, also notes that tests have been performed in which steady state response has been excited by a man moving his center of mass 
TABLE 1. VIBRATION GEHERATOR CHARACTERISTICS

\begin{tabular}{|c|c|c|c|c|}
\hline & $\begin{array}{c}\text { USA } \\
\text { EERI-CIT }\end{array}$ & $\begin{array}{c}\text { USA } \\
\text { Linear/Hydraulic }\end{array}$ & $\begin{array}{l}\text { USSR } \\
W-2\end{array}$ & $\begin{array}{l}\text { USSR } \\
W-3\end{array}$ \\
\hline Number of Units & 4 & 1 & 4 & 6 \\
\hline $\begin{array}{l}\text { Maximum Generated } \\
\text { Force }(\text { ton }=2200 \mathrm{lb})\end{array}$ & 9 & 5.7 & 80 & 200 \\
\hline $\begin{array}{l}\text { Minimum Frequency for } \\
\text { Maximum Force, } \mathrm{Hz}\end{array}$ & 2.5 & 5.7 & 3.7 & 3.5 \\
\hline Frequency Range, $\mathrm{Hz}$ & $1-9.7$ & $1-50$ & $0.4-3$ & $0.4-10$ \\
\hline $\begin{array}{l}\text { Unbalanced Moment, } \\
\mathrm{kg}-\mathrm{m}\end{array}$ & 360 & 700 & 1560 & 4000 \\
\hline $\begin{array}{l}\text { Total Weight } \\
(\text { ton }=2200 \mathrm{lb})\end{array}$ & 3 & 8.8 & 7.7 & 13 \\
\hline Power, kw & 12 & 64 & 50 & 100 \\
\hline
\end{tabular}


at the fundamental frequency of the structure. His example indicates that a $150 \mathrm{lb}$ man moving his body with a double amplitude of $6 \mathrm{in}$. at a frequency of $1 \mathrm{~Hz}$ will exert an inertia force of $46 \mathrm{lb}$. When compared to the effective forces 1 isted in Table 1 , it is apparent that the excitation level is too low to be of interest in testing nuclear power plant structures.

\subsubsection{VARIABLE FREQUENCY EXCITATION}

Variable frequency excitation is common in the testing of equipment with low damping. Here there is great danger that testing at a resonant frequency will quickly lead to equipment damage because of the force buildup. Thus, the frequency of excitation is varied gradually through a range of frequencies to identify beat frequencies from which the mode frequencies can be extracted. This can also be accomplished by operating the oscillator at a high speed and then cutting all power, allowing it to coast or "rundown" through the mode frequencies of the test item. While this method of excitation simplifies the speed control and instrumentation problems, the energy input is too low to represent a viable test procedure for nuclear power plant structures.

A rather unique system of loading a structure with a series of pulses geometrically located and systematically timed to cause the structure to respond in a specified manner has been proposed by Safford and Masri (see Masri and Safford, 1976 and Safford et al., 1977). In this procedure, puises consisting of cold gas, hot gas or solid fuel propellants, depending on the impulse needed, are placed at optimum points on the structure. Feasibility studies, for example, have been conducted to determine the size, quantity and location of pulses required for a 25-story building. An optimization algorithm operates with the building system functions (impedance or transfer function) to compute the pulse train required to produce the specified response. Pulses are varied in amplitude, duration and initiation time. This system could be used to determine mode response characteristics, or to cause the structure to develop a specified response. This system has great potential and is in the process of being developed. 


\section{2 .5 VIBRATION TABLE TESTS}

At the present time, a limited number of shake tables are available (Penzien, 1967) which are being used to test scale models of relatively simple structures. However, shake table as well as field deployed model tests do not appear to be an attractive means of providing experimental verification of the dynamic response of nuclear power plant structures. For example, the largest shake tables could not accommodate even a onetenth scale model of a structural complex such as the Clinch River Breeder Reactor Plant. Model construction is also expensive, and scaling problems become very difficult, if not impossible, to treat. Solls are nonlinear, and the properties of cohesionless materials, for example, are a function of the depth of the overlying soil. Dynamic similarity would have to be maintained (the relative frequency of the structure and input wave motions would have to be scaled) as well as the site and structure geometry, and the soil properties. This is beyond present day modeling techniques and is not therefore recommended.

\subsection{COMPARISON OF TEST RESULTS}

From the description in Section 3.2 of methods that have been used to dynamically load structures, only four justify additional discussion relative to their applicability to testing of nuclear power plant structures. These are loads induced by ambient transient vibrations and steady state mechanical oscillators, and loads induced by explosions and natural earthquakes. The first two represent relatively low energy level loads while the last two represent loads that approximate those developed in an OBE or SSE environment. In this section, examples of test results for each method and comparison of results from the various methods are provided.

An important consideration in evaluating test procedures is the ability to verify test results by either theoretical calculations or by comparison with results from other test procedures. Fortunately, there has been sufficient duplication in analytical studies and test methods that a meaningful comparison of test results can be provided. To avoid duplication, 
the results of a relatively few ambient vibration tests of multistory buildings will be provided first for which a comparison can be made with computed theoretical fundamental periods. This will be followed by a section in which ambient transient and steady state vibratory test data are compared, and by a section in which the response of structures to explosive input are compared to steady state vibratory loads. Finally, the response of structures to natural earthquakes will be considered and the results compared with theoretical analyses and ambient or steady state vibratory test data.

\subsubsection{COMPARISON OF AMBIENT TRANSIENT TEST RESULTS WITH THEORETICAL ANALYSES}

There are numerous examples in the technical literature of the use of ambient transient wind loads as the source of excitation of buildings in tests designed to determine the fundamental periods, modal vectors and damping values. In this section a few representative examples will be cited where there are published values for the computed theoretical fundamental periods also available. Additional ambient vibration results will be presented in the following sections where comparisons are made with measurements obtained with other types of loading.

Table 2 provides a comparison of fundamental periods determined by theoretical calculations and from ambient wind vibration measurements for five buildings. The first four buildings are reported by crawford and Ward for buildings in Ottawa and Montreal, Canada. The buildings vary from 10 to 44 stories in height and both steel and reinforced concrete types of construction are represented. The fifth structure is a reinforced concrete seven story motel located in the San Fernando Valley of California that is of interest for later comparisons because it was subjected to strong earthquake ground motion during the 1971 earthquake. It should be noted that the analytical models used to compute the fundamental periods in most cases were crude compared to present-day capability. One-dimensional discrete mass models were used, and it will be noted that the torsional modes were 
TABLE 2. COMPARISON OF FUNDAMENTAL PERIODS OF BUILDINGS DETERMINED FROM THEORETICAL COMPUTATIONS AND FROM AMBIENT TRANSIENT WIND LOADS

\begin{tabular}{|c|c|c|c|c|c|c|}
\hline \multirow[b]{2}{*}{ Building } & \multirow[b]{2}{*}{ Description } & \multirow[b]{2}{*}{ Direction } & \multicolumn{3}{|c|}{ Fundamental Period, sec } & \multirow[b]{2}{*}{ Reference } \\
\hline & & & Theoretical & $\begin{array}{l}\text { Ambient } \\
\text { Measured }\end{array}$ & $\begin{array}{l}\text { Ratio } \\
\text { T/A }\end{array}$ & \\
\hline $\begin{array}{l}\text { 1. Health and } \\
\text { Welfare Building, } \\
\text { Ottawa, Canada }\end{array}$ & $\begin{array}{l}17 \text { stories, } 140 \mathrm{ft} \times 88 \mathrm{ft} \text { plan, } \\
235 \mathrm{ft} \text { high, reinforced concrete } \\
\text { core with steel frame }\end{array}$ & $\begin{array}{l}\text { Long } \\
\text { Transverse } \\
\text { Torsional }\end{array}$ & $\begin{array}{l}1.4 \\
1.4 \\
-\end{array}$ & $\begin{array}{l}1.3 \\
1.0 \\
0.9\end{array}$ & $\begin{array}{c}1.1 \\
1.4 \\
-\end{array}$ & $\begin{array}{l}\text { Crawford and ward, } \\
1964\end{array}$ \\
\hline $\begin{array}{l}\text { 2. Imperial Bank } \\
\text { Montreal, Canada }\end{array}$ & $\begin{array}{l}44 \text { stories, } 140 \mathrm{ft} \times 100 \mathrm{ft} \text { plan, } \\
603 \mathrm{ft} \text { high, steel frame }\end{array}$ & $\begin{array}{l}\text { Long } \\
\text { Transverse } \\
\text { Torsional }\end{array}$ & $\begin{array}{l}3.3 \\
3.9 \\
-\end{array}$ & $\begin{array}{l}4.7 \\
4.7 \\
3.9\end{array}$ & $\begin{array}{c}0.7 \\
0.8 \\
-\end{array}$ & $\begin{array}{l}\text { Ward and Crawford, } \\
1966\end{array}$ \\
\hline $\begin{array}{l}\text { 3. CIL House, } \\
\text { Montreal, Canada }\end{array}$ & $\begin{array}{l}34 \text { stories, } 168 \mathrm{ft} \times 112 \mathrm{ft} \text { plan, } \\
430 \mathrm{ft} \text { high, steel frame }\end{array}$ & $\begin{array}{l}\text { Long } \\
\text { Transverse } \\
\text { Torsional }\end{array}$ & $\begin{array}{c}3.0 \\
2.6 \\
-\end{array}$ & $\begin{array}{l}3.9 \\
4.5 \\
3.4\end{array}$ & $\begin{array}{c}0.8 \\
0.6 \\
-\end{array}$ & $\begin{array}{l}\text { Ward and Crawford, } \\
1966\end{array}$ \\
\hline $\begin{array}{l}\text { 4. Post office, } \\
\text { Ottawa, Canada }\end{array}$ & $\begin{array}{l}10 \text { stories, } 266 \mathrm{ft} \times 74 \mathrm{ft} \text { plan, } \\
148 \mathrm{ft} \text { high, reinforced concrete }\end{array}$ & $\begin{array}{l}\text { Long } \\
\text { Transverse } \\
\text { Torsional }\end{array}$ & $\begin{array}{l}0.9 \\
0.8 \\
-\end{array}$ & $\begin{array}{l}0.6 \\
0.7 \\
0.3\end{array}$ & $\begin{array}{c}1.5 \\
1.1 \\
-\end{array}$ & $\begin{array}{l}\text { Ward and Crawford, } \\
1966\end{array}$ \\
\hline $\begin{array}{l}\text { 5. Holiday Inn, } \\
8244 \text { Orion St., } \\
\text { Los Angeles, } \\
\text { California }\end{array}$ & $\begin{array}{l}7 \text { stories, } 160 \mathrm{ft} \times 62 \mathrm{ft} \text { plan, } \\
86 \mathrm{ft} \text { high (est) }\end{array}$ & $\begin{array}{l}\text { Long } \\
\text { Transverse } \\
\text { Torsional }\end{array}$ & $\begin{array}{l}0.8 \\
0.9 \\
-\end{array}$ & $\begin{array}{l}0.5 \\
0.5 \\
-\end{array}$ & $\begin{array}{l}1.6 \\
1.8 \\
1.7\end{array}$ & NOAA, 1973a, b \\
\hline
\end{tabular}


not computed. Soil/structure interaction effects, which should have little influence on ambient transient wind vibration results were also neglected in the calculations.

Two points should be particularly noted from the data in Table 2, first the error in the computed periods vary both above and below the measured periods by an average of $35 \%$, with the greatest errors of 60 and $70 \%$ occurring for the most recent structure. Other comparisons will confirm that differences between computed and measured periods of buildings will frequently reach 50 to $100 \%$, and the average value of $35 \%$ deviation noted here is a typical mean value. The second point that should be noted is the close spacing of the torsional and flexural mode periods for all buildings where the torsional mode period was measured. When the modes are closely spaced, coupling between the torsional and flexural modes should be anticipated. This type of behavior has been measured on other structures and will be noted in the next section. It implies that the torsional mode should not be overlooked in design.

Damping values were also estimated for three of the Canadian buildings (Ward and Crawford, 1966) which will be noted for later reference. By power spectral analyses, damping of from 1.0 to $1.8 \%$ was measured for the fundamental modes of response for the three buildings. Values of 1.6 and 1.8 were measured for one fundamental mode of two of the buildings by auto correlation analysis.

\subsubsection{COMPARISON OF AMBIENT TRANSIENT AND STEADY STATE VIBRATION TEST RESULTS}

There are several buildings that have been subjected to both ambient transient and steady state vibratory tests. However, this discussion will be limited to two multistory building examples since the tests are recent and represent current state of the art. Comparative test results on a nuclear reactor structure will also be presented since such structures are the primary area of interest of this investigation. 
Plan and sectional elevations of the two multistory buildings that will be considered are indicated in Figures 5 and 6 . Test results for the fundamental period determination are given in Table 3 . The depth of embedment of the two structures should be particularly noted. The central tower of the San Diego Gas and Electric Building is separated from the wider two story reinforced concrete structure that extends up to floors 2 and 3, by 3-in. wide joints. The tower, therefore, has two lower basement stories, 1 and $A$, that are supported by the wider structure which is bermed with earth to varying heights on the different sides of the structure. Thus, the laterally unsupported tower height of $291 \mathrm{ft}$ is embedded for an additional depth of $28 \mathrm{ft}$ which is slightly less than $10 \%$ of its height.

The Millikan Library, see Figure 6 , is laterally unsupported for a height of $128 \mathrm{ft}$ and is embedded for an additional $14 \mathrm{ft}$ which is also about $10 \%$ of the unsupported height. This is noted for later reference and comparison with nuclear power plant structures which are generally more deeply embedded, relatively to the height.

The results in Table 3 show that excellent comparative results were obtained for the fundamental periods for both structures. Actually, seventeen modes were measured for the San Diego Gas and Electric building (6NS; $5 \mathrm{EW;} 6$ Torsional) with excellent agreement being obtained throughout. A comparison of some of the mode shapes derived by the two methods is provided in Figure 7.

An interesting result from the San Diego Gas and Electric building analysis is shown in Figure 8 . This figure shows the three fundamental modes of response of the twentieth floor. It indicates that the fundamental modes of floor response are not simple orthogonal NS, EW and torsional motion, even though the structure is quite symmetrical. The fact that the fundamental modes are closely spaced no doubt contributes to the mixed response. These modes were broken down into NS, EW and torsional mode components for listing in Table 3 . 


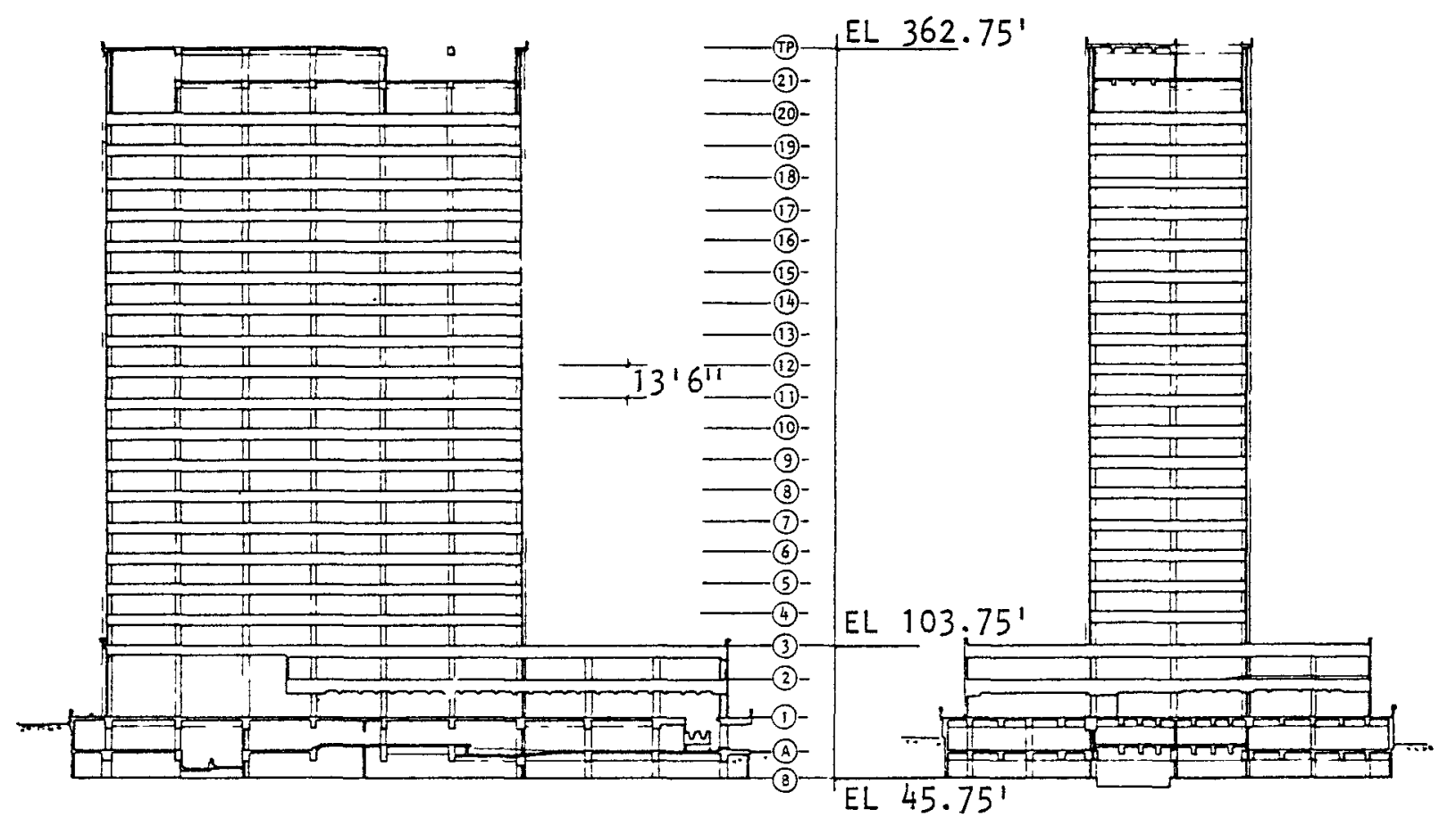
(a) N-S sectional elevation
(b) E-W sectional elevation

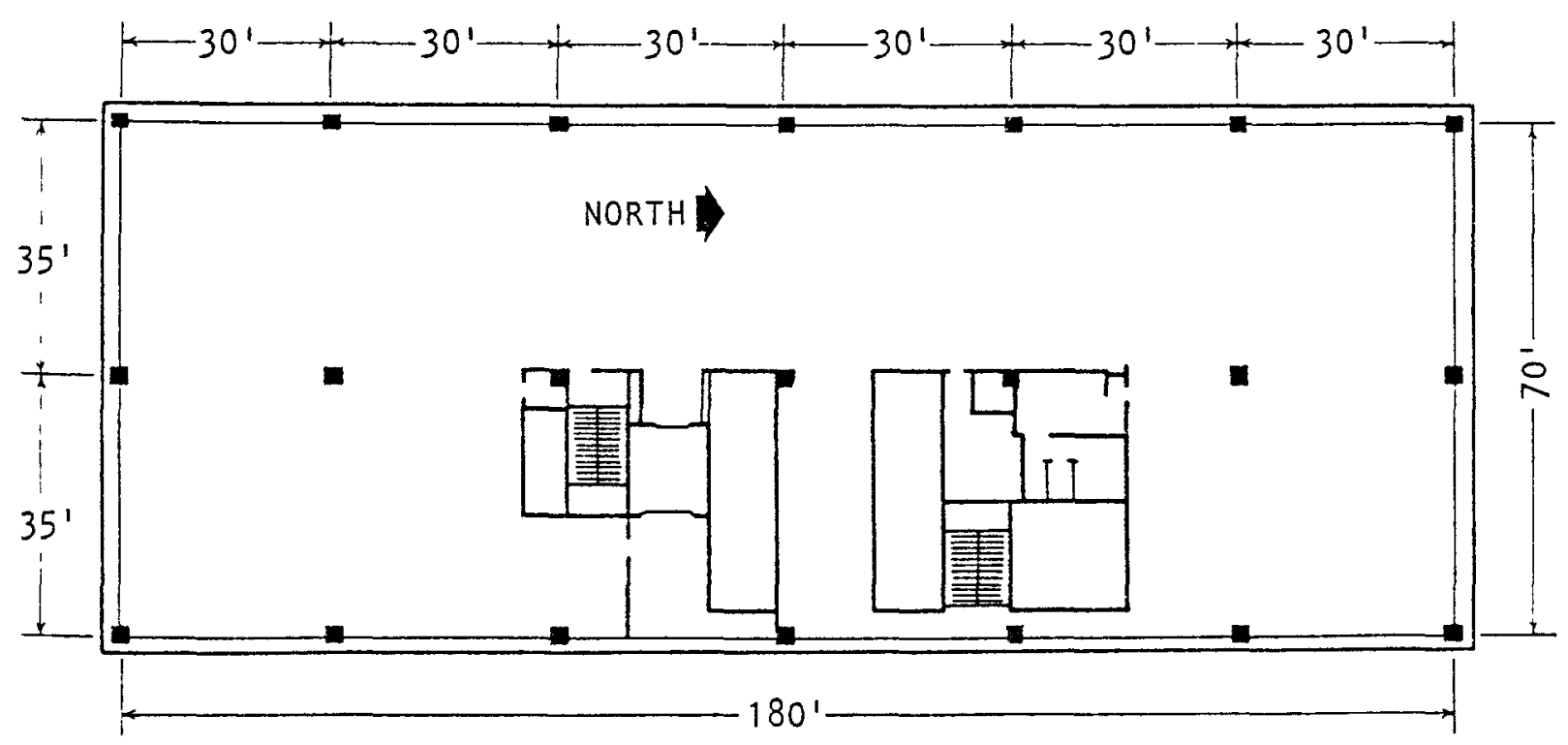

(c) Typical floor plan

FIGURE 5. PLAN AND ELEVATIONS OF SAN DIEGO GAS AND ELECTRIC COMPANY BUILDING (Jennings et al., 1972) 
NORTH

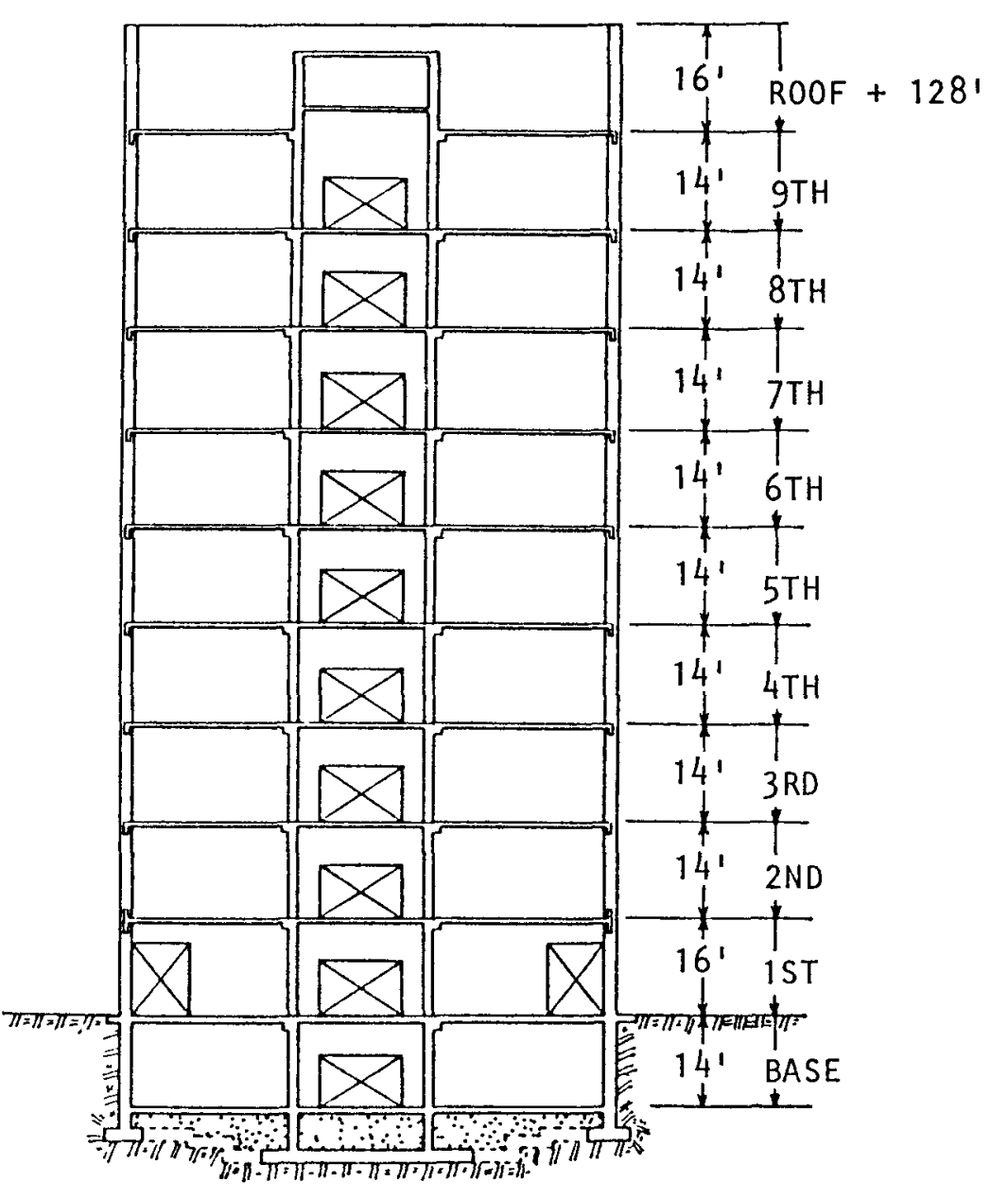

(a) N-S sectional elevation

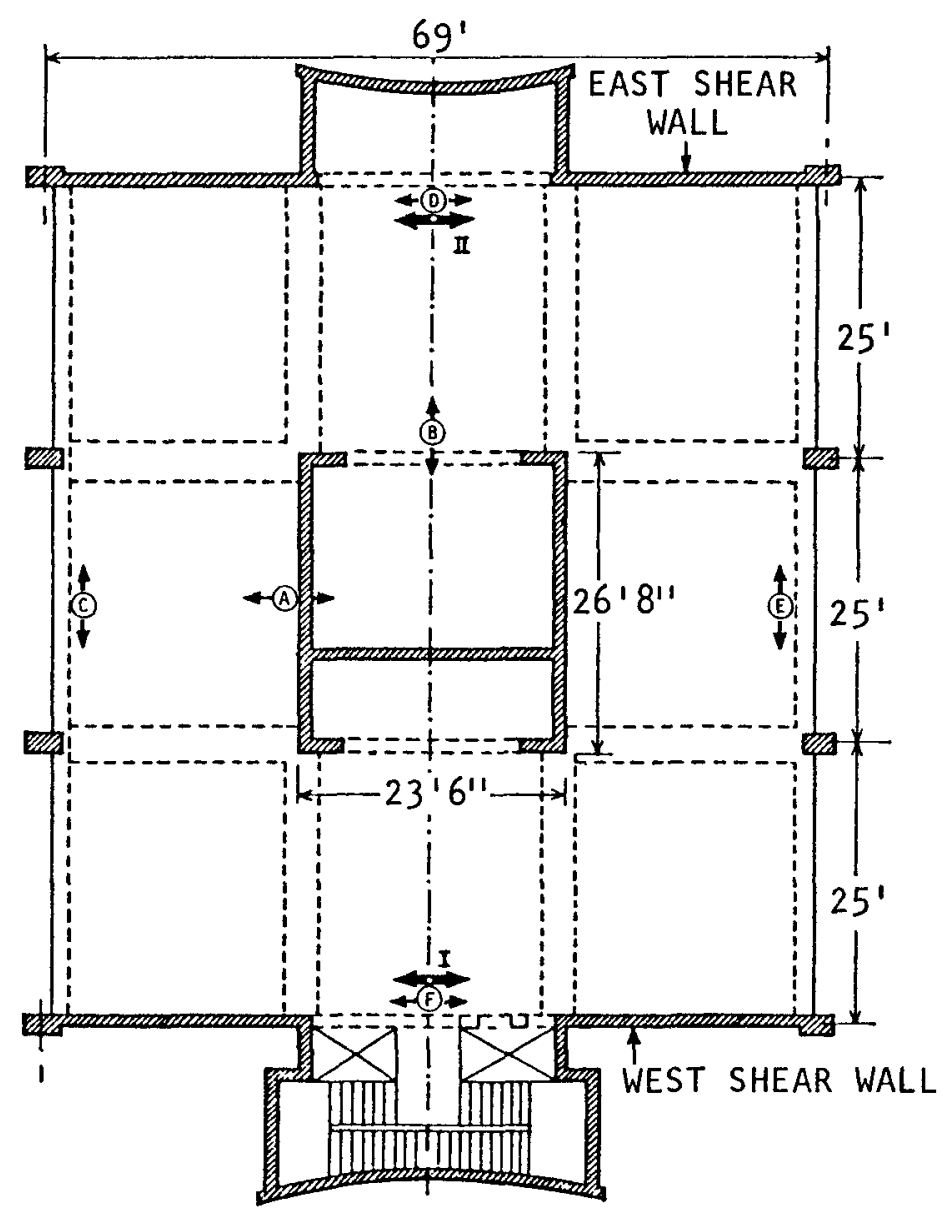

(b) Plan

FIGURE 6. PLAN AND ELEVATION OF MILLIKAN LIBRARY, CALIFORNIA INSTITUTE OF TECHNOLOGY (TrifunaC, 1972) 
TABLE 3. COMPARISON OF FUNDAMENTAL PERIODS OF BUILDIIIGS DETERMINED BY AMBIENT TRANSIENT AND STEADY-STATE VIBRATORY TESTS

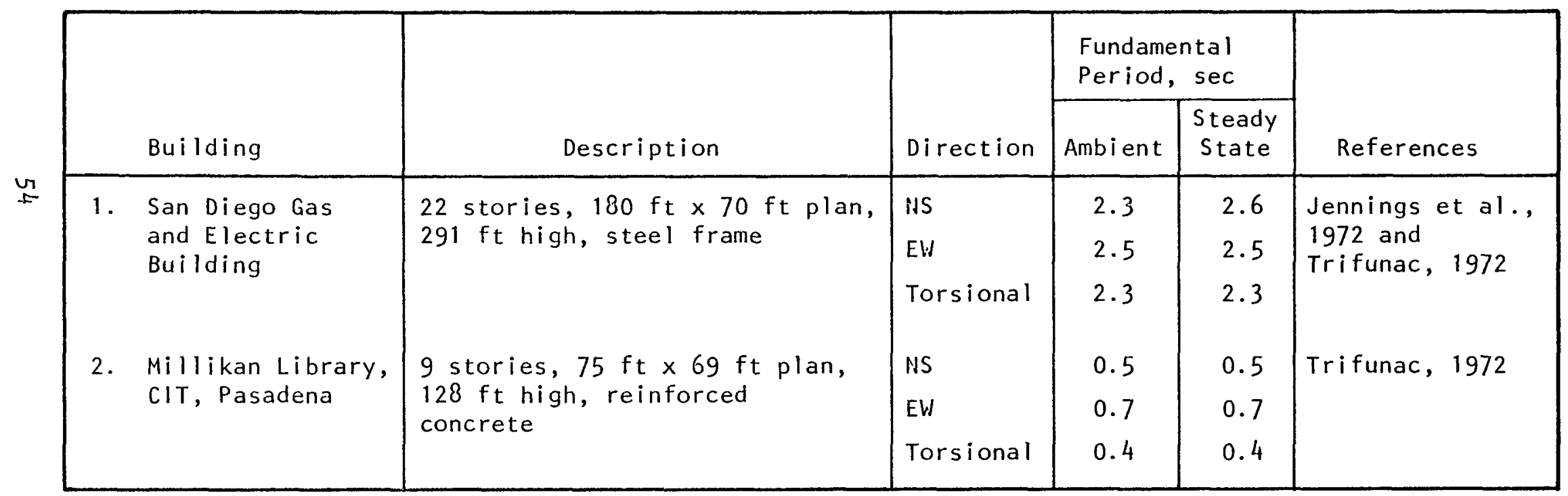



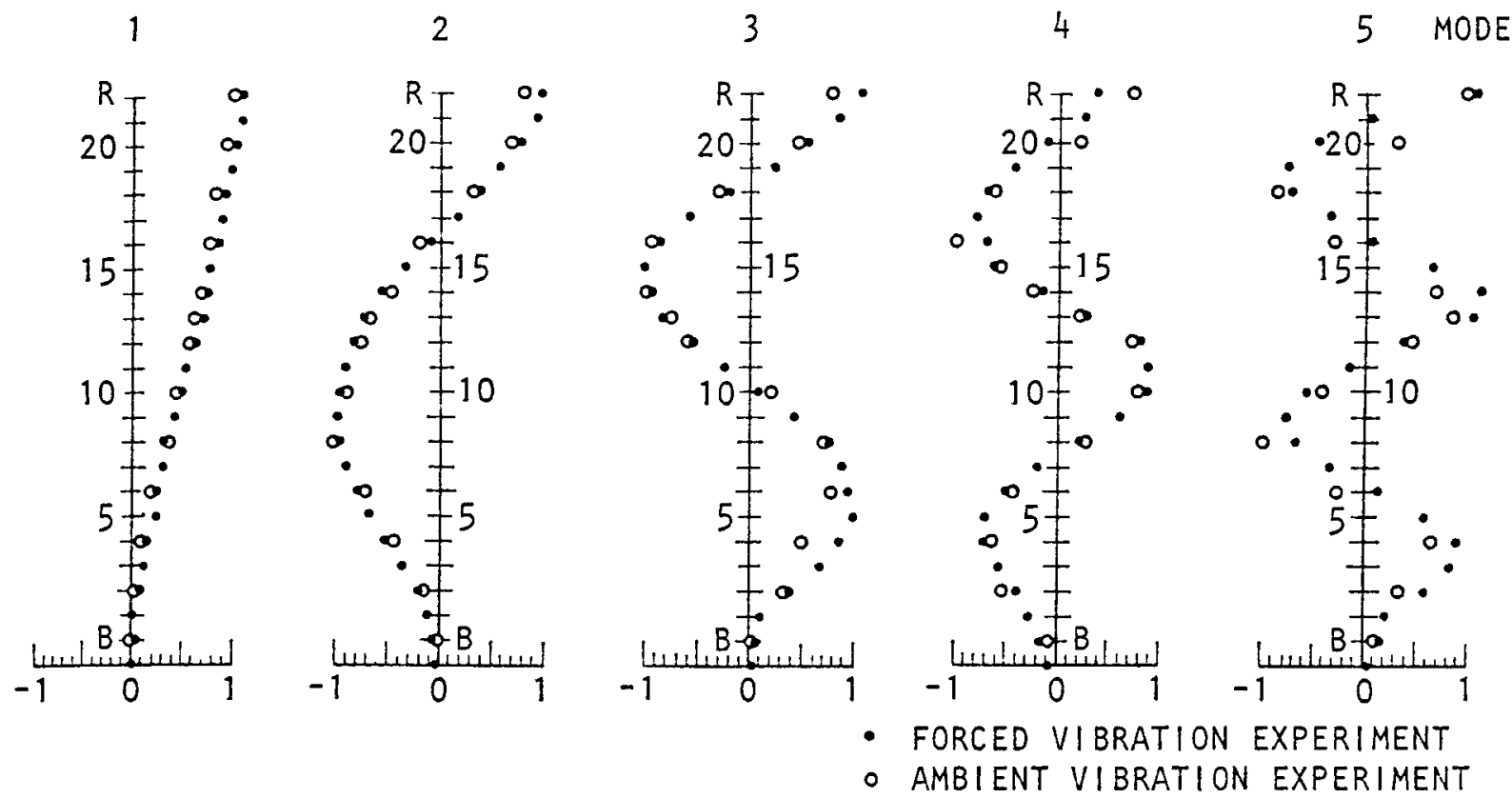

(a) Comparison of E-W mode shapes from ambient and forced vibration experiments
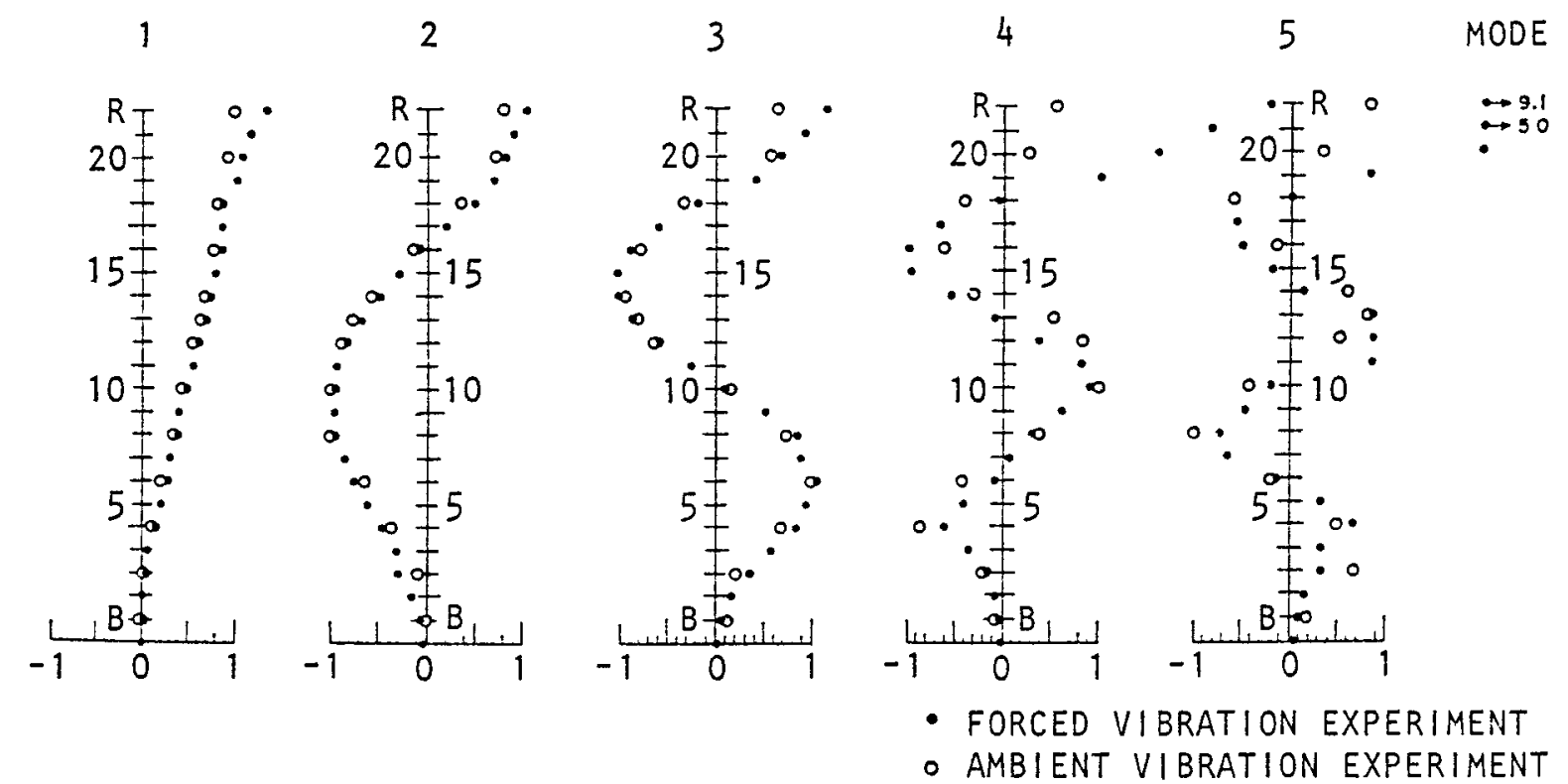

(b) Comparison of torsional mode shapes from ambient and forced vibration experiments

FIGURE 7. COMPARISON OF MODE SHAPES FOR SAN DIEGO GAS AND ELECTRIC COMPANY BUILDING (Trifunac, 1972) 

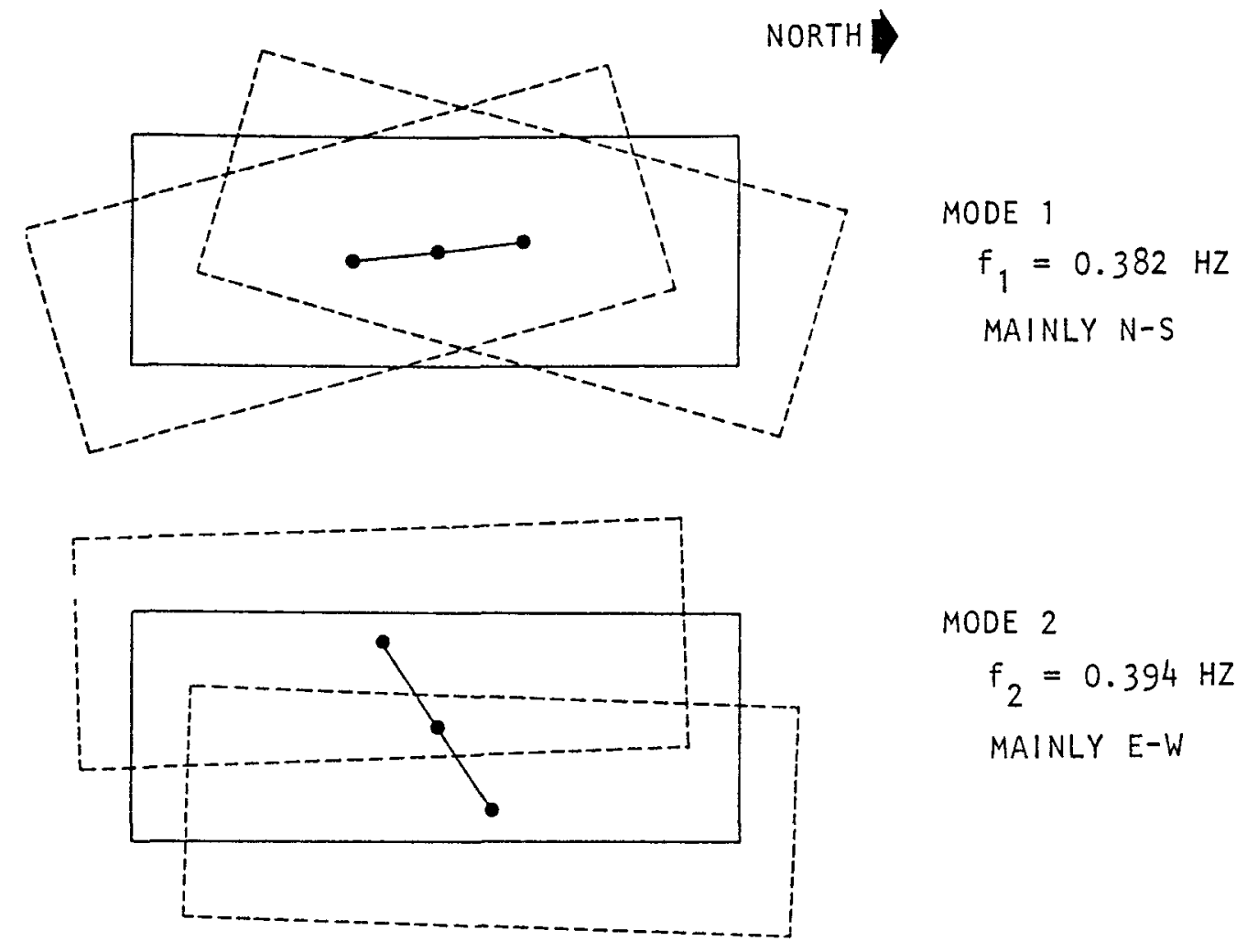

MODE 2

$f_{2}=0.394 \mathrm{HZ}$

MAINLY E-W

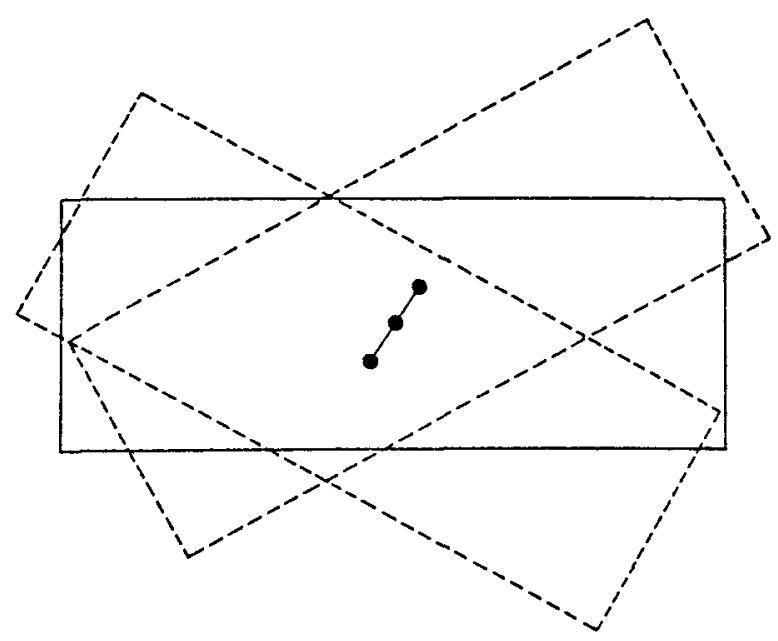

MODE 3

$f_{3}=0.425 \mathrm{HZ}$

MAINLY TORSION

EQUILIBRIUM POSITION

$\because$ MOTION OF CENTROID

MODAL DISPLACEMENT

FIGURE 8. PLAN VIEW OF TWENTIETH FLOOR SHOWING FUNDAMENTAL FLOOR MODES (Jennings et al., 1972) 
Determination of modal damping values from the ambient transient test results proved difficult for the San Diego Gas and Electric building and are not considered reliable. The methods used do not work unless the ambient excitation is truly random and nearly stationary in time. The problem was also complicated by the closely spaced fundamental modes which leads to spectral overlap in the peak areas. For the fundamental modes, the damping values determined from the steady state vibratory tests were 1.6, 2.5 , and $2.0 \%$, respectively, for the NS, EW and torsional components. For the same components of the next two higher modes, the damping varied from 1.6 to $3.7 \%$ with an average of $2.9 \%$. These compare favorably with results given in the previous section for the Canadian ambient transient load tests.

Damping determinations for the Millikan Library were in close agreement for both test methods, with values of 1.6 and $1.5 \%$ being obtained for the NS and EW components, and about $1.1 \%$ resulting for the fundamental torsional mode. Interesting results were obtained for the Millikan Library from steady state resonant frequency tests at different levels of input force. These have been reported by Jennings and Kuroiwa, 1968. Figure 9 provides the response at the eighth floor in the EW direction for different amplitudes of floor acceleration. It should be noted that the highest acceleration level achieved was $0.0125 \mathrm{~g}$ which is more than an order of magnitude lower than experienced from strong earthquake ground motion. (It should be noted that ambient transient vibration tests are usually conducted at a level of about two order of magnitude below the steady state vibratory tests.)

It will be noted in Figure 9 that a shift in frequency results for a change in amplitude of load, which indicates nonlinear behavior. The shift in frequency is noted in Figure 10 by a linearized relationship, which indicates that an increase in resonant amplitude by a factor of ten would result in a drop in frequency of $3 \%$. Thus, increasing the resonant amplitude by an additional factor of 20 would indicate an EW frequency of $1.42 \mathrm{~Hz}$ 


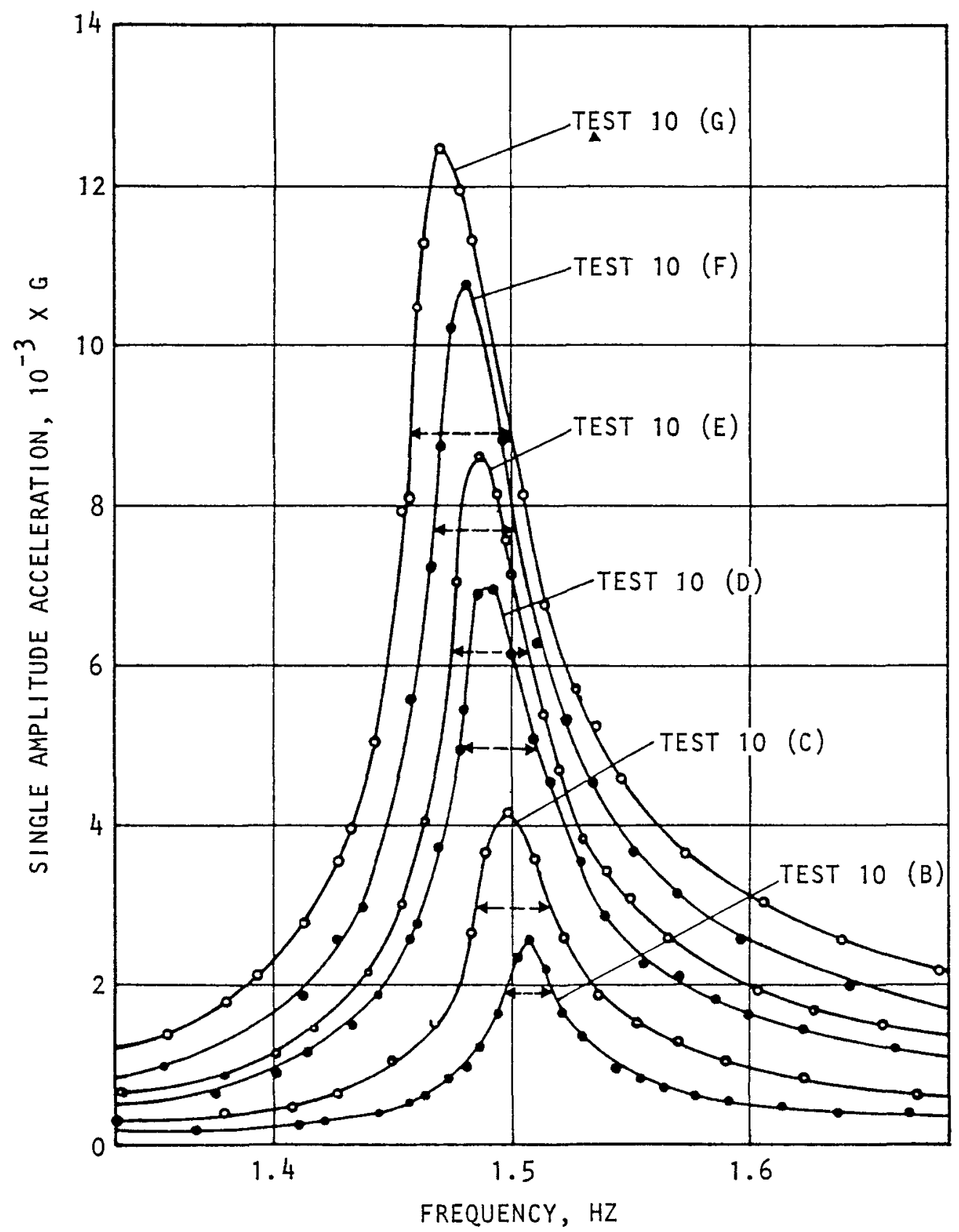

FIGURE 9. RESPONSE OF THE EIGHTH FLOOR IN THE FUNDAMENTAL MODE; E-W DIRECTION OF MILLIKAN LIBRARY AS A FUNCTION OF STEADY-STATE LOAD (Jennings and Kuroiwa, 1968) 


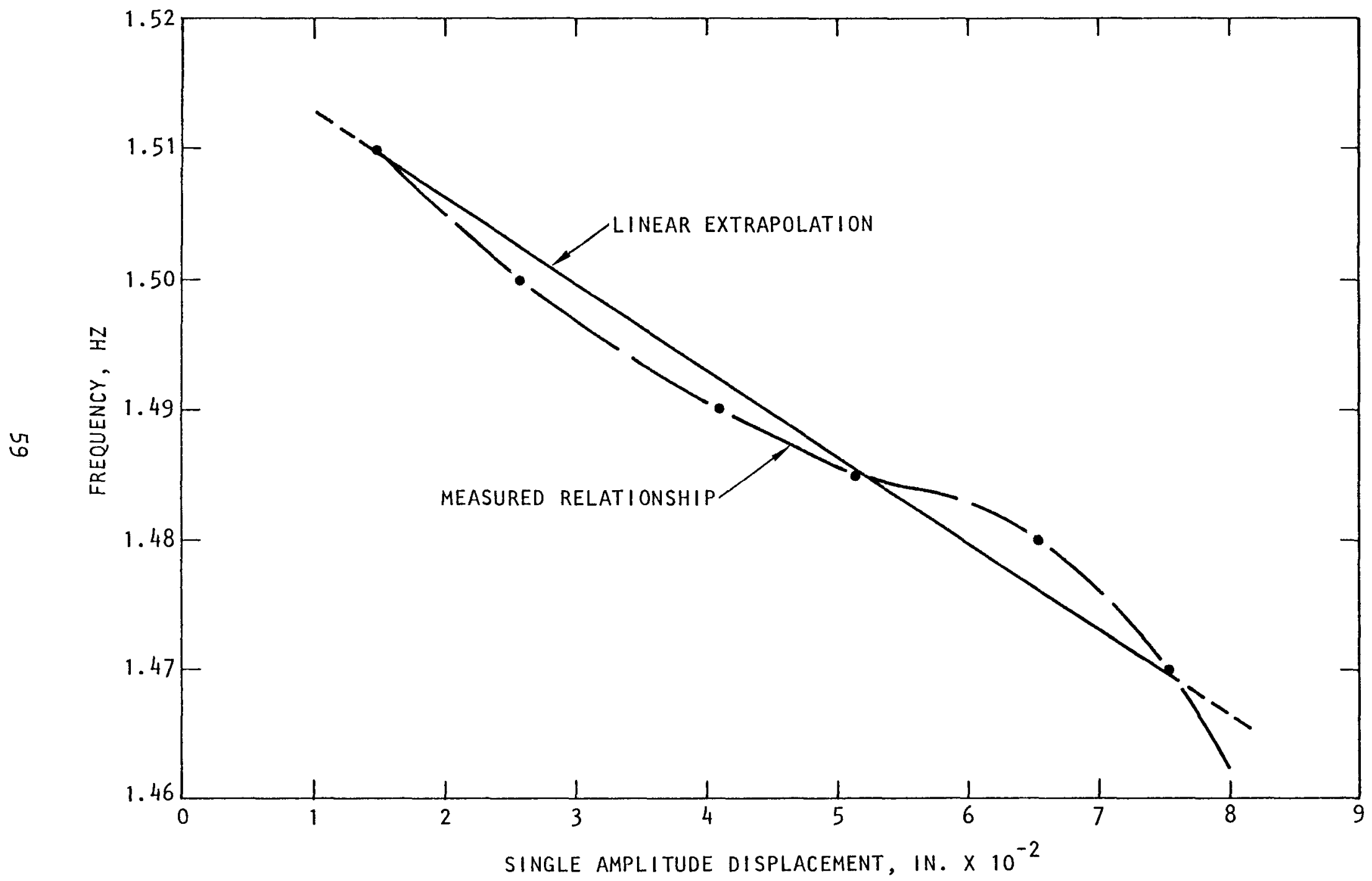

FIGURE 10. E-W FUNDAMENTAL FREQUENCY AS A FUNCTION OF DISPLACEMENT (LOAD) AMPLITUDE, MILLIKAN LIBRARY (Jennings and Kuroiwa, 1968) 
(or a period of $0.7 \mathrm{sec)}$ for a resonant amplitude of $0.25 \mathrm{~g}$. Also shown in Figure 10 by broken line is a nonlinear relationship between resonant amplitude and frequency. The shape of this nonlinear curve is not greatly different from the shape of a stress/strain curve for soil.

If the nonlinearities indicated in Figures 9 and 10 are mostly due to soil/structure interaction (i.e., the nonlinear properties of the soil) then the nonlinearity of the relationship shown in Figure 10 could be expected to increase significantly at higher resonant amplitudes. It should be particularly noted in Figure 10, that the curvature of the relationship has reversed for the two readings of highest amplitude, and that the last increment of loading has produced a very significant change in curvature. Extrapolation of the nonlinear curve is not possible without additional data, but it would obviously lead to a significantly lower frequency (i.e., longer period) than $1.42 \mathrm{~Hz}$ at $0.25 \mathrm{~g}$ resonant amplitude. Fortunately, the Millikan Library was instrumented and a response acceleration was recorded during the San Fernando 1971 earthquake equivalent to a response of about $0.30 \mathrm{~g}$ (with more than one mode participating) at the eighth floor level. A significantly lower fundamental frequency than $1.42 \mathrm{~Hz}$ was recorded $(1.0 \mathrm{~Hz})$ during the strong earthquake ground motion. This will be considered further in Section 3.3.4.

The steady-state vibratory tests of the Millikan Library reported by Jennings and Kuroiwa have other interesting results. Figure 11, for example, provides relative motion measurements of the building and supporting soil for the EW fundamental mode. While the measurements were made at a very low strain level, and their effect on the structure response can be minimized for this particular test, two important points should be noted. First, the source of energy in this case is from oscillators on the structure. Some of the energy imparted to the soil from this source will be radiated out of the system. For large, deeply embedded structures, the radiant effects will be large, thus very high energy inputs will be required 


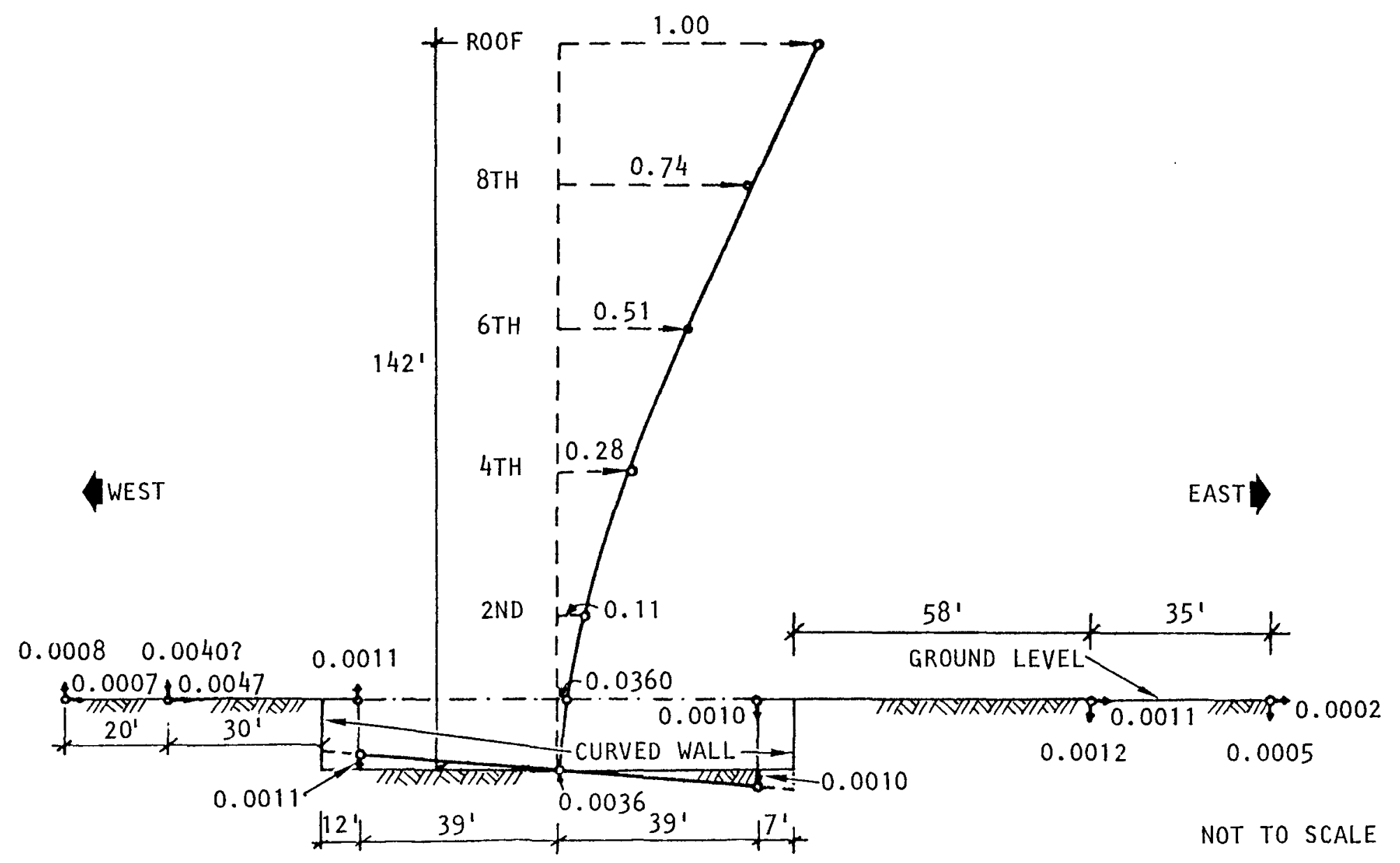

FIGURE 11. MEASURED STRUCTURE AND FOUNDATION DISPLACEMENTS, E-W FUNDAMENTAL MODE, MILLIKAN LIBRARY (Jennings and Kuroiwa, 1968) 
to mobilize steady state response in the soil at strain levels characteristic of an SSE or OBE earthquake environment. Second, at soil strain levels characteristic of SSE and OBE environments, the effective modulus of the soil will be significantly reduced and structure base rotations and translations will be much greater than indicated by a linear extrapolation of the deformations indicated in Figure 11.

Since most dynamic foundation deformation measurements have been made at relatively low soil strain levels, structural engineers are prone to neglect soil/structure interaction effects in the analysis of high rise buildings, based first on the assumption that the effect is negligible, and second on the assumption that most California earthquake records have been recorded in the basements of large buildings and already include soil/structure interaction effects. Both assumptions frequently lead to erroneous conclusions for high rise bulldings. This also will be discussed further in Section 3.3.4. Fortunately, soil/structure interaction effects are not neglected in the analysis of nuclear power plant structures. Likewise, its impact on dynamic testing of nuclear power plant structures should not be overlooked. This will become more evident from the following discussion.

Comparative ambient transient and steady state vibratory tests have also been reported for a nuclear reactor building. These results are of significance since they represent an application of the two test methods to a deeply embedded massive structure, more typical of nuclear power plant structures. The tests were performed on the Carolinas-Virginia Tube Reactor (CVTR) building. The CVTR was a power demonstration reactor designed to produce 17 Mwe. This reactor was constructed near Columbia, South Carolina and was decommissioned and shut down in late 1967. This made it possible to conduct a test program designed to determine the fundamental mode frequencies and damping characteristics of the containment structure and the internal operating floor. The operating floor is completely separated from the outer containment structure, except through a supporting pedestal, which is 
cantilevered vertically from the base of the containment structure. Figures 12 and 13 provide a sectional elevation and a horizontal section, respectively, through the containment building. This structure is nearly completely surrounded by adjoining service buildings which in some cases have foundations in contact with the containment building walls. The CVTR oil-fired steam superheater was also located within $75 \mathrm{ft}$ of the containment building. This facility was found to have a characteristic frequency of $1.52 \mathrm{~Hz}$ which provided a spurious signal to the ambient transient measurements.

The ambient transient vibratory measurements were performed by Earth Sciences (ES, 1968) and the steady state vibratory tests were performed by the University of California, Los Angeles (Matthiesen and Smith, 1969). A report providing an evaluation and comparison of the results of the two studies was prepared by the Idaho Nuclear Corporation, see Schmitt, 1970. These reports should be consulted for additional background on the two tests.

Before considering the results of the test, three important conditions of the test should be noted and discussed. These are: the significance of the depth of embedment of the structure, the low energy level of the two test procedures, and the possible influence of adjoining buildings on the ambient transient vibratory tests. A discussion of these three conditions follows.

The influence of the depth of embedment can be best visualized by considering the characteristics of a mathematical discrete mass model that might be used to perform a dynamic analys is of the structure when subjected to the test loads, such as shown in Figure 14. For a deeply embedded containment structure (see Chapter 2, SAN/1011-111 for procedure), high radiant damping (about 40\%) would be required to account for the energy lost through the soil (i.e., radiant dampers). The above ground portion of the structure and the internal structure, on the other hand, would require 


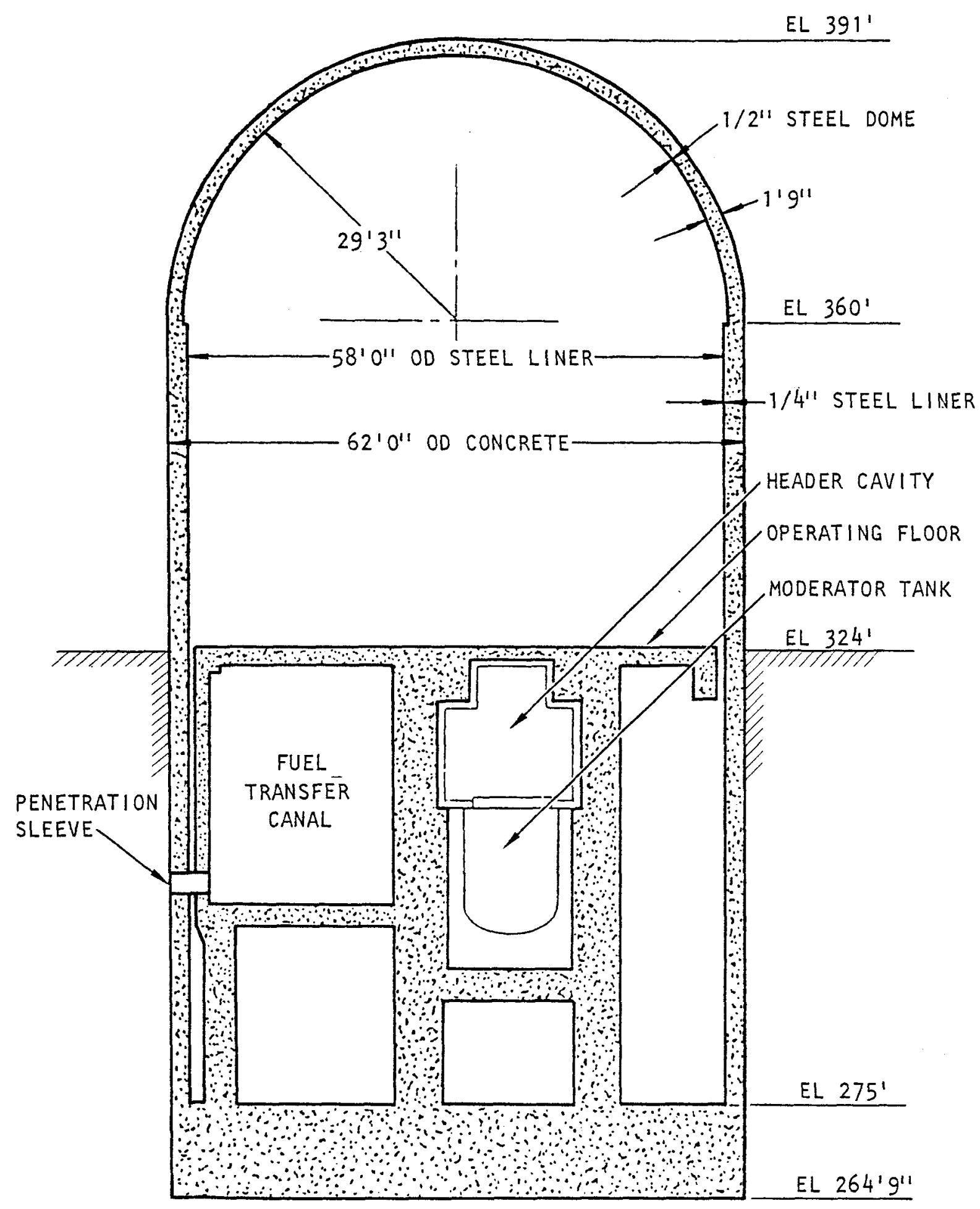

FIGURE 12. SECTIONAL ELEVATION OF CVTR BUILDING THROUGH FUEL TRANSFER CANAL (Schmitt, 1970) 


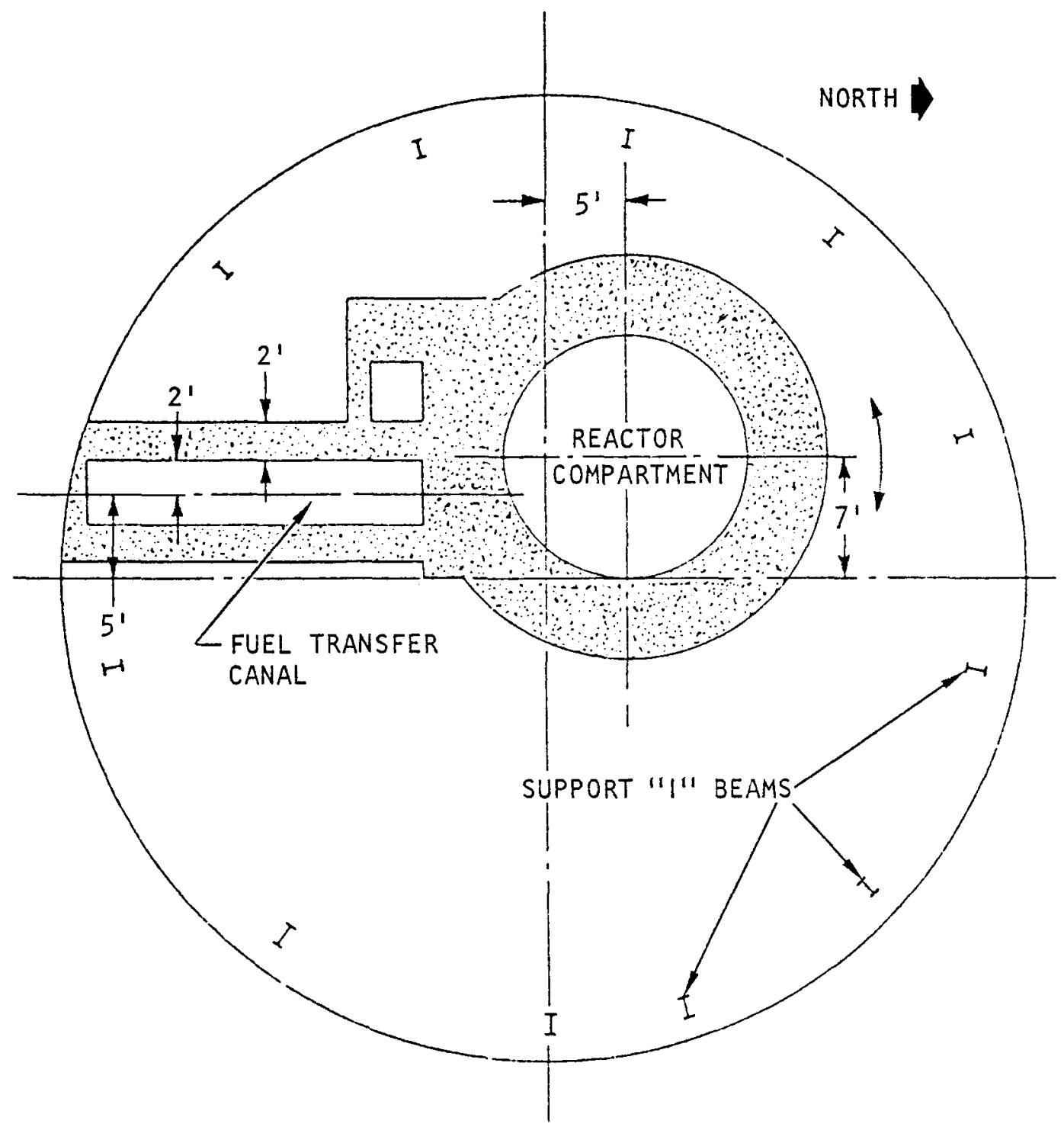

FIGURE 13. HORIZONTAL SECTION OF CVTR BUILDING AT ELEVATION 301 (Schmitt, 1970) 


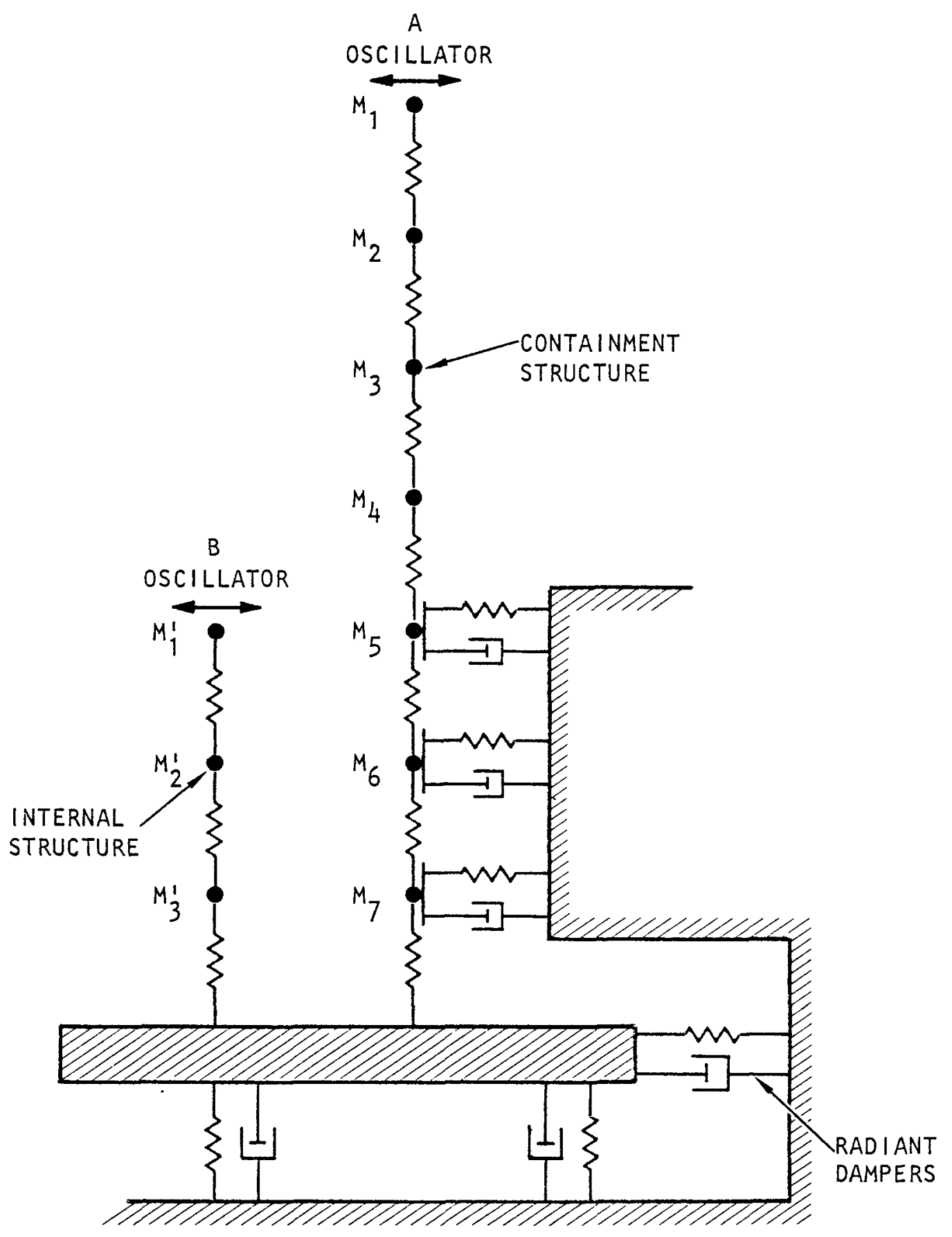

FIGURE 14. ILLUSTRATIVE DISCRETE MASS MODEL 
consideration of only the material damping which would be only a few percent. It should be evident from Figure 14, that any attempt to drive the model with a very low energy level oscillator at either $A$ or $B$ would result in an excitation of the low damped masses to which the oscillator is attached, but it would not develop high resonant response in $M_{5}, M_{6}$, and $M_{7}$, and in the rigid base, because of the radiant dampers. The test results therefore would indicate that the containment structure response could be modeled by fixing the model at $M_{5}$, or very close to this level. This was the conclusion for the steady-state resonant tests.

The above conclusion would not be true for the response of the structure to a seismic input, as the motion would in this case be imparted through the soil, and definite displacements of the lower masses would occur which would excite the upper structure masses. The feedback from the upper masses would remain heavily damped by the radiant dampers. Therefore, the lower structure would follow very closely the free-field soil input motions which could include rocking motion as well as horizontal and vertical translation. However, the lower structure is stiff, and will resist relative soil motions. Therefore it interacts with the soil, and the final motions of the lower structure are modified by the soil/structure interaction. Obviously, the response of the lower structure, which is important to the seismic problem, would not be mobilized by low level steady state vibration input.

The general level of structural excitation achieved in the tests of the CVTR building in the steady state vibration tests supports the above conclusions on the effects of embedment and the difficulty of exciting a stiff massive structure with a low energy level input. In the determination of the fundamental modes of response of the containment structure, the displacement amplitude of the top of the containment shell, which was the point of application of the load, was about $0.0006 \mathrm{in}$. and the resonant acceleration was about $0.004 \mathrm{~g}$. The resonant displacement on the side of the shell $6 \mathrm{ft}$ above the ground (roughly $60 \mathrm{ft}$ below the top of the shell) was 
approximately $0.0001 \mathrm{in}$. with an accompanying resonant acceleration of about $0.0008 \mathrm{~g}$. These responses indicate that the energy level was not great enough to excite the embedded portion of the structure. Schmitt (1970) indicates that it was found that the measured response could be best represented by a linear model that assumed the structure fixed near the foundation level. However, this is not the structural model that would be excited in a strong earthquake as noted above. Ambient transient excitations are usually one to two orders of magnitude less than those measured from the steady state vibratory tests. Response measurements from an ambient transient excitation, if applied aboveground (wind), should be difficult to monitor and interpret for this structure.

The third factor to be considered in interpreting the test results for the CVTR building is the possible effect of adjoining buildings on the ambient transient tests. It has been previously noted that the containment building is almost completely surrounded by adjoining buildings or heavy equipment. The containment building may, therefore, have been partially shielded from ambient wind loads, but these loads on the adjacent buildings may have imparted frequency biased ambient transient motions through the building foundations to the embedded portion of the containment structure. (Adjoining equipment vibrations are known to have been transmitted through the soil to the containment structure.) In order to use the ambient transient loading method, the motion must be random and stationary with respect to time. It is possible that these conditions may not have been satisfied for the CVTR building, although this has not been determined.

A comparison of the test results for the ambient transient and steady state vibratory motion are summarized in Table 4 . With two major exceptions, reasonable agreement was obtained between the two test methods considering the conditions of test (i.e., low energy level, deeply embedded structure and interference from other structures). One of the exceptions is 
the fundamental mode frequencies for the containment structure. The ambient transient tests indicated fundamental mode frequencies of 2.5 and $3.0 \mathrm{~Hz}$, with second mode frequencies of 11.8 and $11.9 \mathrm{~Hz}$. No measurements were recorded above $25 \mathrm{~Hz}$ in these tests. The steady state vibratory test report in contrast indicated fundarnental mode frequencies of 8.2 and $8.3 \mathrm{~Hz}$ and second mode frequencies of 53 and $54 \mathrm{~Hz}$. The cause of this inconsistency is not satisfactorily explained in the reports discussing the results. There is good logic, however, in assuming that the 11.8 and $11.9 \mathrm{~Hz} \mathrm{fre}^{-}$ quencies are the same modes of response measured by the steady-state tests for which frequencies of 8.2 and $8.3 \mathrm{~Hz}$ were recorded. The difference in response could easily be nonlinear behavior resulting from the different amplitudes of input in the two test methods, as discussed for the Millikan Library tests. The explanation of the 2.5 and $3.0 \mathrm{~Hz}$ frequencies is more difficult. Two possible explanations can be offered, although there is no verification for either.

TABLE 4. COMPARISON OF MODAL FREQUENCIES OBTAINED FOR CVTR BUILDING BY AMBIENT TRANSIENT AND

STEADY-STATE VIBRATORY TESTS

\begin{tabular}{|l|l|l|c|}
\hline \multirow{2}{*}{ Element } & \multirow{2}{*}{$\begin{array}{c}\text { Fundamental Mode } \\
\text { Frequencies, Hz }\end{array}$} & \multicolumn{1}{c|}{$\begin{array}{c}\text { Ambient } \\
\text { Transient }\end{array}$} & $\begin{array}{c}\text { Steady } \\
\text { State }\end{array}$ \\
\cline { 2 - 4 } & Direction & $11.8 / 2.5^{*}$ & 8.2 \\
Containment & NS & $11.9 / 3.0^{*}$ & 8.3 \\
Operating Floor & EW & 7.8 & 6.8 \\
and Pedestal & NS & $\sim 4$ & 4.1 \\
& EW & 7.9 & 9.3 \\
\hline
\end{tabular}

* Reported fundamental mode frequencies is 2.5 and $3.0 \mathrm{~Hz}$. Reported second mode frequency is 11.8 and $11.9 \mathrm{~Hz}$. 
A possible explanation is that these frequencies represent a spurious signal resulting from mode interferences, or from biased input (i.e., nonrandom). This could have resulted from the shielding effect of the adjoining structures. The adjoining structures would significantly shield the containment structure from wind loads and are subjected to ambient transient input. It is also quite possible that this ambient transient input was fed through the foundations of the adjoining structures to the CVTR building. Thus, the CVTR building would be receiving an ambient transient input below the ground level. This input could drive the entire CVTR building and its surrounding soil mass at very low amplitude translational frequencies of 2.5 and $3 \mathrm{~Hz}$. This would not be the same structural participation measured in the steady state tests, nor would it be representative of the soil/ structure response in a strong earthquake environment.

The comparative report by Schmitt, 1970, indicates that Earth Science was able, by significant changes in their initial analytical model, to demonstrate fundamental modes of 2.5 and $3.0 \mathrm{~Hz}$ by practically eliminating soil/structure interaction and having the structure essentially rock on its base. This is not a logical explanation, but a comparable response could result if the structure and soil were being driven transversely by very low amplitude input through the foundations of adjoining structures.

Additional important information from the steady-state vibratory tests of the CVTR building was the fact that it was not possible to excite a vertical mode that included soil/structure interaction. From these results, it should be evident that the energy level for both tests was too low to provide reliable and useful information for verifying the response of the structure in a strong earthquake ground motion environment. 
Comments are justified on two additional items of information resulting from the CVTR tests. First, the steady-state vibratory tests indicated high damping with 5 to $10 \%$ being indicated for the containment modes. In contrast, the ambient transient vibratory tests indicated only one-half of $1 \%$ damping. The steady-state values are not, in our opinion, unusual considering the radiant energy loss to the soil. The low values for the ambient transient tests would also not be unusual if the stmucture was being driven through the soiz. Neither level of damping would be characteristic of the behavior under strong earthquake ground motion.

Second, an attempt was made to demonstrate a reciprocity relationship between a point on the containment structure and a point on the operating floor by inputting a steady-state vibration at first one point and then the other, and measuring the response at both points. The relationship could not be established indicating that nonlinear behavior is present. The nonlinearity in this case no doubt resulted from the different degrees of soil/structure interaction mobilized for each test. Tests of the interior support structure at two different steady-state vibratory load amplitudes also clearly showed a shift in mode frequency. This was attributed to differences in soil/ structure interaction, which is probably a correct assumption.

\subsubsection{TESTING WITH BURIED EXPLOSIVES; COMPARISON WITH STEADY-STATE VIBRATORY TEST RESULTS}

Two interesting examples of a ground motion environment induced by underground chemical explosives have been reported by Hudson et al., 1954, 1961. In both cases a large rock quarry blast was used to obtain ground motion and structural response measurements. A plan view of the points of detonation and the ground motion monitoring points is shown in Figure 15 . A brief description of the tests and the results follows.

In the test conducted in 1952, 370,000 lb of explosive (nitramon) were detonated at a distance of about $1100 \mathrm{ft}$ from the base of a steel mill building. The explosive was placed underground in a series of tunnels driven 


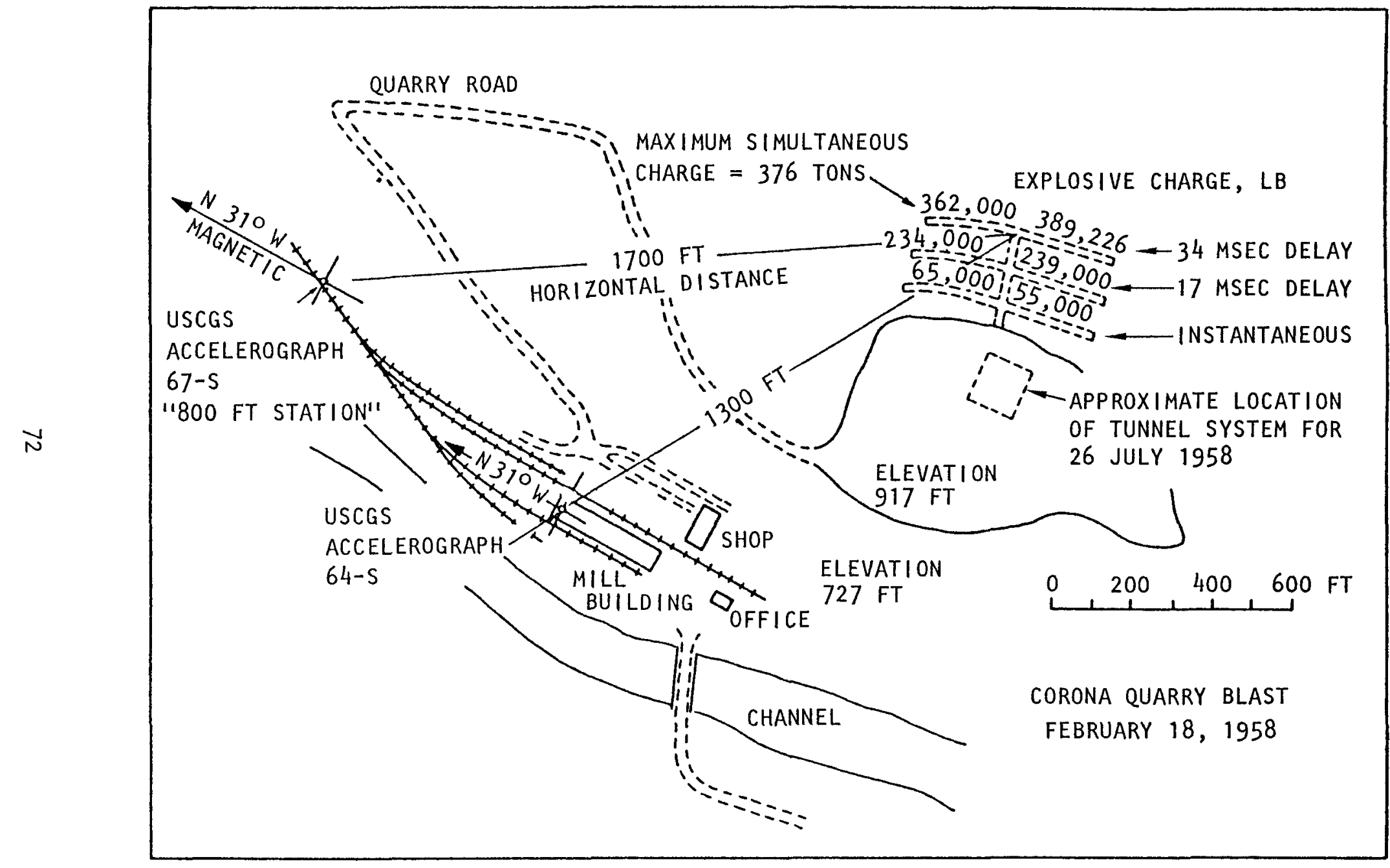

FIGURE 15. GENERAL PLAN OF EXPLOSIVE TEST SITE AND INSTRUMENT LOCATIONS (Hudson et al., 1961) 
approximately $170 \mathrm{ft}$ into the hillside. Because of the topography, the explosive was approximately $180 \mathrm{ft}$ above the ground surface level of the mill building. The accelerations were recorded with a Miller 402-C and a USCGS standard strong motion seismometer. Excellent agreement was obtained with the two instruments.

In the test conducted in 1958, 1,344,000 lb of explosive (nitramite and nilite) were detonated using one instantaneous and two $17 \mathrm{msec}$ delays. The amount of explosive detonated instantaneously and wi th two time delays is indicated in Figure 15. The explosives were again located in underground tunnels. The distance from the explosive to the mill building recorders was about 1200 to $1300 \mathrm{ft}$. An additional USCGS recorder (800-ft station) was also placed about $1700 \mathrm{ft}$ from the detonation but on an azimuth that differed by about $30 \mathrm{deg}$. For the mill building recorder, the major difference in the two tests was the amount of explosive and the use of time delays for the second test. In the second test, the only variable between the two recording stations was distance and azimuth.

The acceleration records obtained from the two explosions are indicated in Figure 16 where it will be noted that about 1-1/2 to $2 \mathrm{sec}$ of strong motion were recorded at the mill building for the two tests. The larger explosive using a $34-\mathrm{msec}$ delay produced only a slightly longer record. However, the 1952 test had a maximum recorded horizontal acceleration of $0.10 \mathrm{~g}$ and a maximum vertical acceleration of $0.12 \mathrm{~g}$, while the 1958 test had maximum recorded horizontal and vertical accelerations of $0.23 \mathrm{~g}$. It is of interest to note that the $300-f t$ station, which was at a slightly greater distance from the point of detonation and at a slightly different azimuth, recorded accelerations in excess of $0.3 \mathrm{~g}$ and the intensity of the strong motion persisted for over $2 \mathrm{sec}$. The results shown in Figure 17 are also of interest and were obtained by resolving the two horizontal acceleration records obtained in the 1952 tests into radial and transverse components. It is significant to note that the motion is predominately radial, and 

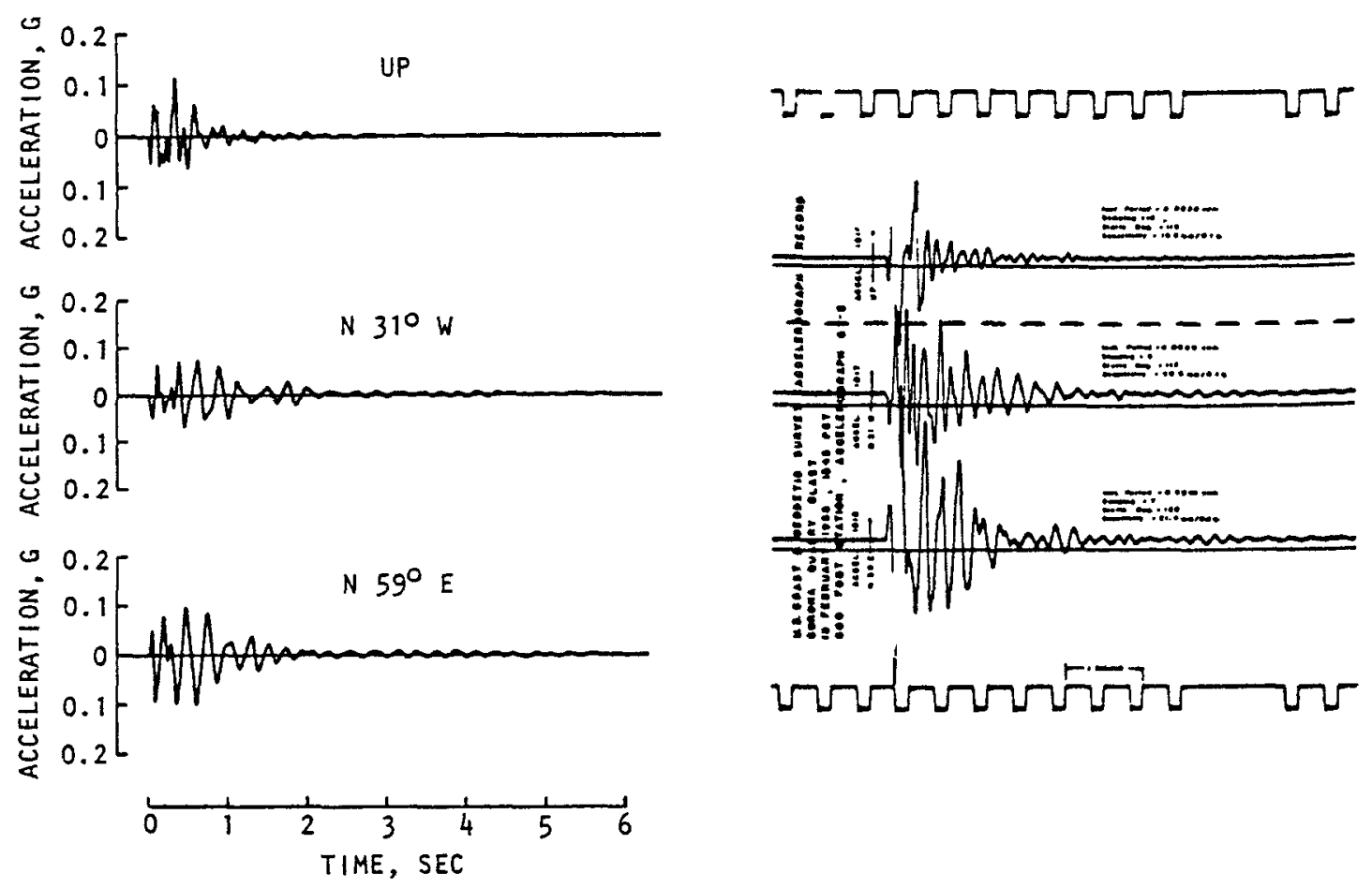

26 JULY 1952--MILL BUILDING STATION

PHOTOGRAPH OF ORIGINAL ACCELERATION-TIME RECORD
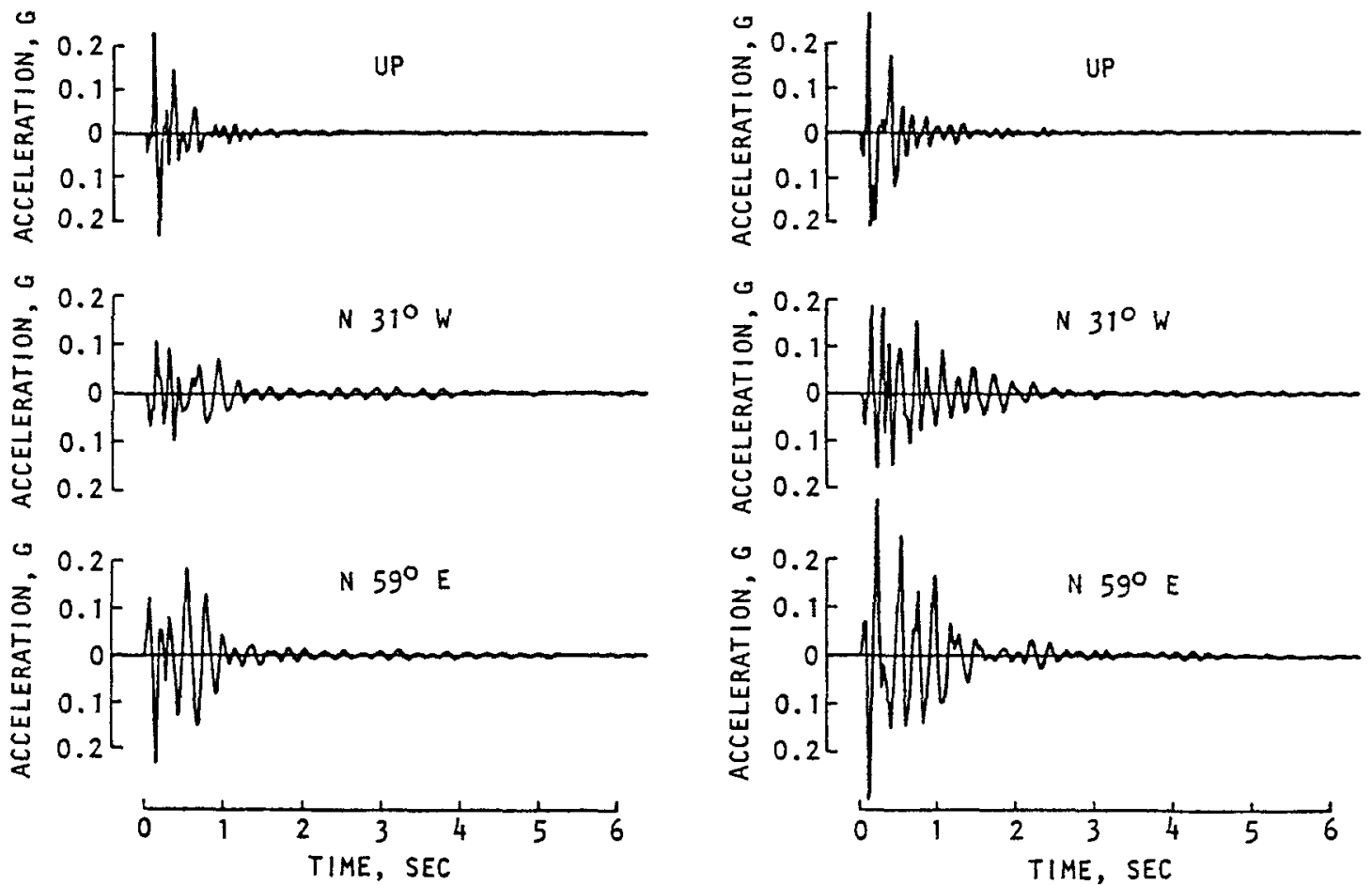

18 FEBRUARY 1958--MILL BUILDING STATION
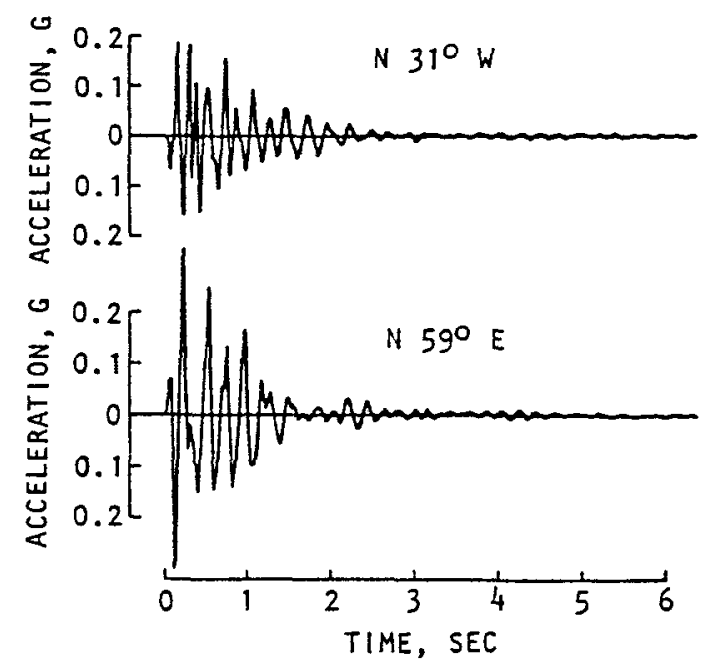

18 FEBRUARY 1958--800 FT STATION

FIGURE 16. GROUND ACCELERATION-TIME RECORDS FOR CORONA BLASTS OF 1952 AND 1958 (Hudson et al., 1961) 


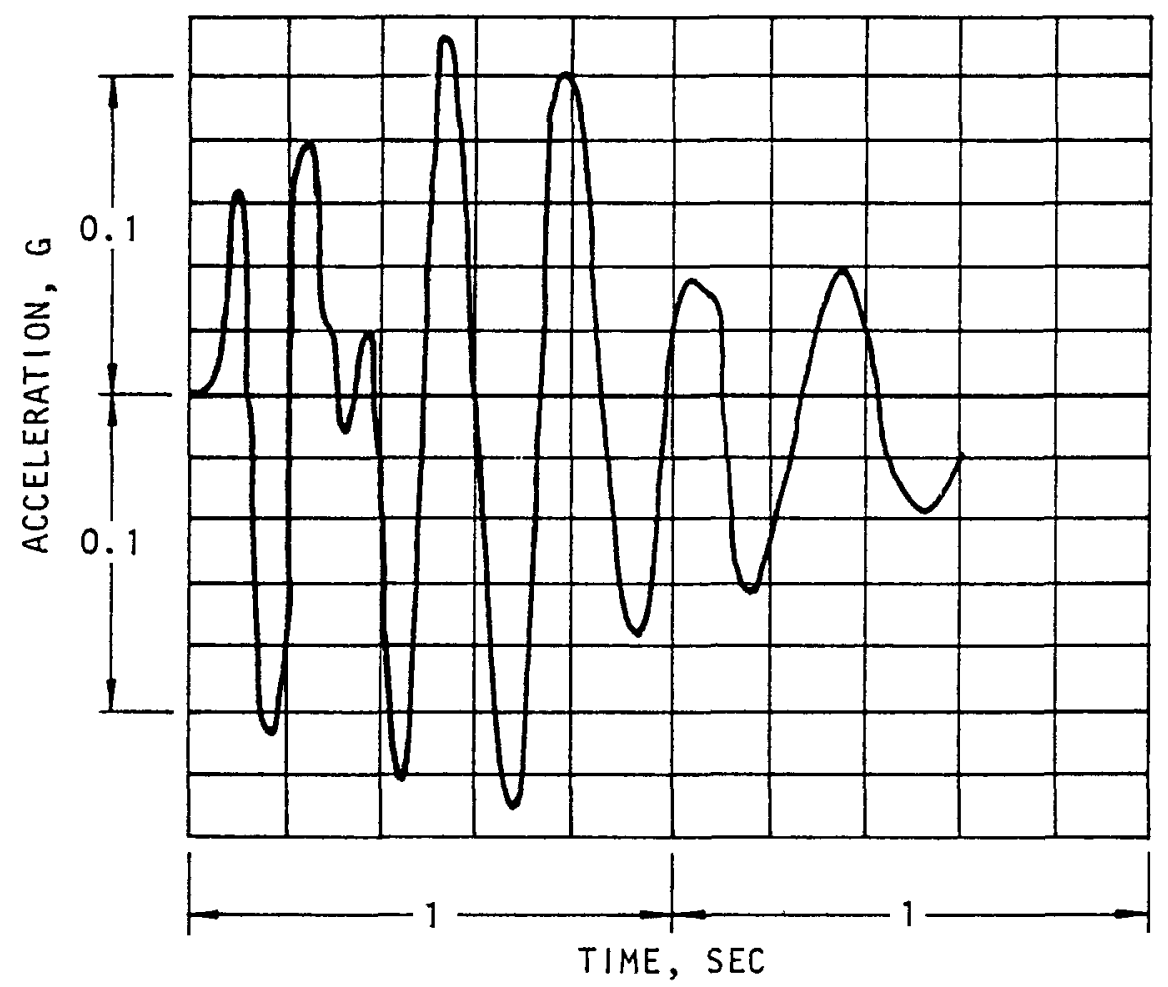

(a) Radial ground acceleration

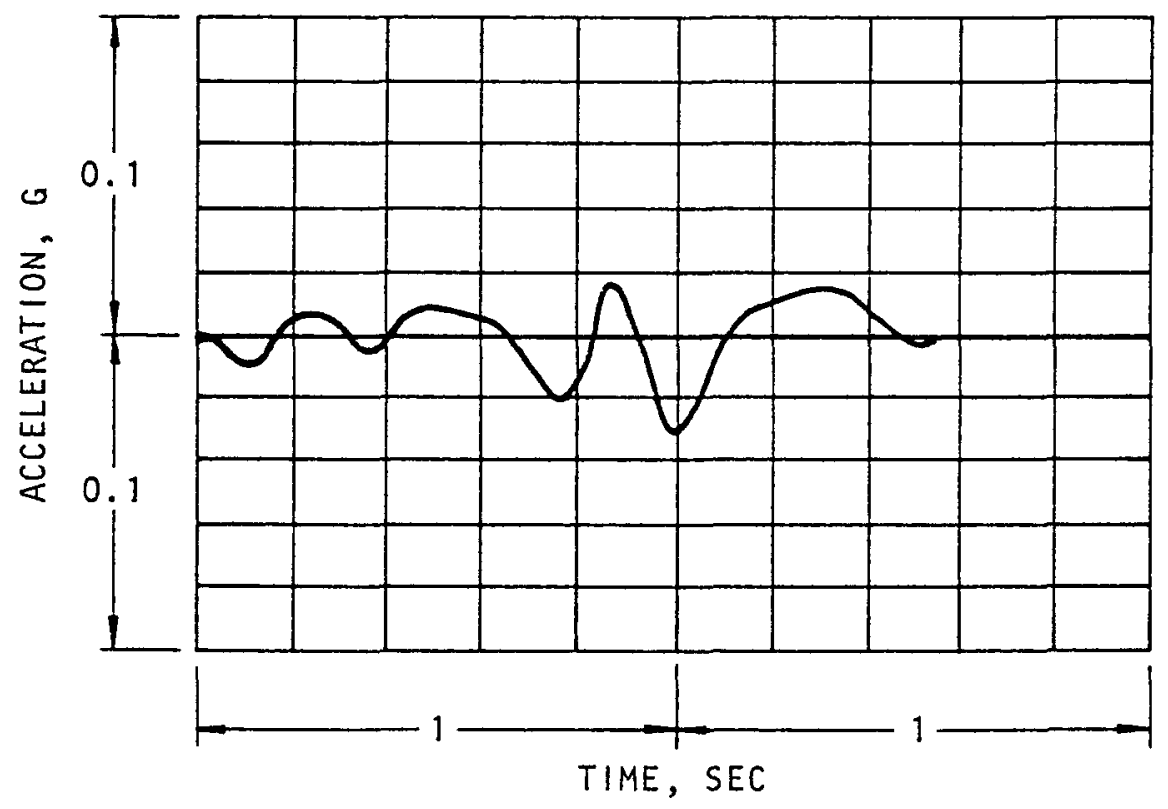

(b) Transverse ground acceleration

FIGURE 17. RADIAL AND TRANSVERSE ACCELERATION RECORDS FOR 1952 TEST (Hudson et al., 1954) 
apparently results from the nearly point source characteristic of the energy release. This characteristic of the motion should be considered when planning explosive tests of structures.

The velocity response spectra for the horizontal components of the 800-ft station 1958 records are shown in Figure 18: The 5\% damped spectrum for the stronger component is also compared in Figure 19 with Regulatory Guide (RG) 1.60 (USAEC, 1973) spectra for 0.2 and $0.3 \mathrm{~g}$ peak ground acceleration. It will be noted that the $0.3 \mathrm{~g}$ component gives response comparable to the RG 160 spectrum for an $0.2 \mathrm{~g}$ peak ground acceleration for frequencies above $3 \mathrm{~Hz}$. This would usually cover the frequency range of most interest to nuclear power plant design. However, the response falls off rapidly below $3 \mathrm{~Hz}$. It is evident that underground detonations of 200 to 500 tons of explosive can produce a strong motion environment at distances of 1000 to $2000 \mathrm{ft}$ that are quite similar to that of a magnitude 5 to 6 earthquake (i.e., comparable to the Golden Gate Park 1957 record, earthquake magnitude of 5.7).

An interesting comparison can be made of steady-state vibratory test results with the results of relatively low yield explosives from tests that have been performed on the Experimental Gas Cooled Reactor (EGCR) located at Oak Ridge, Tennessee. Figures 20 and 21 provide EW and NS sectional elevations of the plant. The total height of the structure is about $216 \mathrm{ft}$ with $147 \mathrm{ft}$ projecting above grade. However, a relatively light structure encloses the major structure below ground to a depth of about $20 \mathrm{ft}$, which reduces the effective depth of embedment to about $50 \mathrm{ft}$. The structure is founded on Cambrian Age shale, which includes thin beds of limestone. These materials should exhibit nearly rock-like properties. Compressional and shear wave velocities at a depth of $63 \mathrm{ft}$ are of the order of $8000 \mathrm{fps}$ and 6000 fps, respectively (Chrostowski et al., 1976). At this depth, these materials should not prove to be significantly strain dependent at the levels tested. 


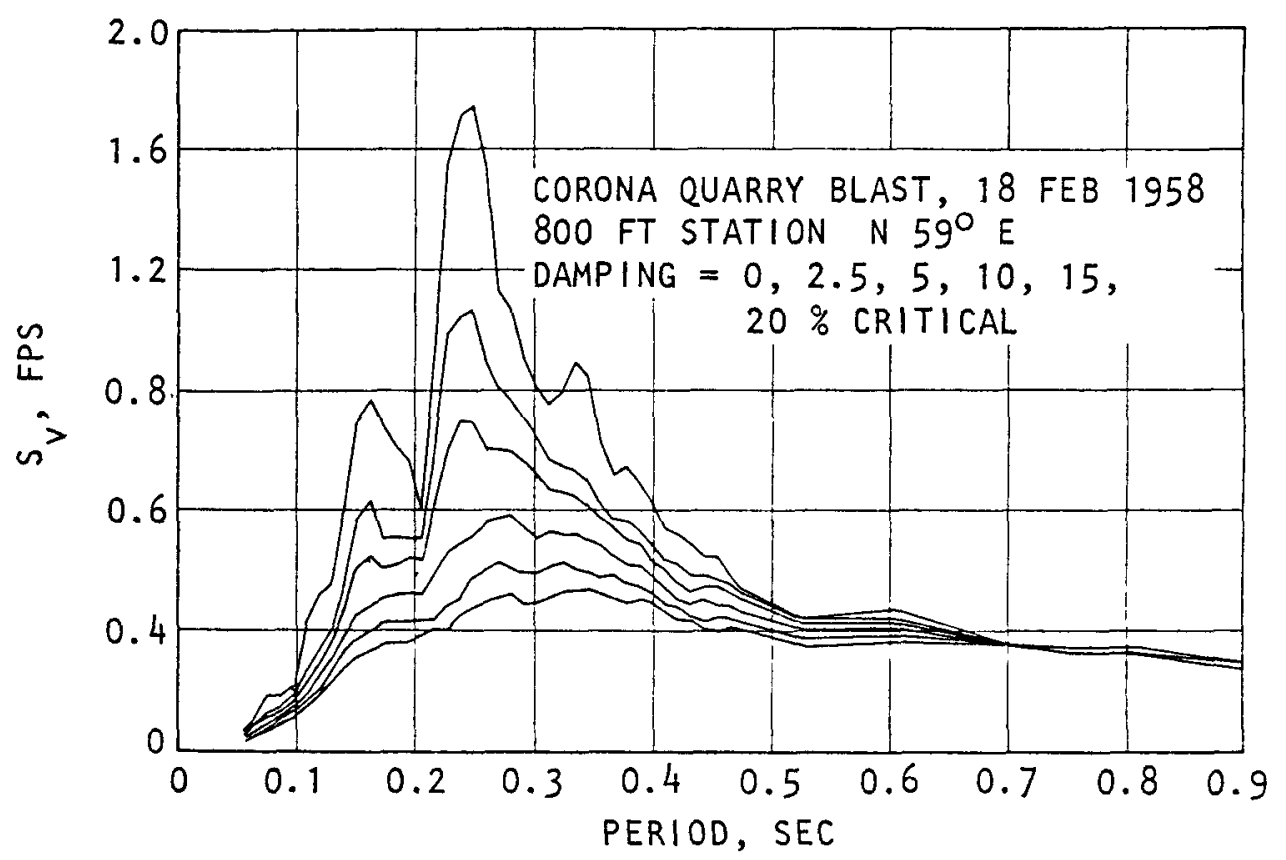

(a) $\mathrm{N} 59^{\circ} \mathrm{E}$

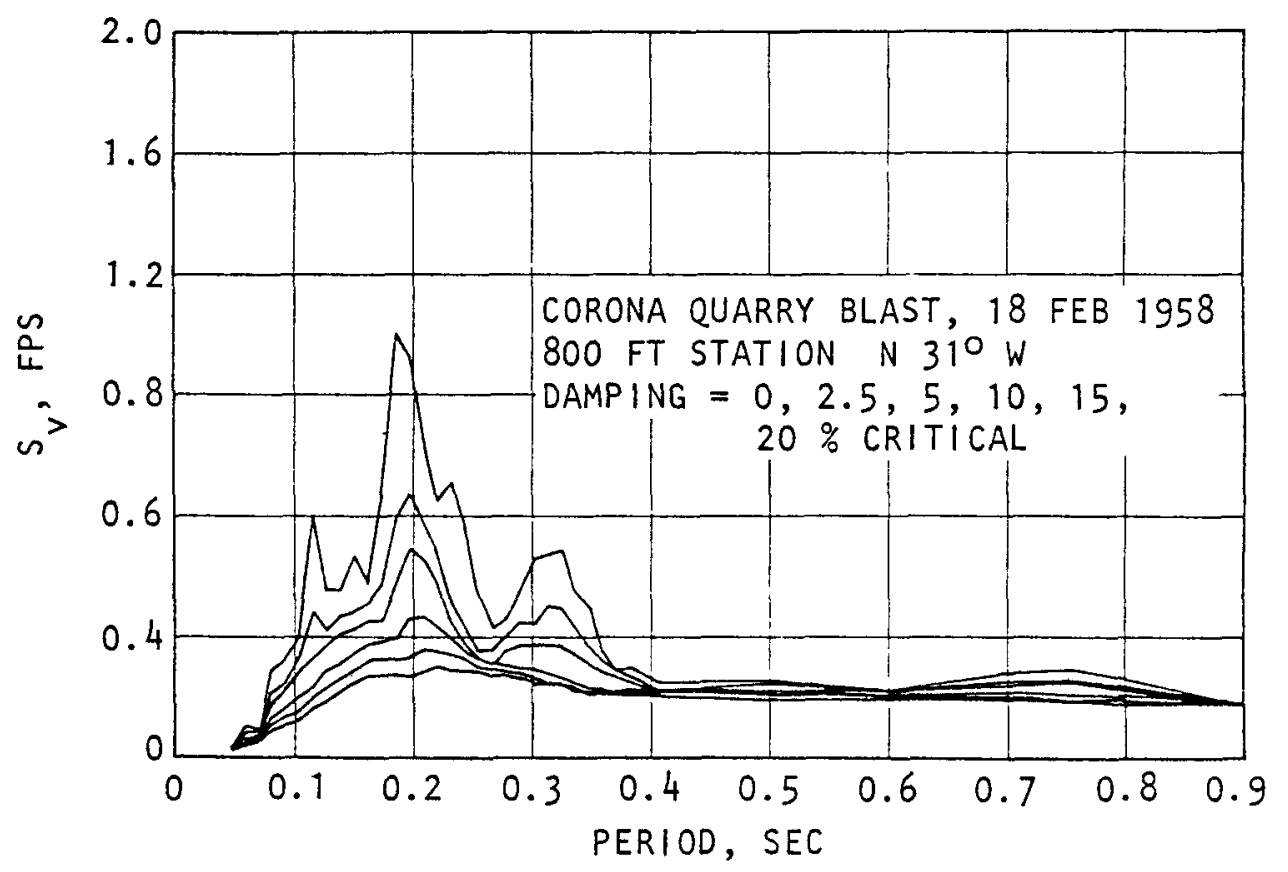

(b) $N 31^{\circ} \mathrm{W}$

FIGURE 18. RESPONSE SPECTRA FOR 1958 CORONA QUARRY BLAST AT 800 FT STATION (Hudson et al., 1961) 


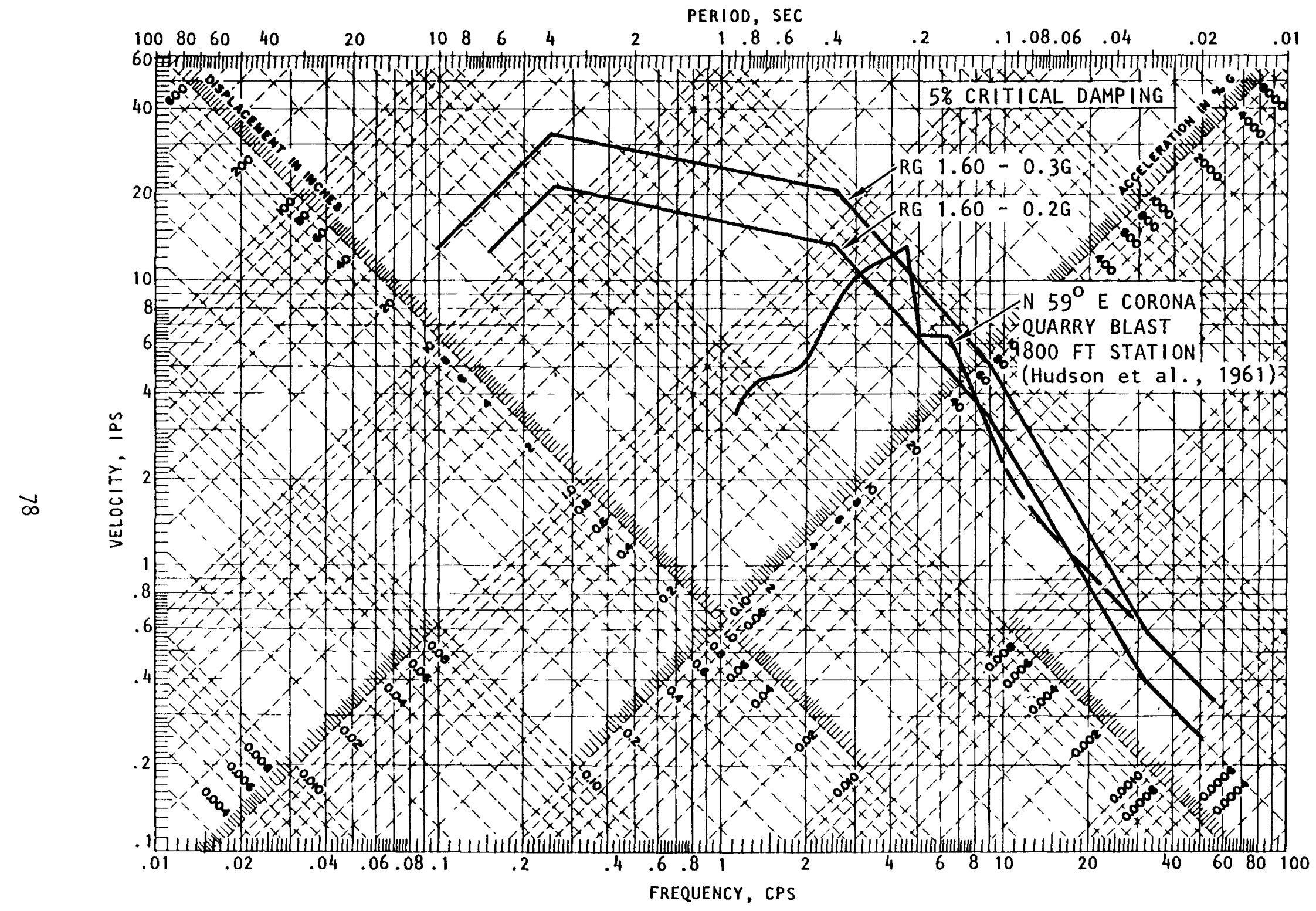

FIGURE 19. COMPARISON OF CORONA QUARRY BLAST RESPONSE SPECTRUM WITH RG 1.60 SPECTRA 


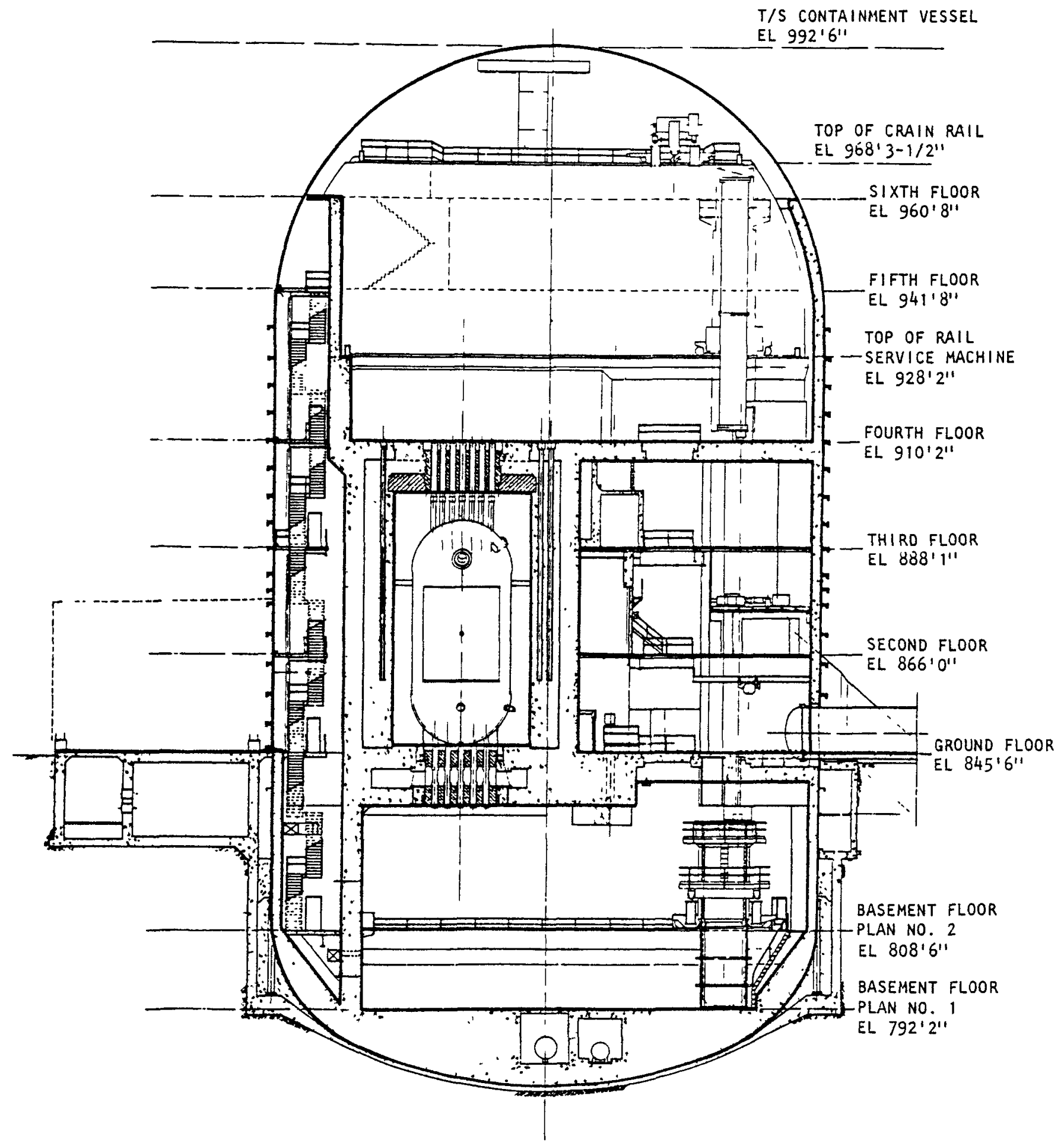

FIGURE 20. E-W SECTIONAL ELEVATION OF EGCR BUILDING (Section on centerline) (Smith and Matthiesen, 1969) 


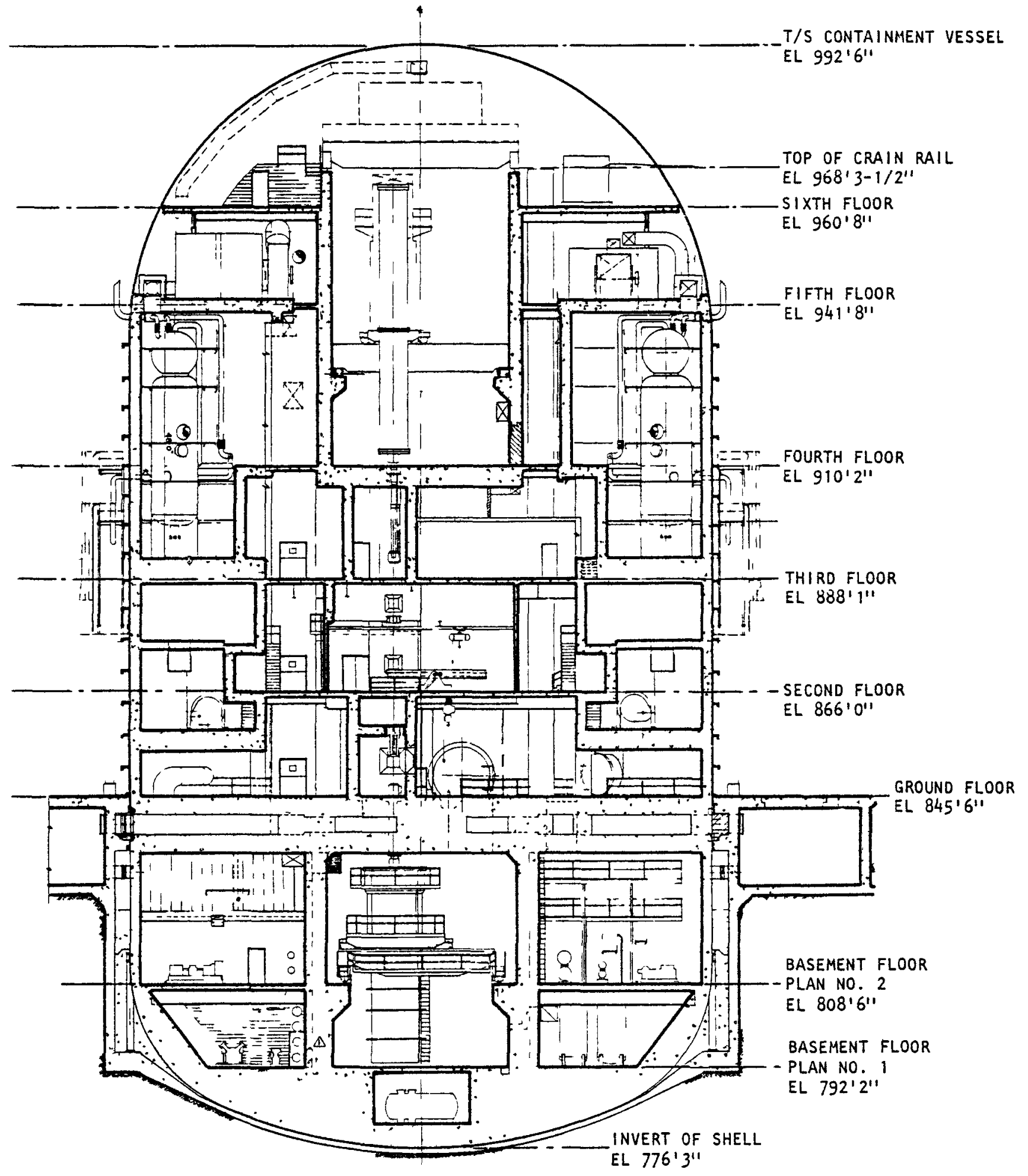

FIGURE 21. N-S SECTIONAL ELEVATION OF EGCR BUILDING (Section on centerline) (Smith and Matthiesen, 1969) 
In the containment structure tests, two mechanical oscillators were placed on the fourth floor, see Smith and Matthiesen, 1969. The response was measured at seven points as indicated in Figures 22 and 23 . The mode shapes and frequencies are shown in Figures 22,23 , and 24 , and are summarized in Table 5 for comparison with the results from the explosion tests. Response accelerations measured at resonance varied from $0.0006 \mathrm{~g}$ to $0.0023 \mathrm{~g}$ for the iN response measurements at the fourth floor. For a load change of a factor of three, no significant frequency shift was noted. In the EW direction, response accelerations at the fourth floor at resonance varied from $0.0013 \mathrm{~g}$ to $0.0036 \mathrm{~g}$, again with no significant frequency shift for a factor of three load changes. Torsional response varied from $0.001 \mathrm{~g}$ to $0.0008 \mathrm{~g}$. Thus, all measurements were at least two orders of magnitude below those that would result in a strong earthquake environment.

TABLE 5. COMPARISON OF EGCR CONTAINMENT STRUCTURE FUNDAMENTAL FREQUENCIES DETERMINED FROM STEADY-STATE VIBRATIONS, AND UNDERGROUND EXPLOSIONS WITH THEORETICAL VALUES

\begin{tabular}{|l|c|c|c|}
\hline \multirow{2}{*}{ Direction } & \multicolumn{3}{|c|}{ Fundamental Frequencies, $\mathrm{Hz}$} \\
\cline { 2 - 4 } & Theoretical & Steady State & Explosion \\
\hline EW & 6 to 12 & 4.65 & 4.4 to 4.5 \\
NS & 6 to 12 & 4.2 & 3.8 to 4.0 \\
Torsion & -- & 8.2 & 8.0 to 8.6 \\
\hline
\end{tabular}




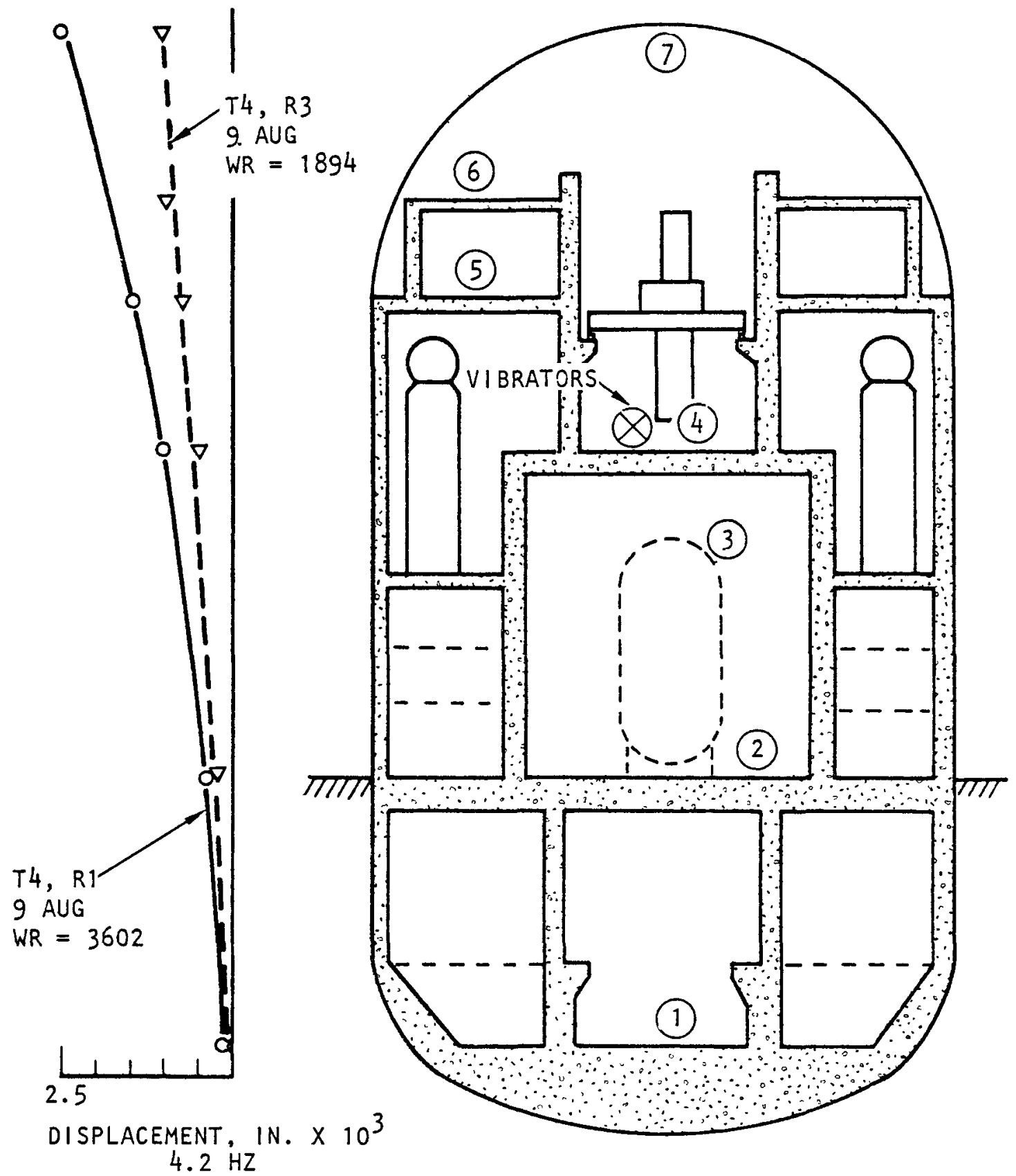

FIGURE 22. EGCR BUILDING NORTH-SOUTH MODE SHAPES AND INSTRUMENTATION POINTS (Smith and Matthiesen, 1969) 


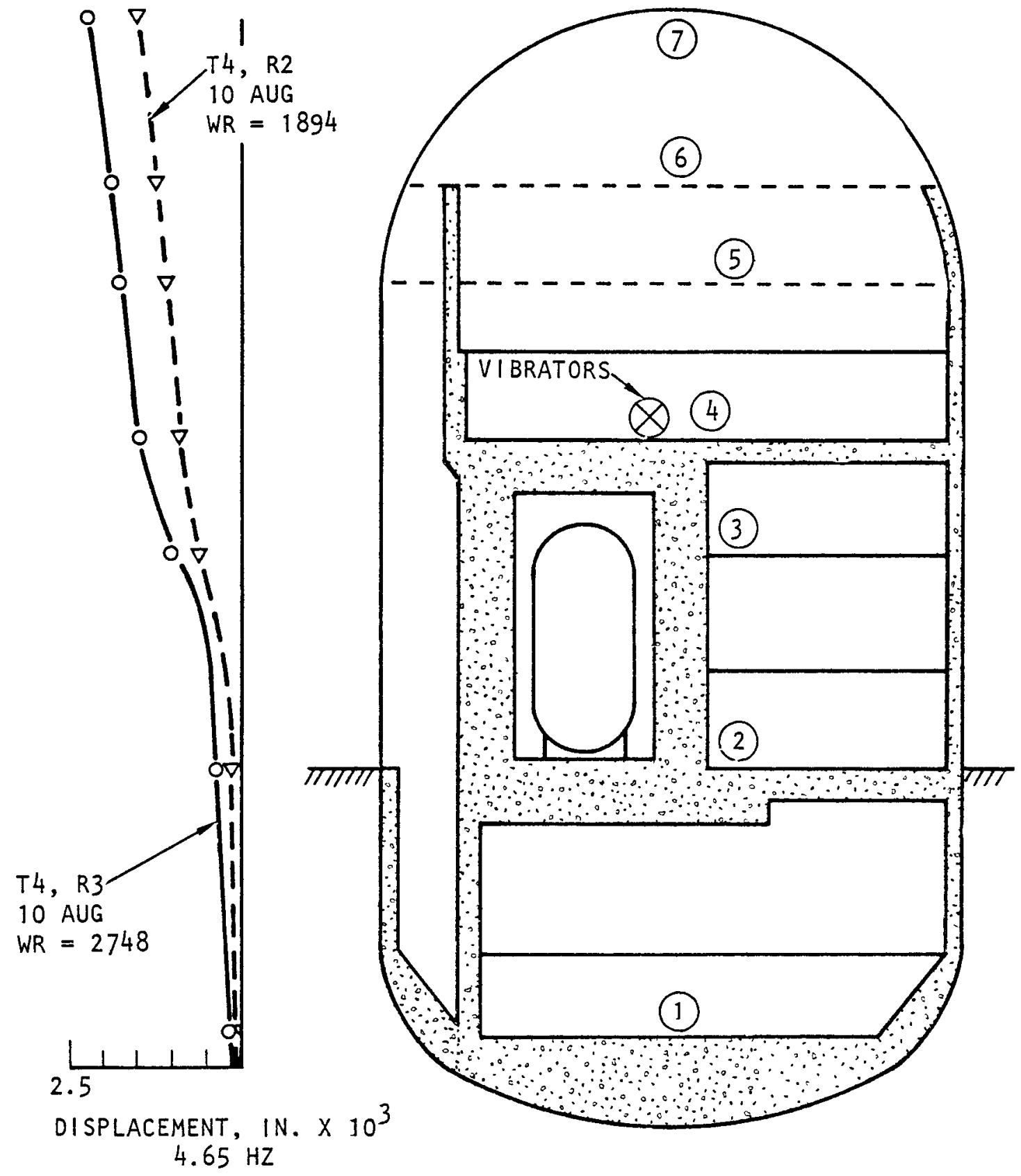

FIGURE 23. EGCR BUILDING EAST-WEST MODE SHAPES AND INSTRUMENTATION POINTS (Smith and Matthiesen, 1969) 

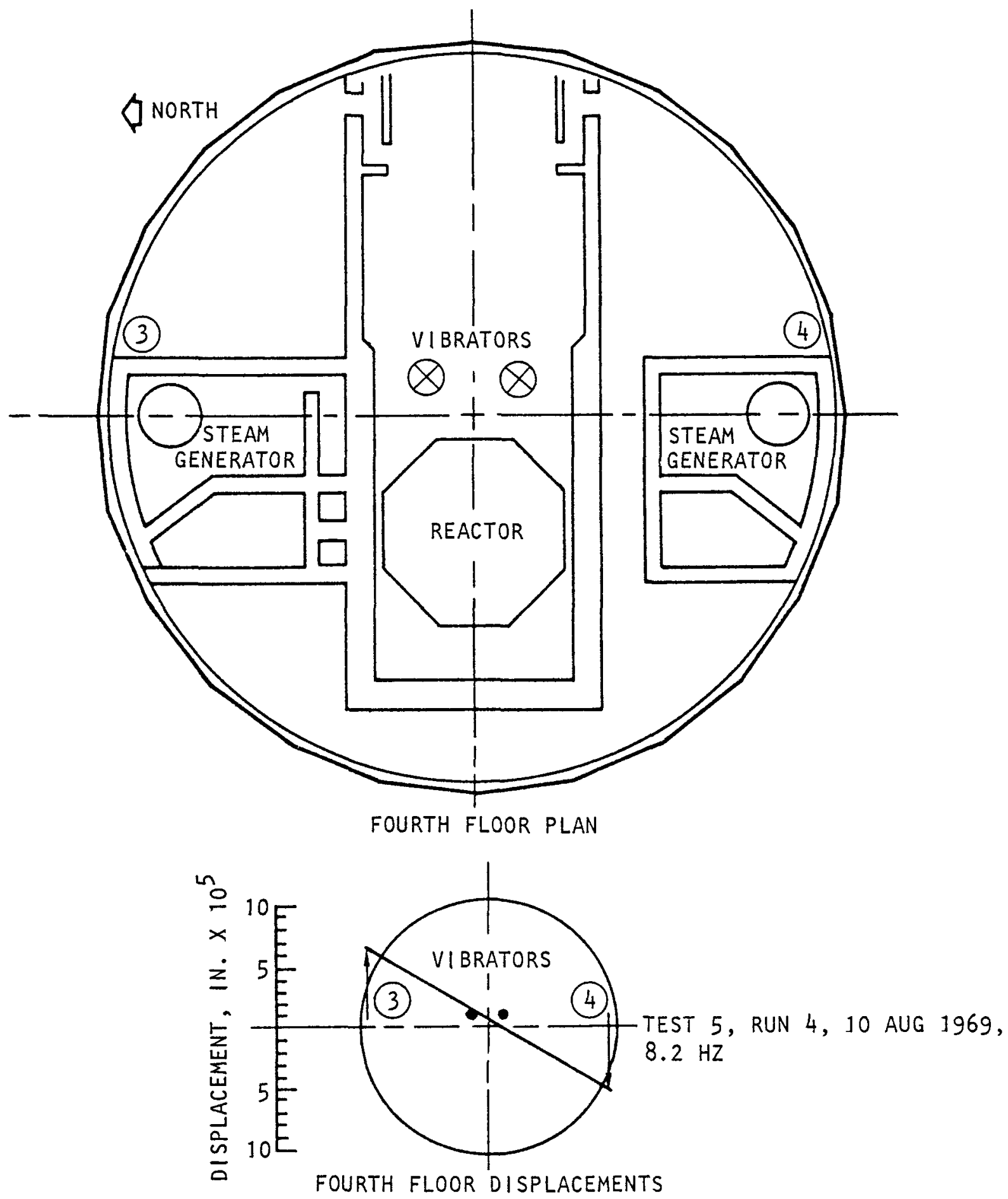

FIGURE 24. EGCR BUILDING TORSIONAL MODE SHAPES AND INSTRUMENTATION POINTS (Smith and Matthiesen, 1969) 
For the explosive tests, charge weights of principal tests were 100,600 , and $2000 \mathrm{lb}$. These were detonated at a depth of 40 to $50 \mathrm{ft}$ and at distances from the building of only 260 to $290 \mathrm{ft}$. The small charge weights and close distances should be contrasted with the rock quarry tests reported by Hudson and discussed above. As a result of the close proximity of the blasts, very intense high-frequency accelerations were measured at the engulfment of the structure by the blast wave $(0.3 \mathrm{~g}$ at $60 \mathrm{~Hz}$ for 2000-1b charge). The primary measurements, however, were the rocking mode response after engulfment. For these responses, accelerations of about 0.02 to $0.03 \mathrm{~g}$ were recorded on the fourth floor of the containment building in the EW direction for 600- and 2000-lb charges. Thus, a response was obtained that was about one order of magnitude higher than obtained for the steady-state vibratory tests. Table 5 indicates that only a slight drop in frequency resulted for the order of magnitude increase in response. However, this response is comparable to the steady-state response for the Millikan Library, see Figure 9. Since this response is an order of magnitude lower than would be experienced in a strong earthquake environment, the frequency shift that would take place under strong motion is uncertain.

The fundamental mode damping estimated from the steady-state tests varied between about 2 and 3.5\%. For the flexural modes, computed damping values varied from about 2.5 to $4.5 \%$ for the explosive tests. Both sets of data appear reasonable, considering the higher level of response for the latter. The rock-like foundation, and the shallow depth of embedment, obviously contributed to the success of the tests. However, larger explosive charge weights placed a greater distance from the structure would help eliminate the high-frequency accelerations and would give much longer response times and higher accelerations, which would be desirable.

Computed theoretical frequencies from the initial design analysis were also listed by Matthiesen and are indicated in Table 5. Calculations for frequencies including soil/structure interaction were also reported by Chrostowski et al., 1976. However, in both cases, the sophistication in the mathematical modeling was significantly less than present state-of-the-art capability. 
3.3.4 COMPARISON OF MEASURED EARTHQUAKE BUILDING RESPONSE WITH AMBIENT TRANSIENT AND STEADY-STATE VIBRATORY TEST RESULTS

It has been noted in Section 3.2.2 that strong motion recorders have been installed in multistory buildings in Los Angeles and other large California cities to collect information on the response of buildings to vibratory earthquake ground motion. In general, the recorders have been installed in the basements, near the mid-heights, and on the roofs of the buildings. This obviously could be an excellent test procedure. However, it also has major disadvantages. First, many years frequently elapse before useful information can be collected. Second, it is expensive to monitor all multistory buildings in order to make certain that a few will experience strong motion. Third, to keep costs within reasonable bounds, only a minimum of instrumentation is provided. As a result, it is usually difficult to determine whether significant torsional response occurred, and in no case has there been sufficient instrumentation to evaluate the influence of soil/structure interaction on the response measurements. Therefore, a complete interpretation of structure response from records that have been obtained is generally not possible. Nevertheless, this is an important method of collecting test information and needs to be considered in this review. The practice of installing strong motion recorders in all nuclear reactor structures should also eventually yield useful information on the response of these more massive and more deeply embedded structures. A review of some of the results of strong motion measurements in conventional structures follows.

The San Fernando earthquake of February 9, 1971 is one of the first earthquakes to provide strong motion records for a significant number of conventional multistory buildings. Records were obtained for about 70 buildings that varied from 7 to 42 stories in height (see NOAA, 1973a). Table 6 provides a summary of data from five buildings (varying from 7 to 20 stories in height) that is characteristic of the general behavior of the multistory buildings on soil foundations during the 1971 earthquake. 
TABLE 6. COMPARISON OF FUNDAMENTAL BUILDING PERIODS BEFORE, DURING, AND AFTER SAN FERNANDO EARTHQUAKE OF FEBRUARY 9, 1971 (NOAA, 1973)

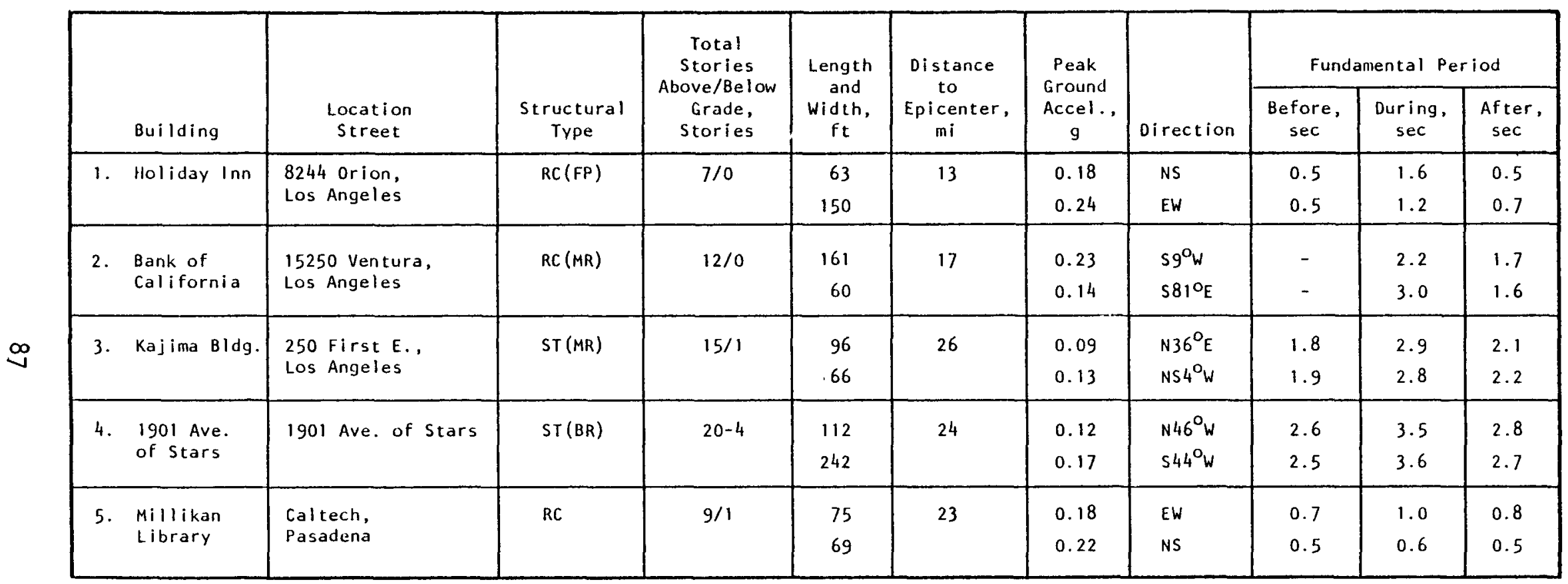

NOTES:

1. Fundamental periods before and after earthquake determined from ambient transient vibrations

2. Fundamental periods during earthquake determined from acceleration records

3. Structural type symbols:

$$
\begin{aligned}
& R C=\text { Reinforced concrete } \\
& F P=\text { Flat plate } \\
& M R=\text { Moment resisting frame } \\
& S T=\text { Structural steel }
\end{aligned}
$$


Postearthquake analyses based on the acceleration records of these and other structures are provided in NOAA, 1973a and b. A brief discussion of the data listed in Table 6 follows.

The general location of the buildings listed in Table 6 is shown in Figure 25, which also indicates the epicentral location and the probable center of energy release of the San Fernando earthquake, and the general geological features of the, area. Since surface faulting was associated with this earthquake, the center of energy release is a more meaningful reference than the epicenter for close-in structures, such as the Holiday Inn. The Bank of America building, it will be noted, is located at a distance that is about $50 \%$ greater than the Holiday Inn from the center of energy release. Even though the peak ground acceleration monitored at these two buildings are approximately the same, the response spectra for the Holiday Inn records indicate nearly twice the response for the range of the fundamental periods of the two buildings (see NOAA, 1973b). The Holiday Inn, therefore, received a much stronger input motion. The remaining three buildings are all about the same distance from the center of energy release (about 17 to 18 miles), and all are separated from the San Fernando valley by a modest topographic feature in the form of the Santa Monica Mountains or the Verdugo Hills.

The Millikan Library and the Kajima building sites have the firmest soil conditions of the five sites. Spread footing foundations were used for these two buildings. The Kajima site has only $30 \mathrm{ft}$ of sand overlying siltstone, and the footings were carried down about $15 \mathrm{ft}$ below grade, the equivalent of one story. The Millikan Library is also carried down a depth of $14 \mathrm{ft}$ (see Fig. 6), but this site has a greater depth of soil overlying bedrock. The 1901 Avenue of Stars Building site has a relatively deep alluvial soil condition, but four sub-basement stories were excavated below grade ( $45 \mathrm{ft}$ ), and the tower was supported on $72-\mathrm{ft}$ long steel $H$ piles that were capped in clusters of 3 to 10 piles. All pile caps were tied laterally with reinforced concrete tie beams. This structure, therefore, was deeply anchored into the soil. 


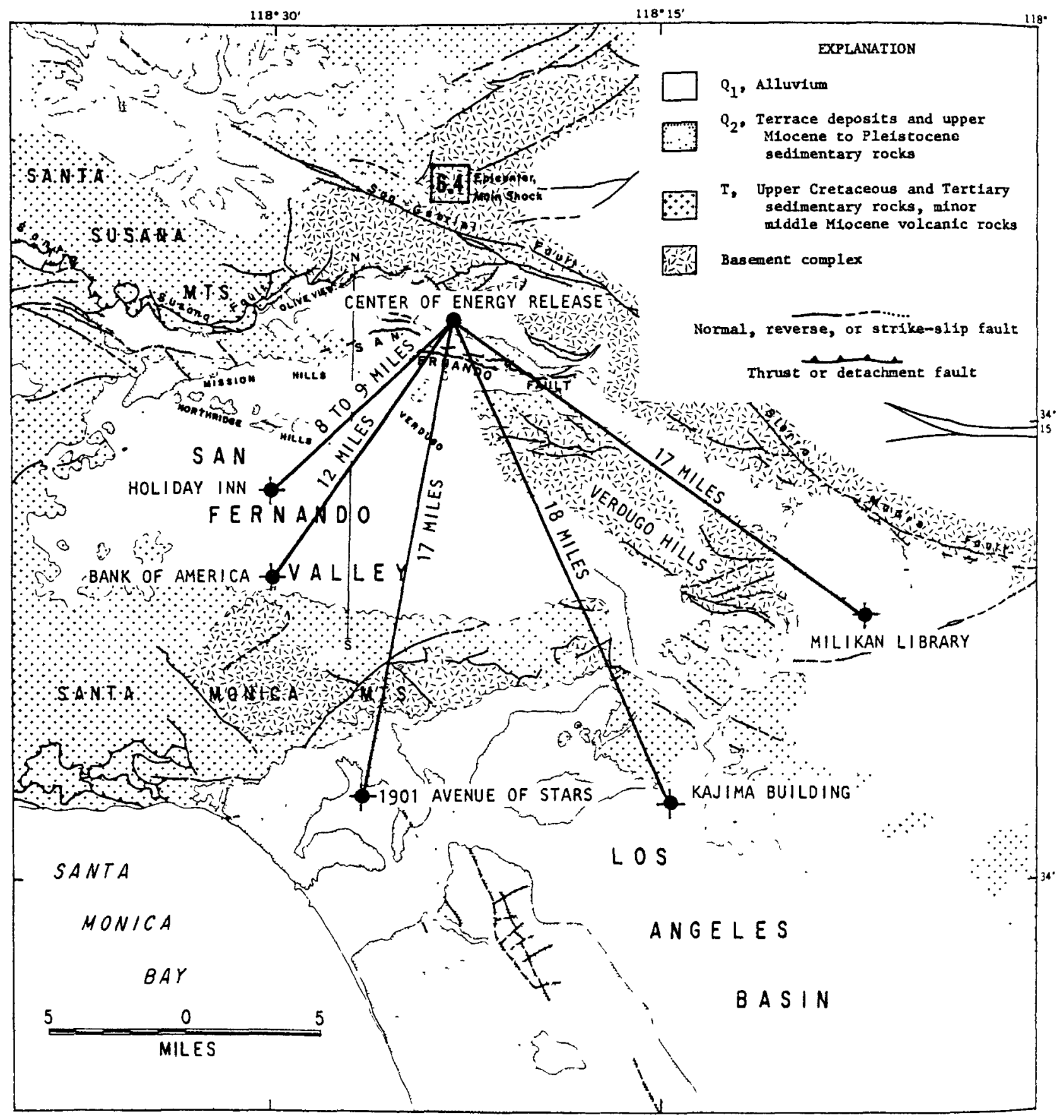

FIGURE 25. GENERAL GEOLOGICAL MAP SHOWING LOCATION OF BUILDINGS IN TABLE 6 RELATIVE TO EPICENTER AND CENTER OF ENERGY RELEASE OF FEBRUARY 9,1971 SAN FERNANDO EARTHQUAKE (Basic figure from NOAA, 1973C) 
The Holiday Inn and the Bank of America building are located on deep alluvial soil sites. At the Holiday $\mathrm{Inn}$ the soil is at least $300 \mathrm{ft}$ deep. The soils at the Bank of America building are shallower, but of unknown depth. Both structures were built on cast-in-place piles that were capped at grade. No basement was provided for either structure. The piles were 40 to $50 \mathrm{ft}$ in length.

The most important information resulting from the analyses of the acceleration records for these two structures was the very significant shift in the fundamental mode periods under strong earthquake input as compared to the periods determined from ambient transient and steady-state vibratory loads. Starting first with the Millikan Library, Table 3 has previously indicated ambient and steady-state test values of $0.7 \mathrm{sec}$ in the EV direction and $0.5 \mathrm{sec}$ in the NS direction for this building. During the 1971 earthquake, the period in the EW direction increased $40 \%$ and in the NS direction $20 \%$. The straightline extrapolation of frequency given previously in Figure 10 indicates that at an eighth floor response acceleration of $0.25 \mathrm{~g}$, a fundamental mode period of about $0.7 \mathrm{sec}$ should have result. Table 6 indicates that a fundamental mode period of $1.0 \mathrm{sec}$ resulted during the San Fernando 1971 earthquake. The eighth floor response acceleration was $0.34 \mathrm{~g}$ for this earthquake input, but this would include response from more than the first mode. The first mode response was probably between $0.25 \mathrm{~g}$ and $0.30 \mathrm{~g}$. The shift in fundamental mode frequency with different levels of response acceleration reported by Trifunac in Figure 10 have been plotted in Figure 26 with the linear extrapolation also indicated. Also shown by broken line in Figure 26 is the extrapolation of the data on a nonlinear basis to intersect a frequency of $1.0 \mathrm{~Hz}$ (period of $1 \mathrm{sec}$ ) at $0.3 \mathrm{~g}$ response acceleration. The data indicates that at the steady-state vibratory test amplitude of $0.0014 \mathrm{~g}$, the structure was approaching a distinct nonlinear level of response. Unfortunately, the experimental data collected during the earthquake do not permit a determination of how much of the nonlinear behavior was due to structural behavior, nor how much was due to soil/structure interaction. 


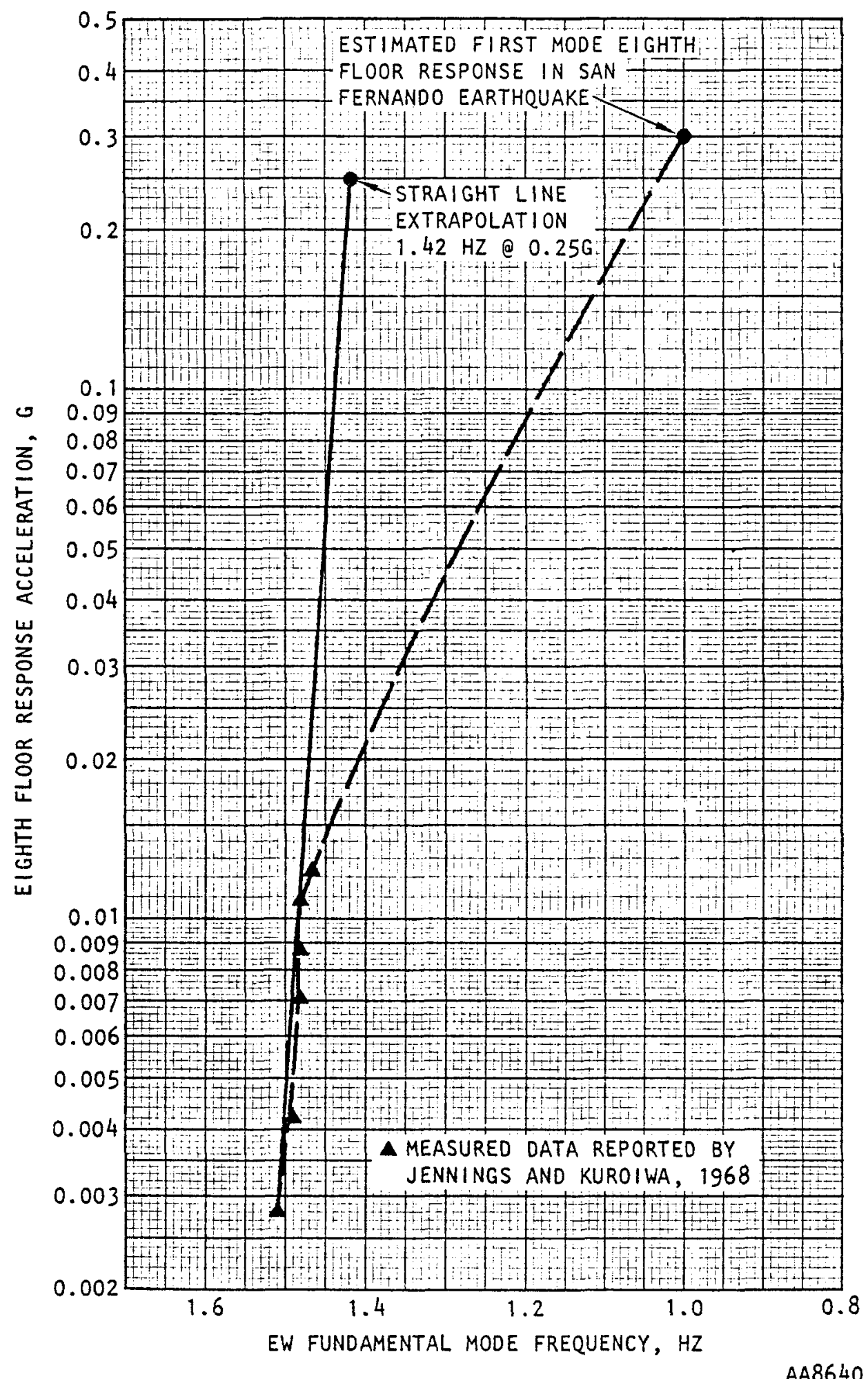

FIGURE 26. COMPARISON OF ESTIMATED FIRST MODE RESPONSE OF MILLIKAN LIBRARY DURING SAN FERNANDO EARTHQUAKE WITH STEADY-STATE VIBRATORY TEST DATA 
The data in Table 6 indicate that the Kajima and 1901 Avenue of the Stars buildings also had a 40 to $50 \%$ increase in fundamental period during this earthquake, as compared to the period determined by ambient transit vibration tests. The Kajima site had a very firm foundation. While the 1901 Avenue of Stars site is a deeper soil site, this building was embedded to a depth of $45 \mathrm{ft}$. This structure was also founded on piles. The intensity of ground motion at the 1901 Avenue of Stars building was comparable to that experienced at the Millikan Library, but the ground motion recorded at the Kajima building was slightly lower. Thus, it is reasonable to conclude that the general response of these three buildings was quite comparable. However, Hart (NOAA, 1973b) was the only investigator of the response of the buildings listed in Table 6 , to indicate that the shift in fundamental period was probably significantly affected by soil/structure interaction.

The data in Table 6 for the Bank of America and the Holiday Inn buildings provide an interesting comparison with the data for the two buildings discussed above. It will be noted that the input at the Bank of America site was comparable to that recorded at the Millikan Library and at the 1901 Avenue of Stars building; but the shift in fundamental period in the transverse direction of the building was nearly $90 \%$ as compared to $40 \%$ for the other two buildings. The shift in the longitudinal direction was only $30 \%$. These comparisons, however, are with ambient transient vibration measurements made after the earthquake rather than before. Those made after the earthquake for the other buildings noted in Table 6 were equal to or slightly higher than measurements made before the earthquake. The shift in fundamental period was therefore higher than observed for the three previous structures. While it is not possible to primarily associate this increase to soil/structure interaction effects, the foundation and structural arrangement were such that greater effects should be anticipated. This becomes more evident when the response of the Holiday Inn is examined. 
The input to the Holiday Inn was significantly stronger than to the Bank of America building, as previously indicated. However, the shift in fundamental period was more than would be indicated by a linear extrapolation of input from the Bank of America site. For the Holiday Inn, the increase in fundamental mode period was $200 \%$ in the transverse direction of the building and $140 \%$ in the longitudinal direction, or an average of $170 \%$. In this case, the site is a deep, saturated alluvial soil, and the structure has negligible embedment. Again, it is not possible to determine how much of the shift in period was due to nonlinear soil/structure interaction and how much was due to yielding of structural members. However, conditions at this site are quite favorable to accentuated soil/structure interaction, and it was not possible in the postearthquake analysis to satisfactorily model the shift in period by changes in structural material properties alone. Two conclusions can be drawn, however. First, fundamental periods of multistory buildings determined by ambient transient and steady-state vibratory test procedures have been found to be in error by 50 to $200 \%$ when compared with the measured response of the structures in a moderately strong earthquake ground motion environment. (Damping in the earthquake environment has also been demonstrated to be 5 to $10 \%$ of critical as compared to 2 to $3 \%$ at steady-state vibration test levels.) Second, additional strong motion instrumentation is needed to permit determination of torsional response and the effect of soil/structure interaction on the structure response in strong earthquake ground motion environments.

Steady-state vibratory tests have been conducted at the San Onofre nuclear power plant, and response to the San Fernando, 1971 earthquake was also recorded (see Ibanez et al., 1970, Matthiesen et al., 1970, and Smith et al., 1971). However, the steady-state vibratory tests were planned primarily for the determination of equipment response, and the input from the San Fernando earthquake was too low $(0.01 \mathrm{~g})$ to provide meaningful response. A comparison of results from these investigations does not, therefore, contribute useful information and has been omitted. 


\subsection{SUMMARY OF TEST RESULTS}

Section 3.3 has provided a comparison of the results of dynamic tests of structures using loads resulting from ambient transient vibrations, steady-state mechanical oscillators, explosions, and natural earthquakes. The objectives of the tests were in general to determine fundamental mode periods, mode shapes, and damping that could be used to estimate the response of the structures to strong earthquake ground motion. Fundamental periods have also been compared with theoretically computed values. This section provides a summary of the results relative to their applicability to seismic design verification of nuclear power plant structures.

\subsubsection{THEORETICALLY CALCULATED FUNDAMENTAL PERIODS}

Theoretically calculated fundamental periods were compared with fundamental periods determined by ambient transient, steady-state mechanical oscillator, explosive and earthquake-induced vibrations. It is important to note that in practically all cases studied, the analytical procedures used to compute the fundamental periods were based on mathematical models that were significantly inferior to present state-of-the-art capability. For highrise buildings, one-dimensional models have normally been used that ignore torsion and soil/structure interaction. Mathematical models used to estimate fundamental periods of nuclear plant structures reviewed in some cases assumed rigid body behavior and in no case used an adequate representation of soil/structure interaction, nor did the procedures approached present Nuclear Regulatory Commission licensing requirements. Primarily because of inadequate mathematical modeling, variations of 100 to $200 \%$ between the theoretically computed and the experimentally measured modal periods by ambient transit, steady-state, and explosive-induced vibratory test procedures resulted. The computed fundamental periods were found to be in error both above and below the measured values. When the computed periods are compared to periods measured for structures during a strong earthquake, the variation should be expected to be as high as 100 to $300 \%$. It is postulated that 
variations between computed fundamental periods for conventional nuclear power plant structures, based on present licensing practice, and values that might be measured in the SSE environment would normally be as great as $100 \%$. It is further postulated that if the very best analytical modeling procedures are used (i.e., better than average practice), the variation can be reduced to about $50 \%$.

\subsubsection{AMBIENT TRANSIENT VIBRATORY TESTS}

The results of the tests examined indicate that when ambient transient vibratory test methods are carefully applied to multistory buildings having a depth of embedment of about $10 \%$ of the aboveground height, or less, modal period determinations can be made that are in excellent agreement with those determined by steady-state vibratory test methods. Modal damping determinations ( 1 to $2 \%$ ) are less certain, particularly when modes are closely spaced. However, levels of excitation are usually three orders of magnitude below that resulting in a strong earthquake environment. Therefore, modal period determinations for multistory buildings in a strong seismic environment can be expected to be 50 to $200 \%$ higher, and damping will be at least a factor of 3 to 5 higher than determined from ambient transient vibration tests. Ambient transient tests on more massive and more deeply embedded structures, which are characteristic of nuclear power plant structures, have not produced reliable results and are not recommended.

\subsubsection{STEADY-STATE VIBRATORY TESTS}

Steady-state vibratory tests of multistory buildings produce response accelerations at least one order of magnitude lower than result in a strong earthquake environment, and for massive, embedded structures, the response may be two orders of magnitude lower. For multistory buildings having a depth of embedment of about $10 \%$ of the aboveground height, or less, more reliable damping and slightly more reliable modal periods can be obtained with steady-state tests than with ambient transient tests. Modal period determinations for multistory buildings in a strong seismic environment, 
however, will usually be 50 to $200 \%$ higher, and damping will be a factor of 3 to 5 higher than determined by steady-state vibratory tests. More massive structures, similar to some nuclear power plant structures, which have a depth of embedment of about $10 \%$ of the aboveground height, or less, and which are supported on rock having nearly strain independent properties, should also yield reasonable modal data when tested with steady-state vibratory procedures. However, steady-state vibratory tests may provide little useful information for massive structures when the depth of embedment is greater than 10 to $20 \%$, and/or the supporting media is soil with nonlinear stress/strain characteristics.

\subsubsection{EXPLOSIVE-INDUCED VIBRATORY TESTS}

Buried explosives can be used to simulate a strong earthquake environment for testing nuclear power plant structures. However, charge weights of 100 to 500 tons buried at distances of 1200 to $1500 \mathrm{ft}$ from the structure are needed to provide realistic response. For these conditions, the duration of strong motion will probably not exceed $2 \mathrm{sec}$, and the freefield response spectra will be deficient below frequencies of 2 to $3 \mathrm{~Hz}$. Much greater charge weights with several time delays would be required to provide more realistic durations of strong motion, and to extend the freefield response spectra into lower frequencies at Regulatory Guide 1.60 spectra levels. Because of the large area that would be subjected to strong ground motion, and the expense of the test, this test procedure can seldom be used to test commercial nuclear power plant structures. Tests at low charge weights, such as one ton or under, are not recommended.

\subsubsection{MEASURED RESPONSE TO NATURAL EARTHQUAKE EXCITATION}

The best experimental information on the response of structures to a strong earthquake environment can be obtained by placing strong motion recorders at selected points in the structure and in the free-field soil environment near the structure. However, the disadvantages of this method 
of testing are the expense of instrumenting many structures in order to make certain that some measurements are obtained, and the long delay before meaningful data can be collected. Also, present instrumentation procedures for multistory buildings do not usually provide sufficient information for an adequate analysis of torsional response, or the influence of soil/structure interactions on the response of the structure. The same shortcomings exist for normal instrumentation of nuclear power plants. 
○

○ 
CHAPTER 4

CONCLUSIONS AND RECOMMENDATIONS

\subsection{INTRODUCTION}

The introductory chapter has indicated that the objectives of seismic design verification of nuclear power plant structures are first, and foremost, to verify that the predicted response of the structures at.equipment and piping support points has been reliably estimated as the response at these points is used as input to the seismic design analysis of the equipment and piping systems. Second, seismic design verification of the structure is needed to assure satisfactory and reliable behavior of the structure in the OBE and SSE environments. It is therefore evident that a reliable determination of the modal periods, vectors, and damping is a prime requisite of the seismic design analysis and for the seismic design verification of the structure.

Chapter 2 has pointed out that seismic design verification of nuclear power plant structures can be provided by design reviews and alternate calculations, or by qualification testing. Discussion in Chapter 2 has also established that qualification testing of the structures, if it could be performed, would be a more reliable verification procedure, unless a high level of confidence can be established for all of the design assumptions. However, at the present time qualification testing is not used, and there is not a high level of confidence in all design assumptions. The question has then been raised whether experimental verification of design assumptions can be provided by a lower energy level of testing than qualification testing.

Different methods of providing dynamic tests of structures have been described and compared in Chapter 3. These results provide background information that has been used to determine whether qualification testing of nuclear power plant structures is possible and feasible, and whether other lower energy level tests could be used to verify the seismic design assumptions. The conclusions and recommendations resulting from this investigation follow. 


\subsection{CONCLUSIONS}

This investigation has lead to the following conclusions relative to qualification tests and lower energy-level verification tests.

\subsubsection{QUALIFICATION TESTS}

As a result of this investigation, it is concluded that it is physically possible to provide a seismic environment adequate for providing a qualification test of nuclear power plant structures. However, this could only be provided by using more than 500 tons of buried chemical explosives, or by underground nuclear explosives. In both cases, an area several square miles in extent would be subjected to ground motions of sufficient intensity to damage conventional structures. Category $\mid 1$ and $|1|$ items associated with the nuclear power plant would also experience some damage. The cost of the test with chemical explosives would be expensive, and the limitations on underground nuclear tests greatly restrict the areas in which such tests can be performed. Therefore, although qualification tests of nuclear power plant structures are physically possible, such tests are not practical, nor feasible, because of the expense of the test and the damage liability.

\subsubsection{LOWER LEVEL EXPERIMENTAL VERIFICATION TESTS}

The objective of verification tests would be to verify the correctness of the seismic design assumptions. The results of this investigation indicate that the greatest uncertainties in assumptions are associated with the mathematical modeling of the structure, and the modeling representation of the soil/structure interaction. Because of these uncertainties, analyses and designs are intentionally made on a conservative basis. However, based on this investigation, it is postulated that modal periods computed by procedures in current practice may frequently be in error by as much as $100 \%$ for the SSE environment. It is further postulated that if the best analytical modeling procedures were used (i.e., better than average practice), the error in modal periods might be reduced to about $50 \%$. Damping values 
used in seismic analyses are intended to be conservative, but the actual damping characteristic for the SSE environment is based more on judgment than on experimental verification. There is, therefore, a need to provide experimental verification of modal periods, vectors, and damping where possible.

It is concluded from this investigation that only in unusual cases can ambient transient vibratory test data be used to provide a reliable estimate of the dynamic response of typical nuclear power plant structures. It is therefore concluded that ambient transient vibration tests should not be used for low level testing of nuclear power plant structures.

This investigation indicates that steady-state mechanical oscillator tests can be used to obtain general information on structural modes when the depth of embedment is about $10 \%$, or less, of the aboveground height of the structure, and the structure is supported on rock with nearly strain independent properties. Such tests should be provided as a part of the verification program. However, before making such tests, analytical studies using the best mathematical modeling procedures available should be made to determine whether a level of response can be achieved that will provide meaningful results. In those cases where meaningful results can be obtained, the mathematical models should be used to extrapolate the structural response to the OBE and SSE ground motion levels. Damping and material behavior assumptions, however, should remain conservative as these properties cannot be verified with low-energy level tests and analysis.

For nuclear power plant structures having more than $20 \%$ embedment, and/or when the supporting media is soil with nonlinear stress/strain characteristics, steady-state vibratory tests will provide little useful information. For such cases, reliance will have to be placed on more sophisticated verification analyses than are conventionally used in design, and upon special tests and observations of structures of the same generic class in strong ground motion environments. These would include special tests with explosiveinduced ground motions, and the observed behavior of instrumented nuclear power plant structures in strong natural earthquake environments. 


\subsection{RECOMMENDATIONS}

Based on the above conclusions, it is evident that some improvements should be instituted in the seismic design verification procedures for future LMFBR structures. These structures will generally be large and massive, and will probably be embedded more tha $20 \%$ of the aboveground height. Careful study will therefore be required for each case to determine whether meaningful experimental data can be obtained from low energy level tests. For those cases where steady-state mechanical oscillator tests will yield reliable information, such tests should be performed and mathematical models of the structure and supporting rock media should be used to extrapolate the response to the $O B E$ and SSE ground motion levels. For those sites where such tests will not provide reliable information (i.e., deep embedment and/or soil sites), more sophisticated analyses should be provided than used in conventional design analyses to verify the structure response in the OBE and SSE ground motion environments.

It is evident that additional test information is needed on the behavior of nuclear power plant structures in a strong earthquake ground motion environment. To provide information on the behavior of massive, deeply embedded nuclear power plant structures, the following programs are recommended.

a. It is recommended that an experimental program be planned and conducted for a relatively few nuclear power plant structures that are relatively deeply embedded in soil sites. Plants should be selected that have been decommissioned, and should be located, if possible, where an earthquake-like environment can be generated with underground chemical explosives without causing damage to other nearby structures. If these conditions can be satisfied, a test plan should be formulated, based on a dynamic analysis of the structure, to make certain that an adequate test environment can be generated, and that proper instrumentation to measure the ground motion environment and structure response can be provided. These tests should then be performed and modal periods, vectors, and damping measured. 
The modal periods and vectors should be compared with the analytical results, and the damping compared with present practice.

b. If decommissioned nuclear power plant with the site conditions described in $a$ can be found, but if off-site environmental conditions prevent the development of an earthquake-like environment with chemical explosives, then it is recommended that an analysis be made to determine if it is possible to generate earthquake-level response with pulse-loading techniques such as described in Section 3.2.4 from the work of Masri and Safford, 1976. If it is found that an adequate input can be generated by this method, then it is recommended that a test plan be formulated using this type of loading device. Modal periods, vectors, and damping should then be determined by this experimental method and compared with analysis results and with practice, as indicated in $a$.

c. Currently, strong motion recorders are required to be installed at all commercial reactors. However, as has been found with the instrumentation program in California for multistory buildings, the instrumentation is generally not sufficient to permit a complete analytical verification of the structure and soil/structure response to strong earthquake ground motion. It is therefore recommended that a study be made of experimental, demonstration, and commercial reactors in areas having high seismic activity, and that representative structures on soil sites be selected for the installation of the additional strong motion instrumentation required to make a complete interpretation possible of the response of the structure and of the soil during a strong earthquake. Complete dynamic analyses using adequate mathematical models should also be performed when planning the instrumentation to make certain adequate 
instrumentation is provided. It should be particularly noted that only sites having a reasonable probability of experiencing strong earthquake ground motion should be selected for additional instrumentation. 
CHAPTER 5

REFERENCES

Agbabian Assoc. (AA). (1976) Seismic Soiz/Stmucture Interaction Analysis Guidelines; Vol. 1, Analysis Techniques, SAN/1011-110; Vol. 2, State-of-the-Art Procedures, SAN/1011-111. El Segundo, CA: AA, Apr.

Agbabian Assoc. (AA). (1977) Seismic Soil/Stmcture Interaction Analysis Guidelines; Vol. 3, Example Analyses, Sep. (in preparation)

Amer. Nat'I Standards Inst. (ANSI). (1974) Quality Assurance Requirements for the Design of Nuclear Power Plants, ANS1-N45.2.11-1974. New York: ANSI.

Army Engineer Waterways Exp. Station (AEWES). (1972) Earthquake Resistance of Earth and Rock-Filz Dams: Feasioility of Simulating Earthquake Effects on Earth and Rock-Eill Dams Using Underground Nuclear Events, Misc. Paper-s-71-17, Rpt. 3. Vicksburg, MS: AEWES, Sep. (AD 748 816)

Carder, D.S. (1936) "Vibration Observations," in Earthquake Investigations in Califomia 1934-1935, Washington, DC: USGPO, PP 75.

-.- and Cloud, W.K. (1959) "Surface Motions from Large Underground Explosions," Int of Geophys. Res. 64:10, Oct.

Cherry, S. and Brady, A.G. (1965) "Determination of Structural Dynamic Properties by Statistical Analysis of Random Vibrations," Proc. 3rd World Conf. on Earthquake Eng. Aukland and Wellington, New Zealand, Jan 1965, Vol. 2, pp 50-67.

Chrostowski, J. et al. (1972) Simulating Strong Motion Earthquake Effects on Nuclear Power Plants Using Explosive Blasts, UCLA-ENG-7119.

Los Angeles, CA: Univ. of Calif., Feb.

Cloud, W.K. (1963) "Period Measurements of Structures in Chile," BuZZ. Seismol, Soc. Amer. 53:2, Feb, pp 359-379.

Corps of Eng. Dept. of the Army (COE). (1977) Hardness Verification, TM 5-858-6. Washington, DC: COE, Jul.

Crawford, R. E Ward, H.S. (1964) "Determination of the Natural Periods of Buildings," Bulz. Seismoz. Soc. Amer. 54:6A, Dec, pp 1743-1756.

Drake, L.A. (1975) "Love and Rayleigh Waves in Nonhorizontally Layered Media," Bulz. Seismol. Soc. Amer. 62:5, Oct, pp 1241-1258.

Earth Sciences (ES). (1968) Ambient Vibration Survey and Mathematical Analysis of the Carolinas-Virginia Tube Reactor. Pasadena, CA: ES, Sep. 
Feng, B.; Enis, R.; and Hunt, J. (1975) "A Seismic Analysis of a Post-Tensional Concrete Containment," Proc. 2nd Conf. on Struct. Des. of Nuc. Plant Facilities, New Orleans, Dec 8-10, Vol. 1-B, pp 1236-1291. New York: Amer. Soc. of Civil Eng.

Hart, G.C.; Bleiwseis, P.; and Smith, C.B. (1970) "Enrico Fermi Nuclear Power Plant Dynamic Response during Blasting," Trans., Amer. Nuc. Soc. $13: 1, p 231$.

Hudson, D.E.; Alford, J.L.; and Housner, G.W. (1954) "Measured Response of a Structure to an Explosive-Generated Ground Shock," BuzZ. Seismol. Soc. Amer. 44:3, Jul.

---; Alford, J.L.; and Iwan, W.D. (1961) "Ground Accelerations Caused by Large Quarry Blasts," BuzZ. Seismoz. Soc. Amer. 51:2, Apr.

-.-. (1962) Synchronized Vibration Generators for Dynamic Tests of Fulz Scale Structures. Pasadena, CA: Calif. Inst. of Tech. Earthquake Eng. Res. Lab., Nov.

-.--. (1970) "Dynamic Tests of Full-Scale Structures," in Earthquake Engineering edited by R.L. Wiegel, Chapt. 7. Englewood Cliffs, $\mathrm{NJ}$ : Prentice-Hall.

-..-. (1976) "Dynamic Tests of Full-Scale Structures," Proc. Dynamic Response of Structures, Instmumentation, Testing Methods, and System Identification, Univ. of Calif. Los Angeles, Mar 30-31, 1976, New York: ASCE (suppl. to Chapt. 7 in Earthquake Engineering edited by R.L. Wiegel)

Ibanez, P.; Matthiesen, R.B.; Smith C.B.; and Want, G.S.C. (1970) San Onofre Nuclear Generating Station Vibration Tests, UCLA-ENG-7037. Los Angeles: Univ. of Calif. Nuc. Energy Lab., Aug.

Jennings, P.C. and Kuroiwa, J.H. (1968) "Vibration and Soil Structure Interaction Tests of a Nine-Story Reinforced Concrete Building," Buzz. Seismol. Soc. Amer. 58:3, Jun, pp 891-916.

--.- et al. (1972) "Forced Vibrations of a Tall Steel-Frame Building," Earthq. Eng. \& Struct. Dyn 1:2, Oct-Dec, pp 107-132.

Keightley, W.0.; Housner, G.W.; and Hudson, D.E. (1961) Vibration Test of the Encino Dom Intake Tower. Pasadena, CA: Calif. Inst. of Tech. Earthquake Eng. Res. Lab., Jul.

Lysmer, J. (1975) FLUSH, A Computer Program for Approximate 3-D Analysis of Soil/Structure Interaction Problems, EERC-75-30. Berkeley, CA: Univ. of Calif. Earthquake Eng. Res. Center. Nov.

Masri, S.F. and Safford, F.B. (1976) "Dynamic Environment Simulation by Pulse Techniques," Proc. ASCE Eng. Mech. Div. 101:EM1, Feb, pp 151-169.

Matthiesen, R.B. and Smith, C.B. (1969) Forced Vibration Tests of the Carolinas-Virginia Tube Reactor (CVTR), Los Angeles: Univ. of Calif. Dept. Of Eng., Feb. 
--.-. Ibanez, P. et al. (1970) San Onofre Nuclear Generating Station Supplementary Vibration Tests, UCLA-ENG-7095. Los Angeles: Univ. of Calif. Nuc. Energy Lab., Dec.

McLamore, V.R. et al. (1971) "Ambient Vibration of Two Suspension Bridges," Proc. ASCE, Struct. Div. 97:ST10, Oct, pp 2567-2532.

Madearis, K., Assoc. (1975) A Comparative Study of Stmuctural Response to Explosion-induced Ground Motions, an ASCE Research Activity. New York: Amer. Soc. of Civil Eng.

Nat'l Uceanic and Atmospheric Administration (NOAA). (1973a) Scon Femando, Califomia, Earthquake of Februamy 9, 1971, Vol. 1, Pt. B. Washington, DC: USGPO.

---. (1973b) San Femando, California, Earthquake of Eebmamy 9, 1971, Vol. 1, Pt. A. Washington, DC: USGPO.

-.-. (1973c) San Eemando, Califormia, Earthquake of Eebmamy 9, 1971, Vol. 2. Washington, DC: USGPO.

Penzien, J. (1967) Feasibility Study of Large Scale Earthquake Simulator Facility, EERC-67-1. Berkeley, CA: Univ. of Calif. Earthquake Eng. Res. Center, Sep. (PB 187 905)

Safford, F.B.; Carlson, L.E.; Walker, R.E.; and Huang, C.C. (1977) 'Air Blast and Ground Shock Simulation Testing of Massive Equipment by Pulse Techniques," to be presented at the 5th Int. Symp. On Military Application of Blast Simulation, Stockholm, Sweden, May 23-26.

Schmitt, R.C. (1970) Evaluation and Comparison of Structural Dynamics Investigations of the Carolinas Virginia Tube Reactor Containment, IN-1372. Idaho Falls, ID: I daho Nuclear Corp., May.

Schnabel, P.B. et al. (1972) SHAKE, A Computer Program for Earthquake Response Analysis of Horizontally Layered Sites, EERC-72-12. Berkeley, CA: Univ. of Calif. Earthquake Eng. Res. Center, Dec. (PB 220 207)

Shannon \& Wilson (SW) \& Agbabian Assoc. (AA) (1972) Soil Behavior Under Earthquake Loading Conditions: State-of-the-Art Evaluation of Soil Characteristics for Seismic Response Analyses. Seattle, WA: SW \& E] Segundo, CA: AA. (TID 26444)

Smallwood, D.O. and Hunter, N.F. (1975) "A Transportable 56-kN, 200-mm Displacement Hydraulic Shaker for Seismic Simulation," Proc. Inst. of Environmental Sci.

Smith, C.B. and Matthiesen, R.B. (1969) Forcea Vibration Tests of the Experimental Gas-Cooled Reactor (EGCR), R-69-42. Los Angeles: Univ. of Calif. Dept. of Eng., Aug. 
-.-- et al. (1971) Response of San Onofre Nuclear Generating Station to Earthquakes, UCLA-ENG-7151. Los Angeles: Univ. of Calif. Dept. of Eng., Jul.

Trifunac, M.D. (1970) Wind and Microtremor Induced Vibrations of a Twenty-Two Story Steel Frame Building, EERL-70-01. Pasadena, CA: Calif. Inst. of Tech.

---- (1972) "Comparisons between Ambient and Forced Vibration Experiments," Earthq. Eng. \& Struct. Dyn. 1:2, Oct-Dec, pp 133-150.

---- and Udwadia, F.E. (1974) "Variations of Strong Earthquake Ground Shaking in the Los Angeles Area," Buzz. Seismol. Soc. Amer. 64:5, Oct, pp 1429-1454.

U.S. Atomic Energy Comm. (USAEC). (1973) "Design Response Spectra for Seismic Design of Nuclear Power Plants," Regulatory Guide 1.60, Rev. 1. Washington, DC: USAEC, Dec.

U.S. Coast and Geodetic Survey (USCGS). (1936) Earthquake Investigations in California, 1934-1935, Special Pub 201. Washington, DC: USGPO.

U.S. Energy Res. E Dev. Admin. (ERDA). (1973) Quality Assurance Program Requirements, RDT Standard-RDT-F-2-2. Oak Ridge, TN: Oak Ridge Nat'l Lab., Aug.

-.--. (1974) Quality Verification Program Requirements, RDT Standard RDT-F-2-4T. Oak Ridge, TN: Oak Ridge Nat'l Lab., Dec.

U.S. Nuc. Regulatory Comm. (USNRC). (1975) Standard Review Plan for the Review of Safety Analysis Reports for Nuclear Power Plants, LWR Edition, 4 vols. Washington, DC: USNRC, Sep. (NUREG 75/087)

-.--. (1975) "Quality Assurance Requirements for the Design of Nuclear Power Plants," Regulatory Guide 1.64, Rev. 1. Washington, DC: USNRC, Feb.

Ward, H.S. E Crawford, R. (1966) "Wind Induced Vibrations and Building Modes," Bulz. Seismol. Soc. Amer. 56:4, Jun, pp 793-813. 
C.C. Bigelow (5 copies)

Div. of Reactor Development and Demonstration

Department of Energy

Mail Stop F-309

Washington, D.C. 20545

\section{J.L. Bitner}

Westinghouse Electric Corp.

Waltz Mill Site, Box 158

Madison, PA 15663

J. Blume

URS/John A. Blume $\varepsilon$ Assoc.,

Engineers

130 Jessie Street

San Francisco, CA 94105

G.T. Bohm

Westinghouse Electric Corp.

Nuclear Energy Systems

Penn Center

Pittsburgh, PA 15235

S.P. Chan

U.S. Nuclear Regulatory Commission

Washington, D.C. 20555

P.W. Dickson

Westinghouse Electric Corp.

Waltz Mill Site, Box 158

Madison, PA 15663

J. Fernandez

Department of Energy

Safety and Environmental

Protection Division

Box 550

Richland, WA 99352

S.H. Fistedis

Argonne National Laboratory

9700 South Cass Avenue

Argonne, IL 60439
J.N. Fox

General Electric Corp.

Fast Breeder Reactor Department

310 DeGuigne Drive

Sunnyvale, CA 94086

W. Gammill, Asst. Dir. for Site Technology

Division of Site Safety and

Environmental Analysis

U.S. Nuclear Regulatory Commission Washington, D.C. 20555

N.A. Goldstein

Stone $\varepsilon$ Webster Engrg. Corp.

P.0. Box 2325

Boston, MA 02107

J.R. Gorga

Burns and Roe, Inc.

670 Winters Avenue

Paramus, NJ 07652

R. Griffith

CRBRP Project office

P.O. BOX U

Oak Ridge, TN 37830

R.P. Gupta

U.S. Nuclear Regulatory Commission

Division of Engineering Standards

Washington, D.C. 20555

A.H. Hadjian

Bechtel Power Corp.

12400 East Imperial Highway

Norwalk, CA 90650

W.J. Hall

1211 Civil Engineering Building

University of 111 inois

Urbana, IL 61801 
J. Harbour, Chief (2 copies)

Site Safety Research Branch

Div. of Reactor Safety Research

Office of Nuclear Regulatory Research

U.S. Nuclear Regulatory Commission

Mail Stop 1130 S

Washington, D.C. 20555

W.W. Hays

U.S. Geological Survey

1486 Johnson Court

Boulder, CO 80303

J.R. Henry

John Henry Associates, Inc.

60 Hickory Drive

Waltham, MA 02154

K. Hikido

Generai Electric Company

310 DeGuigne Drive

Sunnyvale, CA 94086

R. Holliday

Division of Facilities and

Const. Mgmt.

Department of Energy

20 Mass Avenue

Washington, D.C. 20545

\section{D.C. Jeng}

Division of System Safety

Structural Engineering Branch

U.S. Nuclear Regulatory Commission Washington, D.C. 20555

\section{R.P. Kennedy}

EDAC, Inc.

2400 Michelson Drive

Irvine, CA 92715

\section{W.C. Kinsel}

Hanford Engineering Dev. Lab.

Federal Building, Room 115

Richland, WA 99352

G.T. Kitz

Sargent and Lundy Engineers

55 East Monroe

Chicago, IL 60603
Lun K. Liu

General Electric Co.

175 Curtner Avenue

San Jose, CA 95114

J.T. Madell

Argonne National Laboratory

9700 South Cass Avenue

Argonne, IL 60439

J.B. Mahoney

Burns and Roe, Inc.

650 Winters Avenue

Paramus, NJ 07652

F.S. Metzger

Hanford Engineering Dev. Lab.

P.0. Box 1970

Richland, WA 99352

H. Minami

Atomics International

P.O. Box 309

Canoga Park, CA 91304

W. Morrow

Bechtel Power Corp.

P.0. Box 3965

San Francisco, CA 94119

N.M. Newmark

University of 111 inois

1211 Civil Engineering Building

Urbana, IL 61801

L. Nieh

Stone and Webster Engrg. Corp.

99 High Street

P. 0. Box 2325

Boston, MA 02107

D.H. Pai

Foster Wheeler Energy Corp.

110 South Orange Avenue

Livingston, NJ 07039

D. Peck

Combustion Engineering

1000 Prospect Hill Road

Windsor, CT 06082 
T.W. Pickel

Building 1000

Oak Ridge National Lab.

P.0. Box $X$

Oak Ridge, TN 37830

R.H. Prause

Battelle Columbus Laboratories

505 King Avenue

Columbus, OH 43201

J. Prevost

Liquid Metal Engineering Center P.O. Box 1449

Canoga Park, CA 91304

L.K. Severud (2 copies)

Hanford Engineering Dev. Lab.

Stress Analysis and Components

Engrg. Div.

P.0. Box 1970

Richland, WA 99352

G.B. Sigal

Burns and Roe, inc.

690 Kinderkamack Road

Oradell, NJ 07649

D.M. Smith

Department of Energy

Safety and Environmental

Protection Division

Box 550

Richland, WA 99352

C. Stepp, Chief (3 copies)

Geology and Seismology Branch

Division of Site Safety and

Environmental Analysis

U.S. Nuclear Regulatory Commission

Washington, D.C. 20555

J.D. Stevenson

Engineering Decision Analysis Co. 21275 Fairmont Blvd.

$\mathrm{Cleveland}, \mathrm{OH}$
S.W. Tagart

Nurlear Services Corporation

1700 Dell Avenue

Campbel1, CA 95008

D.C. Thompson

Westinghouse Electric Corp.

Waltz Mill Site, Box 158

Madison, PA 15663

D. Tow

General Atomic Company

P.0. Box 81608

San Diego, CA 92138

B. Wei

Division of Reactor Development and Demonstration

Mail Stop F-309

Department of Energy

Washington, D.C. 20545

G.D. Whitman

Building 9204-1

$Y-12$ Plant

P.O. Box $Y$

Oak Ridge, TN 37330

J.P. Wicks

Stone $\varepsilon$ Webster Eng. Corp.

245 Summer St.

Boston, MA 02125

J.P. Wilson

General Electric/FBRD

310 DeGuigne Drive

Sunnyvale, CA 94086

R. Wray

Teledyne Material Research

303 Bear Hill Road

Waltham, MA 20154

G.A. Young (5 copies)

Agbabian Associates

$250 \mathrm{~N}$. Nash Street

El Segundo, CA 90245 